\title{
The Future is Now
}

Citation for published version (APA):

Bedaf, S. M. A. (2017). The Future is Now: The Potential of Service Robots in Elderly Care. [Doctoral Thesis, Maastricht University]. Datawyse / Universitaire Pers Maastricht.

https://doi.org/10.26481/dis.20171221sb

Document status and date:

Published: 01/01/2017

DOI:

10.26481/dis.20171221sb

Document Version:

Publisher's PDF, also known as Version of record

\section{Please check the document version of this publication:}

- A submitted manuscript is the version of the article upon submission and before peer-review. There can be important differences between the submitted version and the official published version of record.

People interested in the research are advised to contact the author for the final version of the publication, or visit the DOI to the publisher's website.

- The final author version and the galley proof are versions of the publication after peer review.

- The final published version features the final layout of the paper including the volume, issue and page numbers.

Link to publication

\footnotetext{
General rights rights.

- You may freely distribute the URL identifying the publication in the public portal. please follow below link for the End User Agreement:

www.umlib.nl/taverne-license

Take down policy

If you believe that this document breaches copyright please contact us at:

repository@maastrichtuniversity.nl

providing details and we will investigate your claim.
}

Copyright and moral rights for the publications made accessible in the public portal are retained by the authors and/or other copyright owners and it is a condition of accessing publications that users recognise and abide by the legal requirements associated with these

- Users may download and print one copy of any publication from the public portal for the purpose of private study or research.

- You may not further distribute the material or use it for any profit-making activity or commercial gain

If the publication is distributed under the terms of Article $25 \mathrm{fa}$ of the Dutch Copyright Act, indicated by the "Taverne" license above, 


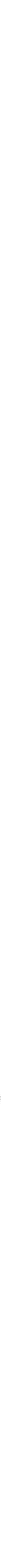


The research presented in this thesis was funded by the European project Acceptable robotiCs COMPanions for AgeiNg Years (ACCOMPANY) [grant agreement No. 287624] and Zuyd University of Applied Sciences.

Cover design: Stefan Hensen

(C) copyright Sandra Bedaf, Maastricht 2017

Printing: Datawyse | Universitaire Pers Maastricht

ISBN 9789461597496

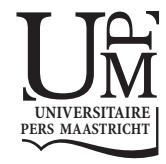




\title{
The Future is Now
}

\section{The Potential of Service Robots in Elderly Care}

\author{
DISSERTATION \\ to obtain the degree of Doctor at Maastricht University, \\ on the authority of the Rector Magnificus, Prof. Dr. Rianne M. Letschert \\ in accordance with the decision of the Board of Deans, \\ to be defended in public \\ on Thursday 21 December 2017, at 14.00 hours
}

by

Sandra Bedaf 


\section{Supervisor}

Prof. dr. L.P. de Witte

\section{Co-supervisors}

Prof. dr. P. Marti (University of Siena, Italy; Technische Universiteit Eindhoven) dr. G.J. Gelderblom† (Zuyd Hogeschool, Heerlen)

\section{Assessment Committee}

Prof. dr. J.M.G.A. Schols (chairman)

Prof. dr. V. Evers (Universiteit Twente)

Prof. dr. K. Horstman

Prof. dr. T.J. Prescott (University of Sheffield, The United Kingdom)

Prof. dr. G.B. Weiss 


\section{CONTENTS}

Chapter 1 General Introduction

Chapter 2 ACCOMPANY project

Chapter 3 Overview and Categorization of Robots Supporting Independent Living of Elderly People: What Activities Do They Support and How Far Have They Developed

Chapter 4 Which Activities Threaten Independent Living of Elderly when Becoming Problematic; Inspiration for Meaningful Service Robot Functionality

Chapter 5 Can a Service Robot which Supports Independent Living of Older People Disobey a Command? The Views of Older People, Informal Carers and Professional Caregivers on the Acceptability of Robots

Chapter 6 What are the Preferred Characteristics of a Service Robot for the Elderly? A Multi-Country Focus Group Study with Older Adults and Caregivers

Chapter 7 A Multiperspective Evaluation of a Service Robot for Seniors:

The Voice of Different Stakeholders

Chapter 8 General Discussion

Chapter 9 Valorisation

Summary

Nederlandse Samenvatting

Dankwoord

About the Author

List of Publications 


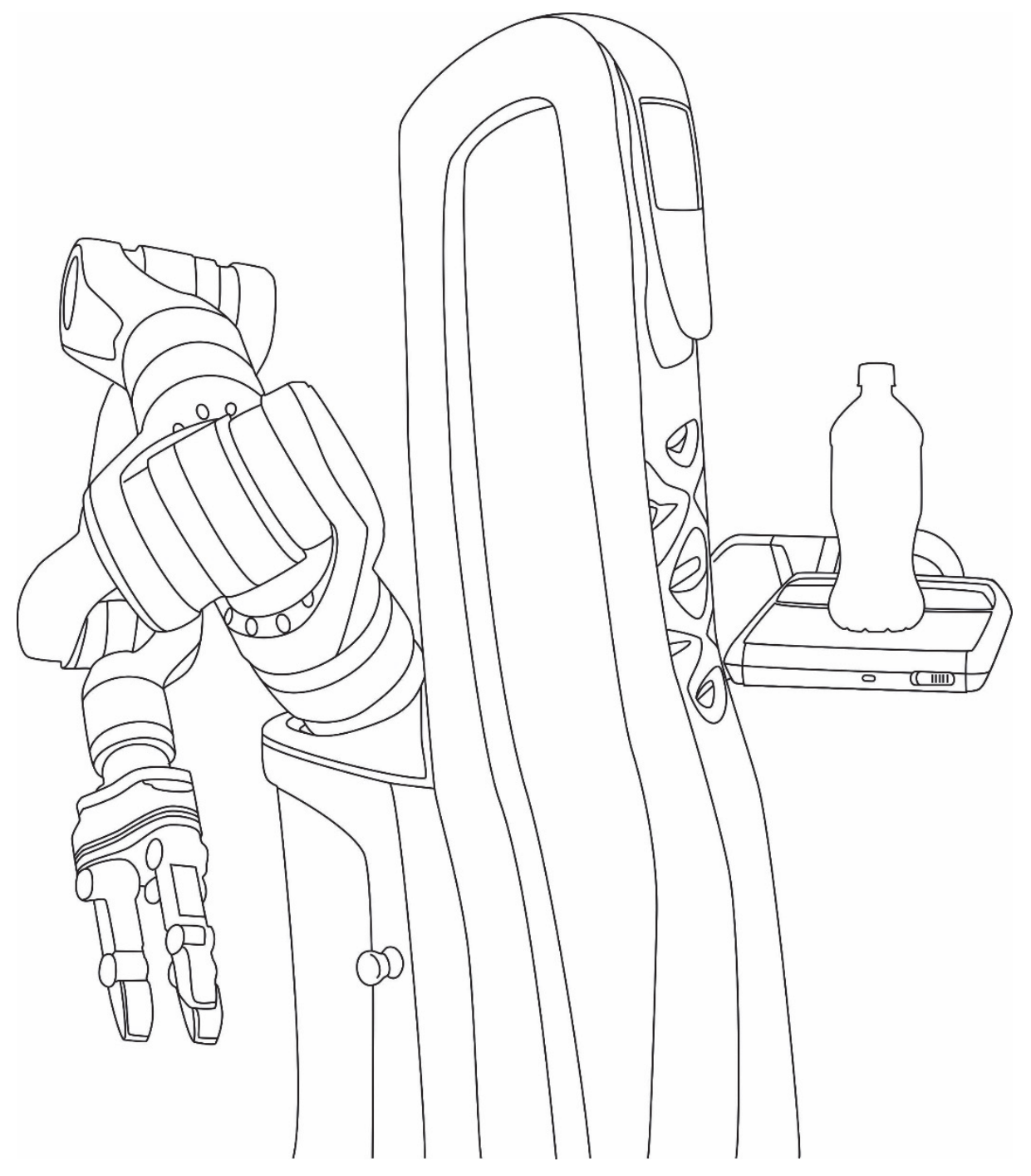




\section{CHAPTER 1 \\ General Introduction}


With immense progress in technological development, the use of robots in daily life is no longer science fiction. Robots are already easily accessible and commercially available to consumers (e.g., robotic vacuum cleaners such as the Roomba ${ }^{\circledR}$ ) and substantial efforts are being made to develop new applications. Further, the potential of robotics in addressing complex challenges and major concerns effectively has been highlighted globally, as well as regionally, for example by the European Commission, which has many H2020 work programmes focused on the development of this field [1]. Within this context there are many different spheres for which robots are being developed. A specific field that has been paid an increasing amount of attention in recent years is the development of social robotics, which concentrates on the development and design of robots that interact socially with humans.

The work described in this thesis focuses on the human-robot interactions of service robots within the domain of elderly care. The outcomes described in this thesis are based on multi-cultural studies that were conducted in Europe and involve a range of relevant stakeholders, including older adults, informal caregivers, and professional caregivers. Human needs and ethical considerations were combined in order to create a human centred view of how a service robot should behave when executing a task. This knowledge is relevant for robot developers and needs to be used as input for making the right choices when developing service robots for older adults. Although the work described in this thesis focuses exclusively on the domain of elderly care, it may also be relevant to the related fields of service and assistive robotics (e.g., in the care for disabled and chronically ill people), and the general domains of home assistance and entertainment robotics.

\section{Elderly Care}

The ageing population is an interesting target group as the baby boomer generation is now reaching retirement age, and the proportion of elderly citizens is growing rapidly and significantly, raising the costs associated with elderly care. In 2014, the proportion of the population aged 65+ in Europe was 18,5\% [2]. This means that per 100 persons of working age (i.e. $15-64$ years old), 28,1 persons were aged 65+. Comparable data indicate that the number of persons aged 65+ per 100 persons of working age, was much lower, at 21,6 persons, 20 years ago. This ageing population is expected to continue to grow in coming years, both globally as well as specifically in Europe [3-5]. While they area a diverse group with differing needs, older adults (those of 65+ years of age) generally prefer to live at home and may be reluctant to move to residential care facilities as they grow older. However, a large part of this population will experience problems due to agerelated changes in physical [6] and mental abilities. In order to maintain independent living, they must be able to perform everyday tasks, such as getting dressed and going to the toilet, by themselves, which may become difficult over time. A range of solutions are 
offered, with the intention of maintaining their capacity to live independently, to those experiencing difficulties with the execution of everyday tasks, including the provision of home care. Providing good quality home care can be labour-intensive. Traditionally this care is provided either informally by those from the direct social environment (e.g. family), or more formally, by professional caregivers funded by either public or private means. However, unfortunately there is a shortage of informal caregivers and formal caregivers, making the provision of such care challenging [7-9]. For those who are unable to maintain their independent living (with the help of others), an institutional arrangement of dependent living or institutionalisation may be the final solution. However, the exact causes of institutionalisation of older persons are complex [10], and the problematic activities that cause institutionalisation of older adults with no cognitive decline are yet to be determined.

\section{Service Robots}

Alternative ways of providing care to older adults are being investigated. Robotics is a promising domain within technology for supporting care and independence in many ways [11]. According to the International Federation of Robotics, a service robot can be defined as an actuated mechanism that is programmable in two or more axes with a degree of autonomy (i.e. the ability to perform intended tasks based on current state and sensing, without human intervention), can move within its environment, is able to perform useful tasks for humans excluding industrial automation application, is used for non-commercial tasks, and is usually used by a lay person (e.g. domestic servant robot, personal mobility assist robot) [12]. A service robot can provide support to a user [13-15], alert his or her family in case of emergencies [16, 17] and is available at all times. However, service robots are relatively new to the elderly care sector, and people are often sceptical about robots caring for the older adults, considering them to be as inhumane. However, when someone is dependent on a caregiver, they often have to adapt their daily schedule to the schedule of their caregiver. For example: Mary (78) lives alone and has trouble getting in and out of bed, showering and dressing herself due to physical problems. A caregiver visits Mary twice a day: at 8 o'clock in the morning, the caregiver helps Mary get ready for the day and at 9 o'clock in the evening, to go to bed. However, when Mary wakes up at 6 o'clock in the morning, she is forced to wait two hours before she can start her day. The same goes for the evening: even if Mary is not tired at 9 o'clock, she still has to go to bed, as her caregiver is only available to support her at that time. If she were to have the support of a service robot, Mary would be able to get up in the morning and go to bed at any time, based on her preferences, as, in contrast to a caregiver, the robot is always present and never gets tired.

The industry acknowledges the market potential of service robotics in elderly care. However, although several service robots have been developed to support different 
activities for older adults, only a small number of these robots have actually been brought to the market or made available to support care for individuals in their daily lives. This may be due to the lack of knowledge concerning the actual needs of older adults, and raises questions concerning the suitability and acceptability of such robots. Most robot development still appears to be technology-driven (i.e. primarily guided by technical feasibility), and driven to a lesser degree by the needs and wishes of potential end users [18]. A user-centered approach from the start of the development of a service robot is essential for usability (i.e., human robot interaction should lead to task fulfilment in a user-friendly way) and acceptability with the regard to future users (i.e., a service robot should be accepted by users) [19]. Fortunately, the importance of, and need for, robot development from a user perspective is becoming clearer to robot developers. However, robot developers often still do not have a good understanding of the needs and preferences of potential end users.

\section{Human Robot Interaction}

Existing literature on human robot interaction indicates that a robot with a human-like appearance creates the expectation of human-like intelligence and skills of the robot [20]. A robot that resembles a human being closely, but does not possess matching humanlike behaviour creates a feeling of aversion as in the 'Uncanny Valley' ${ }^{1}$ proposed by Mashiro Mori [21-23]. When designing a robot with capacity for natural language-based interaction, it is important that the robot does not produce sentences that are more complex than those it can understand, so that the user is aware that the robot has only a partial knowledge of the language [24]. This means that a robot should be designed in such a way that its limitations are visible to the user and it should not be similar to the human being it is trying to imitate. However, much is still unknown with regard to how a robot should act in the presence of humans, especially older adults, in order to be found acceptable.

\section{Objective and research questions}

The main objective of this thesis is to contribute to the development of service robots to prolong independent living of older adults from a user perspective through gaining knowledge on what potential end users need, want and find acceptable. To achieve this, the following research questions are addressed:

\footnotetext{
${ }^{1}$ The dip that is visible in the graph that plots the emotional response of a human being to a robot against the increase in the perceived realism of a robot. At this point robots closely resemble, but not exactly, human beings which causes people to experience a feeling of revulsion.
} 
1. What kinds of robots are available for older adults living independently?

2. Do these robots match the needs of older adults?

3. What ethical boundaries should be taken in to account when developing robots for older adults?

4. What are the preferred characteristics of service robots for older adults?

5. How do potential users experience executing a task together with a service robot?

\section{Methodology}

The work described in this thesis was part of the Acceptable robotiCs COMPanions for AgeiNg Years (ACCOMPANY) project (see chapter 2 for more details about the project) [25]. In order to answer the five research questions described above several studies have been conducted, including focus group sessions. During our studies we were particularly looking for an open approach to explore the themes that were found to be most important from the perspective of older adults, informal caregivers and professional caregivers. Focus group sessions permitted the participants in our studies to freely discuss the given topics and provided them the opportunity to react on each other. It also gave us insight in what potential end users think, how they think and why they think in that way [26]. Additionally, this method does not require any specific expertise or skills from the participants, which makes it an ideal means to involve older adults and caregivers in the development process.

To provide an overview of available robots that claim to support independent living of older adults (research question 1) a systematic review of several databases (i.e., Cinahl, IEEE, Pubmed, and PsycInfo), reference tracking and grey literature was performed (see chapter 3). However, before being able to tell if these robots focus on the right activities and offer the type of support older adults need (research question 2), the needs of older adults were studied. A qualitative study was conducted in which focus group sessions with older adults, informal caregivers and professional caregivers were performed. The overall goal of this study was to create an overview of prioritised problematic activities that were found to be threatening independent living of older adults and should be solved first according to the participants. Older adults, informal caregivers, and professional caregivers in the United Kingdom (UK), France and the Netherlands were invited to participate in these sessions and were first asked which problematic activities in daily life are most threatening the independence of older adults? And second, which problematic activity is most important for independent living and should be solved first? In order to give all participants the opportunity to share their ideas with the group and to stimulate group discussion the Metaplan method was used (see chapter 4 for more details about the procedure) [27]. To ensure consistency in the procedure across the focus group sessions run in the three different countries and with different facilitators a common 
topic guide was created by Zuyd University of Applied Sciences. Additionally, a preparatory meeting was held with the facilitators to reach agreement on the procedure. In this study the data from the focus group sessions was not analysed in depth; the aim was to identify the most problematic activities that limit people's independence. Of every focus group only the problematic activities participants felt should be solved first (i.e., the final lists) were translated into English by the facilitators, along with the clustered topics that were created by the participants during the sessions, including a short summary explaining the content of these clustered topics. To create an overview of the prioritised problematic activities that should be solved first according to the participants, the final lists from all focus group sessions of all countries were clustered per group separately (i.e., older adults, informal caregivers and professional caregivers). This overview was then compared to the results of a systematic literature search of Pubmed, focussed on the risk factors (related to daily activities) for institutionalization. The consensus between the results from the group discussions and the literature review lead to a top 3 of most problematic activity domains threatening independent living of older adults.

During the next step the ethical boundaries that should be taken in to account when developing robots for older adults were studied (research question 3). This was done in a second qualitative study in which focus group sessions with older adults, informal caregivers and professional caregivers were held in the UK, France and the Netherlands. To make this question more concrete and to create a shared understanding amongst the participants about the possible use of a robot, a short scenario was presented to the participants during these focus group sessions. In this scenario an older lady resists the efforts of a robot to encourage movement and is not honest with her nurse about how much she is moving. This scenario was designed by partners within the ACCOMPANY project to highlight the potential tensions between three values that were identified during a previous theoretical analysis performed within the ACCOMPANY project on the ethical values that should govern the use of social robots [28]:

1. Autonomy: being able to set goals in life and choose means.

2. Independence: being able to implement one's goals without the permission, assistance or material resources of others.

3. Privacy: being able to pursue and realise one's goals and implement one's choices unobserved.

During the focus group sessions participants were asked to comment on various aspects of this scenario, through the usage of open questions and prompts. A common topic guide was created by partners within the ACCOMPANY project to ensure consistency across the focus group sessions run in the three different countries and with different facilitators and a training session was held with all facilitators. All sessions were audio and/or video recorded and described verbatim. In order to deal with the different languages during the coding process three of the six transcripts of focus group sessions conducted in the Netherlands were translated into English (i.e., one transcription of a 
focus group session conducted with older adults, one with informal caregivers and one with professional caregivers). The same was done for three of the nine transcripts of focus group sessions that were conducted in France. These six translated transcripts were, together with the transcripts of all the focus group sessions in the UK, coded and discussed until agreement was reached about the initial coding themes by a researcher from the University of Birmingham and a researcher from the University of Warwick using a combination of directed analysis and Ritchie and Spencer's Framework Analysis [29]. The Ritchie and Spencer's Framework Analysis consisted of five steps:

1. All transcripts were read several times (familiarisation).

2. Data was coded using a combination of descriptive, in vivo and initial coding (identifying a thematic framework) [30]. The descriptive codes referred to the values mentioned above.

3. An approach similar to constant comparative analysis [31] was used in sorting the quotes, searching for correlations and contradictions between quotes (indexing).

4. A thematic organisation of the quotations was conducted which provided a systematic way to manage data directly relevant in answering the research aims/questions (charting).

5. A mind map of the data's main themes, subthemes and their connections was created (mapping and interpretation).

These mind maps were shared and discussed with the facilitators of all sessions in order to create a shared understanding of the analysis process and initial themes. The remaining original language transcripts (i.e., three Dutch and six French) were then independently coded by the facilitators of the sessions with a view to confirming initial themes and finding new themes that may not have been reflected in the initial coding themes. Illustrations were drawn from the transcripts and translated into English. All data was then combined into a final report which was analysed by the primary researcher from Zuyd University of Applied Sciences with the main interest in what the boundaries of a robot intervention should be if the intervention was to be acceptable to potential end users and how potential end users would resolve the tensions between the values that were present in the scenario (i.e., autonomy, independence and privacy). The results of this analysis were discussed with one of the researchers that created the original coding (i.e., the researcher from the University of Birmingham), which resulted in seven main topics that are described in the results section of chapter 5 .

A third qualitative study, in which focus group sessions with older adults, informal caregivers and professional caregivers were held in the UK, France and the Netherlands, was conducted to study the preferred characteristics of service robots for older adults (research question 4). To make this question more concrete and to create a shared understanding amongst the participants, a second more elaborate scenario was used to facilitate the group discussion during the focus group sessions. This scenario was created 
by the ACCOMPANY consortium and was based on the results of the study presented in chapter 4 as well as the feasibility of the technical development within the ACCOMPANY project. During the focus group sessions a storyboard of the scenario, consisting of seven pictures, was presented to the participants so they could experience the visualized interactions by empathizing with the user and reflect of this from their own experience [32]. Participants were asked to give feedback on each picture. Seven main topics were used to guide the discussion. These seven main topics were created by the research team (i.e., Zuyd University of Applied Sciences, University of Hertfordshire and Maintien en Autonomie à Domicile des Personnes Agées) and derived from a group discussion within the consortium. A topic guide was created to ensure consistency across the focus group sessions run in the three different countries and with different facilitators (see chapter 6 for more details about the procedure). Due to the given time constraints and the fact that we needed to keep in pace with the technical development in the ACCOMPANY project, only detailed summaries of the sessions were created by the facilitator of each site and translated into English. The seven main topics were used as the basis for each summary. The summaries of the groups were combined per group (i.e., older adults, informal caregivers and professional caregivers). This dataset was analysed for commonalities, differences and interrelationships and how often opinions were shared for each of the seven main topics (see chapter 5 ).

Finally, a multi-perspective evaluation of a service robot for older adults was conducted to study how potential users experience executing a task together with a service robot (research question 5). A realistic user scenario was designed by the ACCOMPANY consortium, based on previous findings in the ACCOMPANY project (including the findings of the studies presented in chapters $3-6$ ), and realised at Zuyd University of Applied Sciences in Heerlen, the Netherlands (see chapter 7 for a more detailed description of the scenario). This realised scenario was used to conduct individual user tests with older adults. A Likert-scale questionnaire, which was drawn up by the research team based on the actions described in the scenario, was used to assess the experience of the participants when executing a task together with the robot. Additional semi-structured interviews were conducted with older adults, informal caregivers and professional caregivers in order to reflect on the interaction with the robot and to discuss the possible role of the robot in the daily living situation. An interview guide with questions regarding these two topics was used to guide the interviews. All interviews were audio recorded. As the informal caregivers and professional caregivers were not present during the user tests, a video of the executed scenario was shown during the start of each interview [33]. Due to the given time constraints and the fact that we needed to keep in pace with the technical development in the ACCOMPANY project, only summaries of the interviews were created by the researcher that conducted the interviews. These summaries were structured by the questions asked. Two researchers independently coded all summaries. The open-ended questions of the interview were used as initial coding categories. Text that could not be coded into one of these initial 
coding categories was coded with another label that represented its essence. The resulting coding was discussed between the two researchers until agreement was reached. The findings of this analysis can be found in chapter 7 .

\section{Outline}

In chapter 2 the ACCOMPANY project is explained, together with a technical description of the Care-O-bot ${ }^{\circledR} 3$ robot that functioned as an example for all studies.

Chapter 3 provides an overview of robots that claim to support independent living of older adults without cognitive decline. A total of 107 robots for older adults were identified. Robots were categorized based on their progression towards market readiness (i.e., concept phase, development phase or commercially available to consumers), the activity domains they claim to support, and the type of support provided (i.e., physical, non-physical, and/or non-specified).

When developing a service robot to prolong independent living of older adults, it is important to know which daily activities may cause dependency. Chapter 4 presents the results of a literature study and focus group sessions highlighting the activities that can potentially compromise the independence of older adults. The set of prioritised activities for which older adults need support is hoped to inspire robot developers, and serve as a wish list for future robot development.

The ethical considerations of introducing a robot to one's life are discussed in chapter 5 . This chapter presents the results of a qualitative study conducted in the UK, France, and the Netherlands, concerning the limits of a robot intervention if the intervention was found to be acceptable to potential end users.

The characteristics of a service robot that are preferred by potential end users, and necessary in order to be found acceptable when executing a task, are discussed in chapter 6 . The findings from focus group sessions carried out in order to explore these aspects - an existing service robot (i.e., the Care-O-bot ${ }^{\circledR} 3$ ) was used as a reference point - are presented in this chapter.

Chapter 7 presents the findings of a multi-perspective evaluation of a service robot involving potential end users. As part of this study, elderly participants had to execute two tasks with the Care-O-bot ${ }^{\circledR} 3$ in a home-like environment, and were asked to complete a questionnaire. Additionally, interviews were conducted with the elderly participants, informal caregivers, and professional caregivers.

Finally, in the main findings and lessons learned from this thesis will be discussed in chapter 8. Suggestions for the future development of robots based on the conclusions drawn from this thesis are presented in this chapter. 


\section{References}

[1] Robotics. (2016, October 28). Retrieved from http://ec.europa.eu/programmes/horizon2020/en/h2020 section/robotics

[2] Old age dependency ratio. (2016, January 25). Retrieved from http://ec.europa.eu/eurostat/tgm/table.do ?tab=table\&init=1\&plugin=1\&language=en \&pcode=tsdde510

[3] Soede, A.J., Vrooman, J.C., Ferraresi, P.M., \& Segre, G. (2004). Unequal welfare states: Distributive consequences of population ageing in six European countries. The Hague: Social and Cultural Planning Office.

[4] Verzijden, D. \& Fransen, J. (2004). Vergrijzing in Nederland. Onderzoek uitgevoerd in opdracht van de Rijksvoorlichtingsdienst / Publiek en Communicatie ten behoeve van het ministerie van Volksgezondheid, Welzijn en Sport Veldkamp.

[5] World Health Organisation. (2011). Global health and aging. Retrieved from http://www.who.int/ ageing/publications/global_health.pdf

[6] Barea, R., Bergasa, L. M., López, E., Escudero, M. S., Hernández, J. A., \& Willemaers, Y. (2004). Telemedicine system based on a personal robotic assistant. In 10th IEEE International Conference on Methods and Models in Automation and Robotics MMAR (Vol. 4, pp. 909-915).

[7] Cameron, C., \& Moss, P. (2007). Care work in Europe: Current understandings and future directions. Oxford: Routledge.

[8] Super, N. (2002). Who will be there to care?: The growing gap between caregiver supply and demand. Washington, DC: National Health Policy Forum.

[9] Murray, M. K. (2002). The nursing shortage: past, present, and future. Journal of Nursing Administration, 32(2), 79-84. doi: 10.1097/00005110-200202000-00005.

[10] Miller, E. A., \& Weissert, W. G. (2000). Predicting elderly people's risk for nursing home placement, hospitalization, functional impairment, and mortality: a synthesis. Medical Care Research and Review, 57(3), 259-297. doi: 10.1097/00005110-200202000-00005.

[11] Bekey, G., Ambrose, R., Kumar, V., Sanderson, A., Wilcox, B., \& Zheng, Y. (2006). WTEC Panel Report on International Assessment of Research and Development in Robotics. World Technology Evaluation Centre.

[12] International Federation of Robotics. (2014, July 29). Retrieved from http://www.ifr.org

[13] Yamazaki, K., Ueda, R., Nozawa, S., Kojima, M., Okada, K., Matsumoto, K., ... \& Inaba, M. (2012). Homeassistant robot for an aging society. Proceedings of the IEEE, 100(8), 2429-2441. doi: 10.1109/JPROC.2012. 2200563.

[14] Bohren, J., Rusu, R.B., Jones, E.G., Marder-Eppstein, E., Pantofaru, C., Wise, M., ... \& Holzer, S. (2011). Towards autonomous robotic butlers: Lessons learned with the pr2. In IEEE International Conference on Robotics and Automation (ICRA), (pp. 5568-5575).IEEE. doi: 10.1109/ICRA.2011.5980058.

[15] Fischinger, D., Einramhof, P., Wohlkinger, W., Papoutsakis, K., Mayer, P., Panek, P., ... \& Weiss, A. (2013). Hobbit-the mutual care robot. In Workshop Proceedings of ASROB.

[16] Coradeschi, S., Cesta, A., Cortellessa, G., Coraci, L., Galindo, C., Gonzalez, J., ... \& Loutfi, A. (2014). GiraffPlus: a system for monitoring activities and physiological parameters and promoting social interaction for elderly. In Human-Computer Systems Interaction: Backgrounds and Applications 3 (pp. 261271). Springer International Publishing. doi: 10.1007/978-3-319-08491-6_22.

[17] Graf, B., Reiser, U., Hägele, M., Mauz, K., \& Klein, P. (2009). Robotic home assistant Care-O-bot ${ }^{\circledR}$ 3-product vision and innovation platform. In IEEE Workshop on Advanced Robotics and its Social Impacts (ARSO), (pp. 139-144). IEEE. doi: 10.1007/978-3-642-02577-8_34.

[18] Butter, M., Rensma, A., Boxsel, J. V., Kalisingh, S., Schoone, M., Leis, M., ... \& Thielmaan, A. (2008). Robotics for healthcare: final report. DG Information Society, European Commission, Brussels.

[19] Doering, N., Poeschl, S., Gross, H.M., Bley, A., Martin, C., \& Boehme, H.J. (2015). User-centered design and evaluation of a mobile shopping robot. International Journal of Social Robotics, 7(2), 203-225. doi: 10.1007/s12369-014-0257-8. 
[20] Goetz, J., Kiesler, S., \& Powers, A. (2003). Matching robot appearance and behavior to tasks to improve human-robot cooperation. In Proceedings of the 12th IEEE International Workshop on Robot and Human Interactive Communication (ROMAN) (pp. 55-60). IEEE. doi: 10.1109/ROMAN.2003.1251796.

[21] Mori, M., MacDorman, K.F., \& Kageki, N. (2012). The uncanny valley [from the field]. IEEE Robotics \& Automation Magazine, 19(2), 98-100. doi: 10.1109/MRA.2012.2192811.

[22] Dautenhahn, K. (2002). Design spaces and niche spaces of believable social robots. In Proceedings of the 11th IEEE International Workshop on Robot and Human Interactive Communication (pp. 192-197). IEEE. doi: 10.1109/ROMAN.2002.1045621.

[23] Woods, S., Dautenhahn, K., \& Schulz, J. (2004). The design space of robots: Investigating children's views. In 13th IEEE International Workshop on Robot and Human Interactive Communication (ROMAN) (pp. 4752). IEEE. doi: 10.1109/ROMAN.2004.1374728.

[24] Norman, D.A. (1994). How might people interact with agents. Communications of the ACM, 37(7), 68-71. doi: 10.1145/176789.176796.

[25] ACCOMPANY. (2014, March 6). Retrieved from www.accompanyproject.eu

[26] Kitzinger, J. (1995). Qualitative research. Introducing focus groups. BMJ: British Medical Journal, 311(7000), 299. doi: 10.1136/bmj.311.7000.299.

[27] Schnelle, E., \& Thiersch, M. (1979). The Metaplan-Method: Communication tools for planning \& learning groups. Metaplan $\mathrm{GmbH}$.

[28] Draper, H., Sorell, T. (2012). ACCOMPANY Deliverable 6.2: Identification and discussion of relevant ethical norms for the development and use of robots to user older users. Available online http://accompany project.eu/

[29] Ritchie, J., \& Spencer, L. (2002). Qualitative data analysis for applied policy research. The Qualitative Researcher's Companion, 573(2002), 305-329. doi: 10.4324/9780203413081_chapter_9.

[30] Saldaña, J. (2009). The Coding Manual for Qualitative Researchers. London: Sage.

[31] Glaser, B.G. (1965). The constant comparative method of qualitative analysis. Social Problems. 12(4), 436445.

[32] Van der Lelie, C. (2006). The value of storyboards in the product design process. Personal and Ubiquitous Computing, 10(2-3), 159-162. doi: 10.1007/s00779-005-0026-7.

[33] Fraunhofer IPA (2013, December 5). Robot companion for the elderly. [Video file]. Retrieved from https:// www.youtube.com/watch?v=Z1MJPdhniXc 


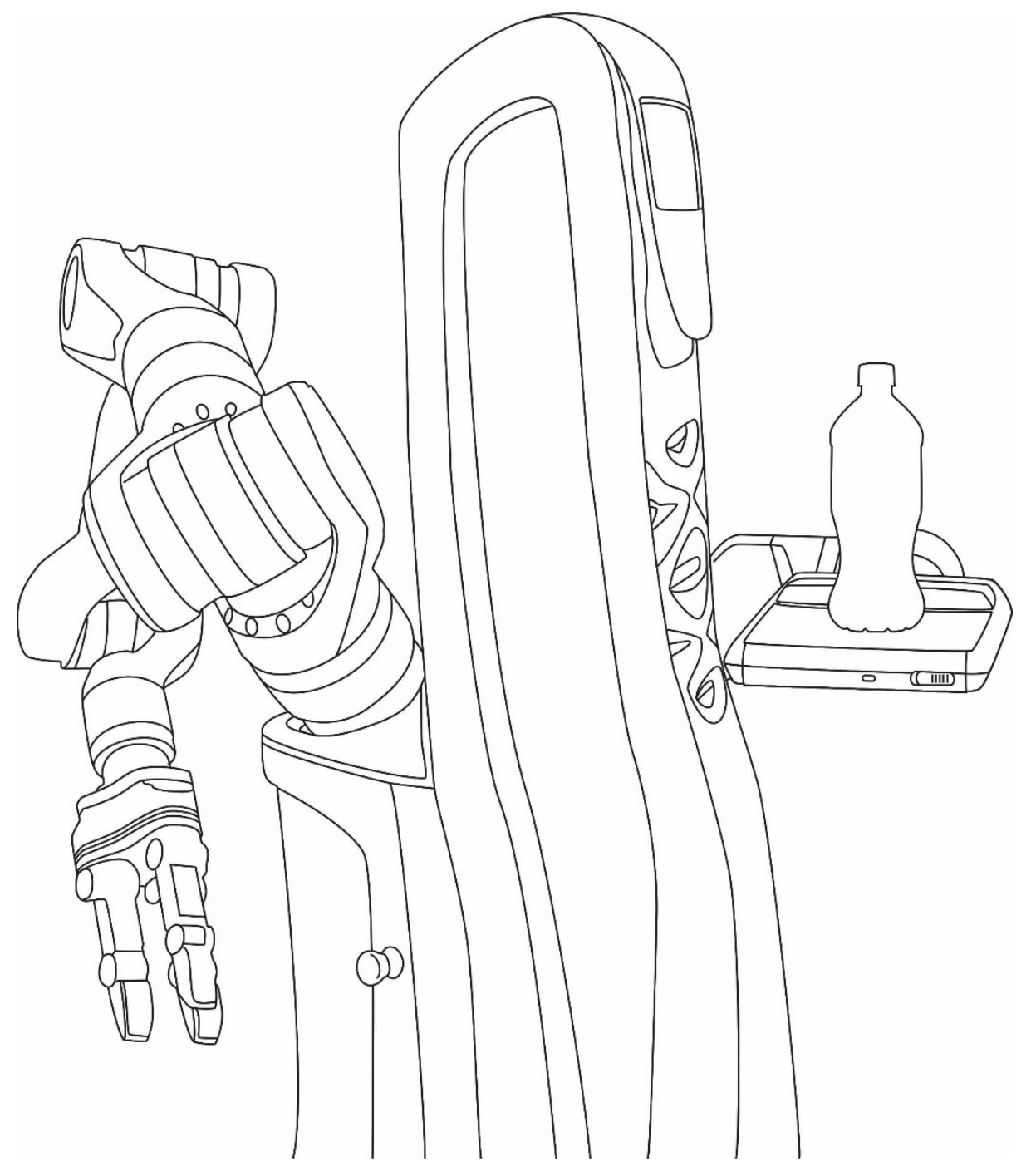




\section{CHAPTER 2 ACCOMPANY project}



The work described in this thesis was part of the larger project: Acceptable robotiCs COMPanions for AgeiNg Years (ACCOMPANY) [1], which was funded by the European Commission Framework 7 programme [2]. The overall goal of this three-year European project was to further develop the functionalities of an existing service robot, the CareO-bot ${ }^{\circledR} 3$ [3], in order to prolong independent living of older adults by providing physical, cognitive and social assistance for everyday home tasks in a socially acceptable manner, and to contribute to the re-enablement of the user (i.e., enable older adults to carry out relatively difficult daily tasks on their own). The relationship envisaged between the user and the robot was that of a co-learner, in which the robot and the user provide mutual assistance (i.e., the robot should not dominate the user, but empower the user). As such, the ACCOMPANY project was required to facilitate the development of flexible, as well as appropriate, robot behaviour.

The project aimed to progress beyond the state of the art in multiple areas, such as empathic and social human robot interaction, robot learning and memory visualisation, monitoring persons and chores at home. It also sought to achieve the technological integration of these multiple approaches in the Care-O-bot ${ }^{\circledR} 3$, and in the context of a smart-home environment utilising a multitude of sensors arrays [4]. The project was implemented using a demand-driven development approach [5], and focus group sessions were conducted with potential users during its different phases.

ACCOMPANY identified three types of potential users: (1) cognitively unimpaired older adults who need some support to remain independent in their own homes; (2) informal caregivers; and (3) professional caregivers. Three test sites - each in a different European country (i.e., the UK, France, and the Netherlands) - were used to ensure an extensive testing and evaluation process, while also addressing differences in elderly care between the countries and possible differences in attitudes of users towards the use of service robots in elderly care.

\section{Consortium}

The ACCOMPANY project consisted of six different development areas [6]: (1) User requirement analysis and scenario development, (2) social and empathic interaction design, (3) robot learning and adaptive interaction, (4) environment and activity monitoring, (5) integration and showcase, and (6) evaluation and ethical issues. A multidisciplinary consortium including the University of Hertfordshire, the University of Birmingham, the University of Warwick (United Kingdom), Zuyd University of Applied Sciences, the University of Amsterdam, the University of Twente (The Netherlands), Fraunhofer (Germany), the University of Sienna (Italy), and Maintien en Autonomie à Domicile des Personnes Agées (France), was established to tackle the technological as well as the human-centered and ethical challenges of this project. Each project partner had, depending on their expertise, their own responsibilities within the six development 
areas. For example: the University of Hertfordshire, the University of Amsterdam and Fraunhofer mostly focussed on the technical development areas (i.e., robot learning and adapting interaction, environment and activity monitoring, and the integration), while the University of Sienna concentrated on the social and empathic interaction design. Zuyd University of Applied Sciences was in charge of the design of the focus group sessions and the analysis of these sessions in order to provide input for the further development of the Care-O-bot ${ }^{\circledR} 3$ based on user consultation throughout the project. Zuyd University of Applied Sciences also facilitated the focus group sessions that were conducted in the Netherlands. The focus group sessions that were conducted in France were facilitated by Maintien en Autonomie à Domicile des Personnes Agées and in the UK by the University of Hertfordshire and in one case also by the University of Birmingham.

The research described in this thesis was conducted by Zuyd University of Applied Sciences, with the author being the primary researcher.

\section{Care-O-bot ${ }^{\circledR} 3$}

The Care-O-bot ${ }^{\circledR} 3$ has a rather machine-like appearance (see Figure 1 ) and is equipped with omnidirectional drives that allow the robot to move flexibly in any direction. It can autonomously calculate and follow the optimum, collision-free path to a given destination and is also capable of detecting and avoiding moving obstacles. The Care-Obot $^{\circledast} 3$ can manipulate objects with its highly flexible lightweight arm, which has seven degrees-of-freedom, and its three-finger gripper. The fingers of this gripper contain tactile sensors that enable the robot to adjust its grasping force accurately when manipulating an object. The tray of the robot can be used to carry objects to be exchanged between the user and the robot. The 'head' of this robot contains range and image sensors enabling object learning and detection, as well as three-dimensional supervision of the environment in real time. It can move autonomously, fetch, carry and manipulate objects. The robot can be operated with a remote control (i.e. tablet) and is part of an intelligent environment. 


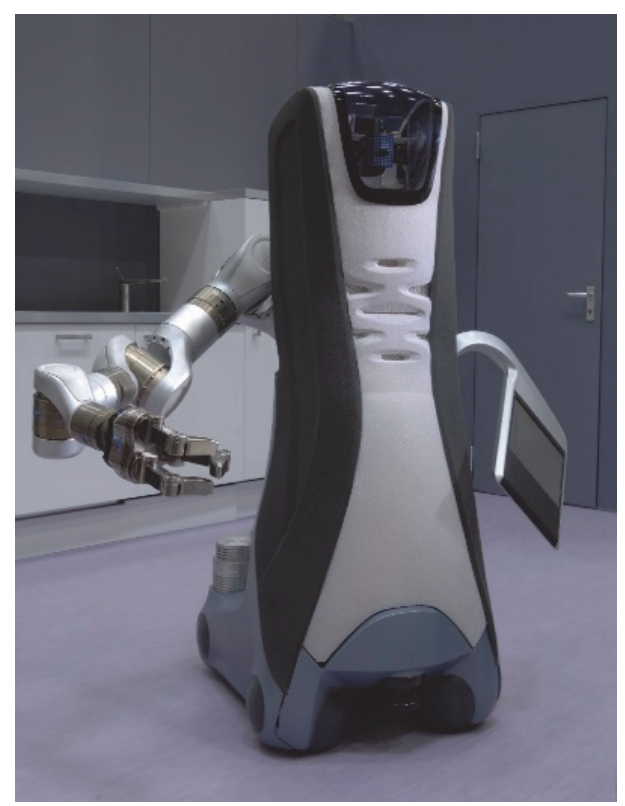

Figure 1: Care-O-bot ${ }^{\circledR} 3$. 


\section{References}

[1] ACCOMPANY. (2014, March 6). Retrieved from www.accompanyproject.eu

[2] FP7. (2017, January 20). Retrieved from https://ec.europa.eu/research/fp7/index_en.cfm

[3] Fraunhofer IPA. (2014, March 6). Retrieved from http://www.care-o-bot.de/en/care-o-bot-3.html

[4] Amirabdollahian, F., Op Den Akker, R., Bedaf, S., Bormann, R., Draper, H., Evers, V., ... \& Hu, N. (2013). Assistive technology design and development for acceptable robotics companions for ageing years. PALADYN: Journal of Behavioural Robotics. doi: 10.2478/pjbr-2013-0007.

[5] Gulliksen, J., Göransson, B., Boivie, I., Blomkvist, S., Persson, J., \& Cajander, Å. (2003). Key principles for user-centred systems design. Behaviour and Information Technology, 22(6), 397-409.

[6] Amirabdollahian, F., op den Akker, R., Bedaf, S., Bormann, R., Draper, H., Evers, V., ... \& lacono, I. (2013). Accompany: Acceptable robotiCs COMPanions for AgeiNG Years-Multidimensional aspects of humansystem interactions. In the 6th International Conference on Human System Interaction (HSI) (pp. 570-577). IEEE. doi: 10.1109/HSI.2013.6577882. 



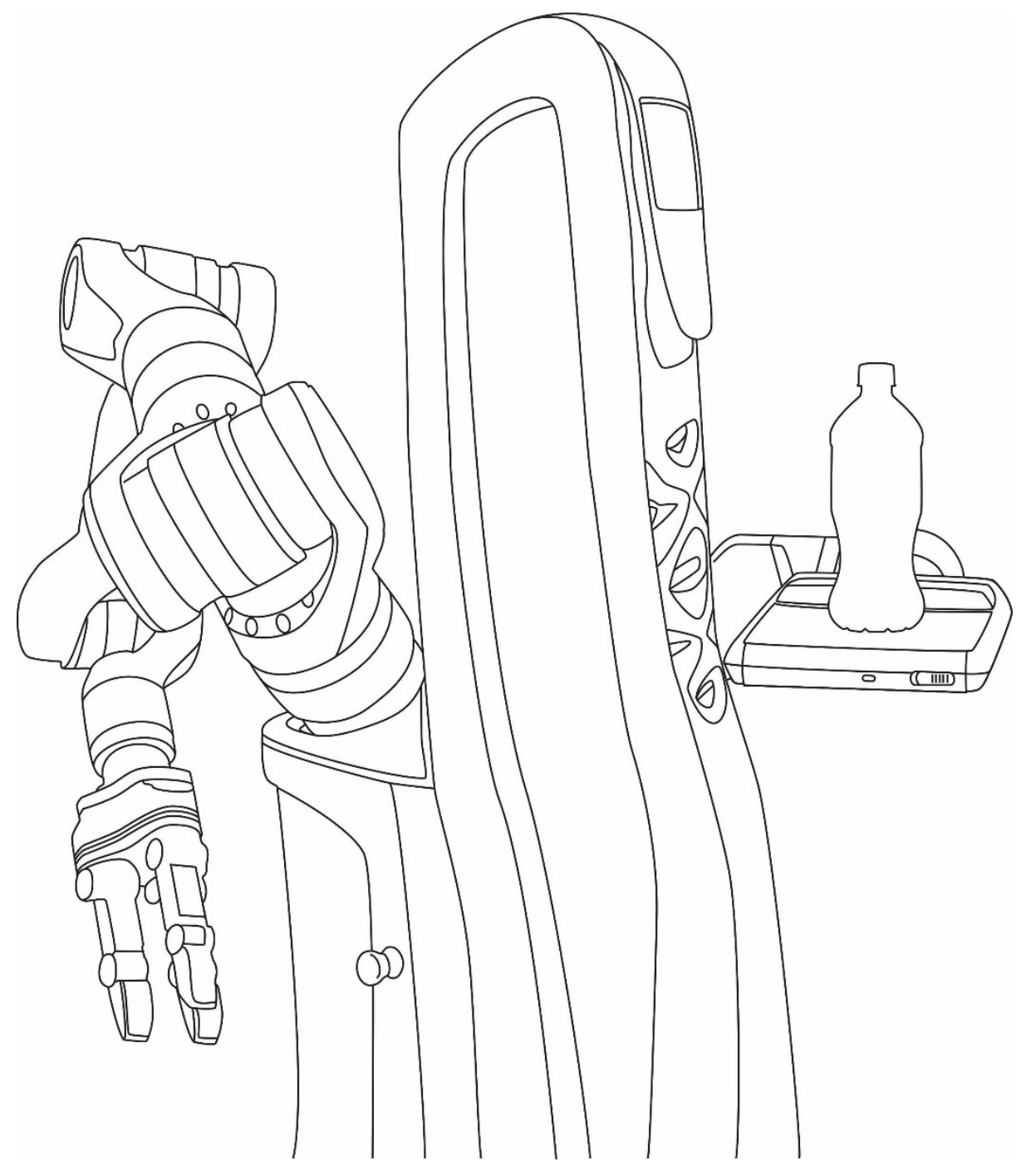




\section{CHAPTER 3 \\ Overview and Categorization of Robots Supporting Independent Living of Elderly People: What Activities Do They Support and How Far Have They Developed}

This chapter was published as:

Bedaf, S., Gelderblom, G. J., \& de Witte, L. (2015). Overview and Categorization of Robots Supporting Independent Living of Elderly People: What Activities Do They Support and How Far Have They Developed. Assistive Technology: The Official Journal of RESNA, 27(2), 88-100. doi: 10.1080/10400435.2014.978916. 


\begin{abstract}
Over the past decades many robots for the elderly have been developed, supporting different activities of elderly people. A systematic review in four scientific literature databases and a search in article references and European projects was performed in order to create an overview of robots supporting independent living of elderly people. The robots found were categorized based on their development stage, the activity domains they claim to support and the type of support provided (i.e. physical, nonphysical, and/or non-specified). In total 107 robots for the elderly were identified. Six robots were still in a concept phase, 95 in a development phase and six of these robots were commercially available. These robots claimed to provide support related to four activity domains: mobility, self-care, interpersonal interaction \& relationships, and other activities. Of the many robots developed, only a small percentage is commercially available. Technical ambitions seem to be guiding robot development. To prolong independent living the step towards physical support is inevitable and needs to be taken. However, it will be a long time before a robot will be capable of supporting multiple activities in a physical manner in the home of an elderly person in order to enhance their independent living.
\end{abstract}




\section{Introduction}

The population in many societies is aging. Most citizens prefer to stay at home for as long as possible. Age-related changes in mental and physical abilities can make living at home independently challenging or even impossible for elderly. In a recent literature review based on 19 studies it was found that activities concerning mobility, self-care, and interpersonal interaction \& relationships are most threatening with regard to the independent living of the elderly [1]. It is often a combination of problematic activities that causes institutionalization. In order to meet the preferences of this group and to overcome the increasing shortage of care staff [2] alternative solutions have been given increased attention to maintain the quality of home care for the elderly. Available assistive technology (AT) for the elderly, such as stair lifts, patient hoists, and accessibility adaptations of the home, have come a long way in supporting the independence of the elderly [3]. Care robotics is an emerging field in AT in which many developments are taking place. According to the International Federation of Robotics a robot is an actuated mechanism programmable in two or more axes with a degree of autonomy (i.e., the ability to perform intended tasks based on current state and sensing, without human intervention), moving within its environment, to perform intended tasks [4]. The target group most often addressed in this context is elderly persons. Robots are seen to have the potential to support the care and independence of elderly people [5].

Over the past decades many robots for the elderly have been developed, aiming to support a range of different activities of elderly people. The focus in this paper will be on robots supporting elderly people, with no cognitive decline, in their home situation in order to prolong independent living, with the aim to create a state-of-the-art overview of these robots, to have a closer look at the activities they claim to support, and how far the activities these robots aim to support are in line with the actual needs of elderly people. The International Classification of Functioning (ICF) was adopted in this paper to structure the variety of supported activities [6]. Further, the robots were categorized based on their progression toward market readiness. This understanding is required to identify the functional abilities and limitations in current robot designs and to see to what extend current robot developments are actually capable of supporting independent living of elderly people in order to guide future developments.

\section{Method}

A systematic search of the scientific literature was performed to create an overview of robots which are potentially relevant for elderly care. Several methods were used including a systematic search of Cinahl, IEEE, Pubmed, and Psyclnfo and an additional hand search of references and relevant European projects (see Figure 1). 


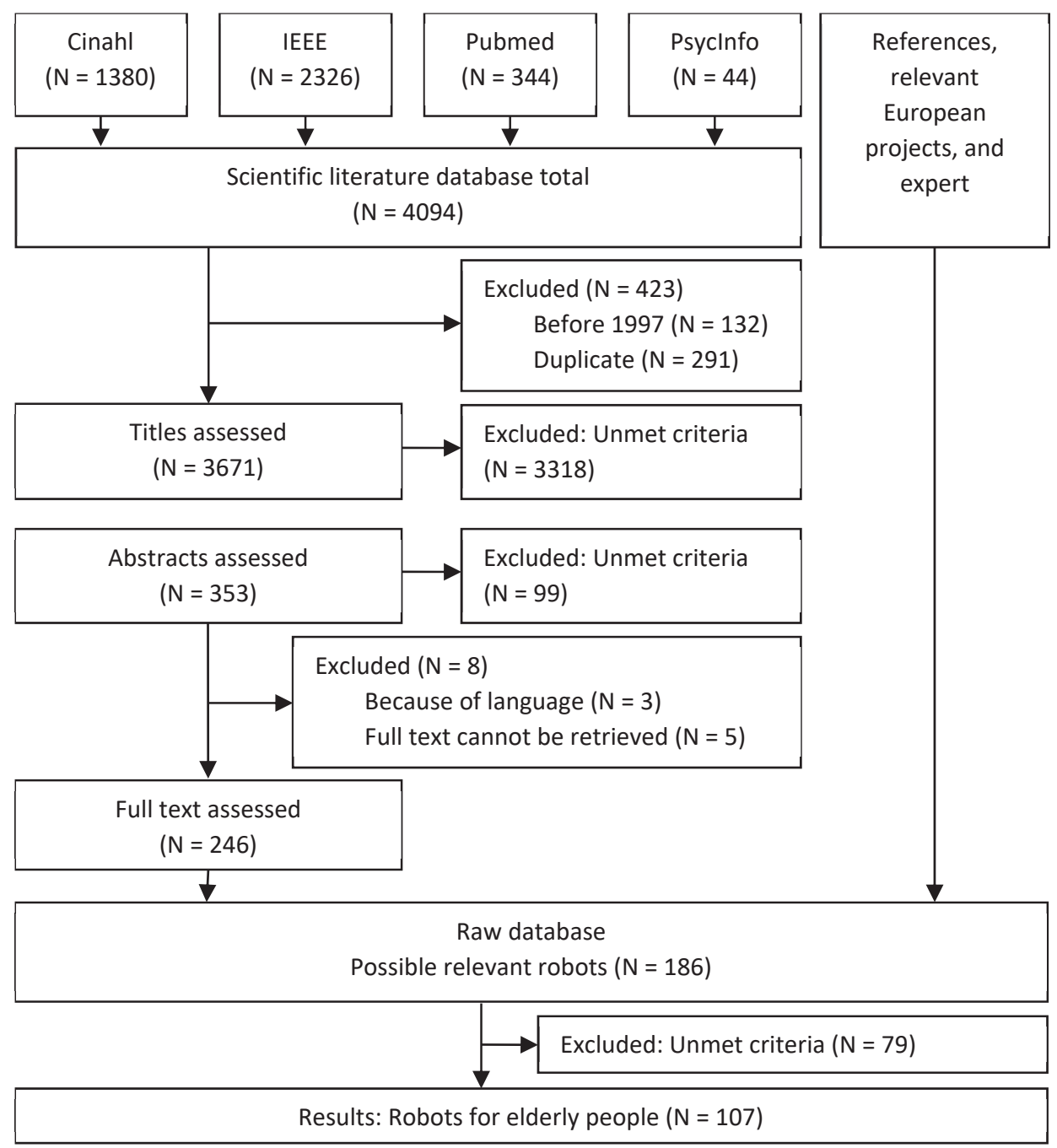

Figure 1: Overview data collection process.

The systematic literature search of Cinahl, IEEE, Pubmed, and Psyclnfo was performed for records until November 2013. The databases were searched using the following terms: assistive technology, self-help device, robotics, gerontechnology, health technology, care technology, service robot, assistive robot, robotic support, and robotic device combined in all possible ways with old age, old aged people, older person, older adults, aged population, 65+, ageing people, frail elderly, elderly, and ageing population (for a complete list of search terms see Appendix 1). Quality assessment of the publications retrieved was not part of this study. Articles with a publication date prior to 1997 were excluded. Two researchers (SB and RH) independently screened and scored the initial set 
of titles. Studies were selected as relevant if they reported information on robots (in any stage of development) for the elderly. A smart technology was qualified as a robot when it was able to perform physical activity (e.g., have movable parts and/or be mobile). Articles were also included if the term technology device, domotics or robot was used. Articles concerning surgery, rehabilitation, clinical conditions (e.g., stroke, Alzheimer's, dementia), interfaces, avatars, monitoring systems and software were excluded. If the full text was not written in English, the article was also excluded. Articles obtained 0 points when failing to meet the inclusion criteria, 1 point when in doubt and 2 points when meeting the inclusion criteria.

The scores of both researchers were summed. Studies receiving a total score of 2 points or more were selected for inclusion in the next round. In the second round, two researchers (SB and KP) independently screened and scored all abstracts using the same inclusion and exclusion criteria as for scoring the titles. When no abstract could be retrieved, only the title was presented in the abstract list. The scores of both researchers were added and when the total score equaled two or more, a researcher (SB) scanned the full text. The text was scanned for robots for the elderly. If a name or direct reference to a robot appeared in the text, the name of this potentially relevant robot was added to the database. Cohen's kappa was calculated to determine the level of agreement between the two reviewers in the title assessment and in the abstract assessment.

In addition, a hand search of European projects and references was adopted to retrieve data. Names of potentially relevant robots from these sources were added to the database. Three researchers (SB, CH, and RB) independently screened and scored the database for possible robots for the elderly based on three criteria: (1) The robot is designed for elderly or has been used in elderly care; (2) The robot is designed for the home situation and assigned to a single household; and (3) A smart technology qualified as robot when it contained electronics and was able to perform physical activity (e.g., have movable parts and/or be mobile). Robots designed for people with specific clinical conditions (e.g. stroke patients, Alzheimer's patients) were excluded as the intention of the search was to find robots matching the target group elderly and not to find robots matching clinical conditions. Robots obtained 0 points when not meeting all the inclusion criteria and 1 point when meeting all three inclusion criteria. Robots could only be included or excluded with the consensus of all three researchers. Robots receiving a total score of 3 were automatically added to the final list. Robots receiving a total score of 1 or 2 were discussed until consensus between the three researchers was reached. This led to a final collection of robots.

Of these robots, articles and web pages were used to extract information. With the collected information an overview was created of the activities these robots claim to support. In order to structure the variety of supported activities a researcher (SB) categorized the activities into the ICF classifications. Then activities were categorized in one of the three activity domains most threatening the independent living of the elderly (i.e. mobility, self-care, or interpersonal interaction \& relationships) [1]. A fourth activity 
domain was created for all remaining ICF activities not related to mobility, self-care or interpersonal interaction \& relationships. Finally, the robots were categorized based on their progression toward market readiness. A division was made, based on the information derived from articles and web pages, between robots with no physical prototype (group 1: concept phase), robots with a physical prototype for research purposes (group 2: under development), and for consumers' commercially available robots (group 3: for consumers' commercially available).

\section{Results}

The scientific literature search of the databases yielded an initial list of 4094 references (see Figure 1). After the exclusion of articles before 1997 and duplicates, a list of 3671 titles was created. Cohen's kappa for agreement regarding the title scoring was 0.67 between reviewers SB and $\mathrm{RH}$, which is substantial [7]. The scoring and selection of titles resulted in a list of 353 abstracts. No abstract could be retrieved for 22 selected titles, therefore only the titles of these 22 articles were presented in the abstract list. Cohen's kappa for scoring the abstracts between reviewers SB and KP was 0.56, which is moderate [7]. For 5 abstracts no full papers could be found. This resulted, after the additional exclusion of 3 non-English articles, in 246 full-text articles. In these full-text studies 168 different robots could be distinguished. Efforts in the additional searches (i.e., references and relevant European projects) led to 18 additional possibly relevant robots. This resulted in a final database of 186 different robots. After the consensus of the three reviewers, based on the selection criteria, 107 were regarded as robots for the elderly intended for their home situation.

These robots claimed to support various activities which were categorized into the ICF. A second categorization was made based on the activity domains most threatening the independent living of elderly [1]: (1) Mobility; (2) Self-care; and (3) Interpersonal interaction \& relationships (see Table 1). An extra fourth category was added, which included all remaining ICF activities that were not related to mobility, self-care or interpersonal interaction \& relationships. Secondly, a distinction could be made between three different types of support the robots claim to provide: physical support, nonphysical support and non-specified support. Robots providing physical support to the user physically support the user with activities such as standing up, fetching and carrying objects, carrying objects, walking, climbing stairs, washing, dressing, eating, drinking, preparing meals and cleaning. The following tasks are performed by robots providing non-physical support:

- Providing reminders (i.e., carrying out daily routines: agenda function; maintaining one's health: reminder for medication/health measurement; acquisition of goods and services: support shopping cognitive). 


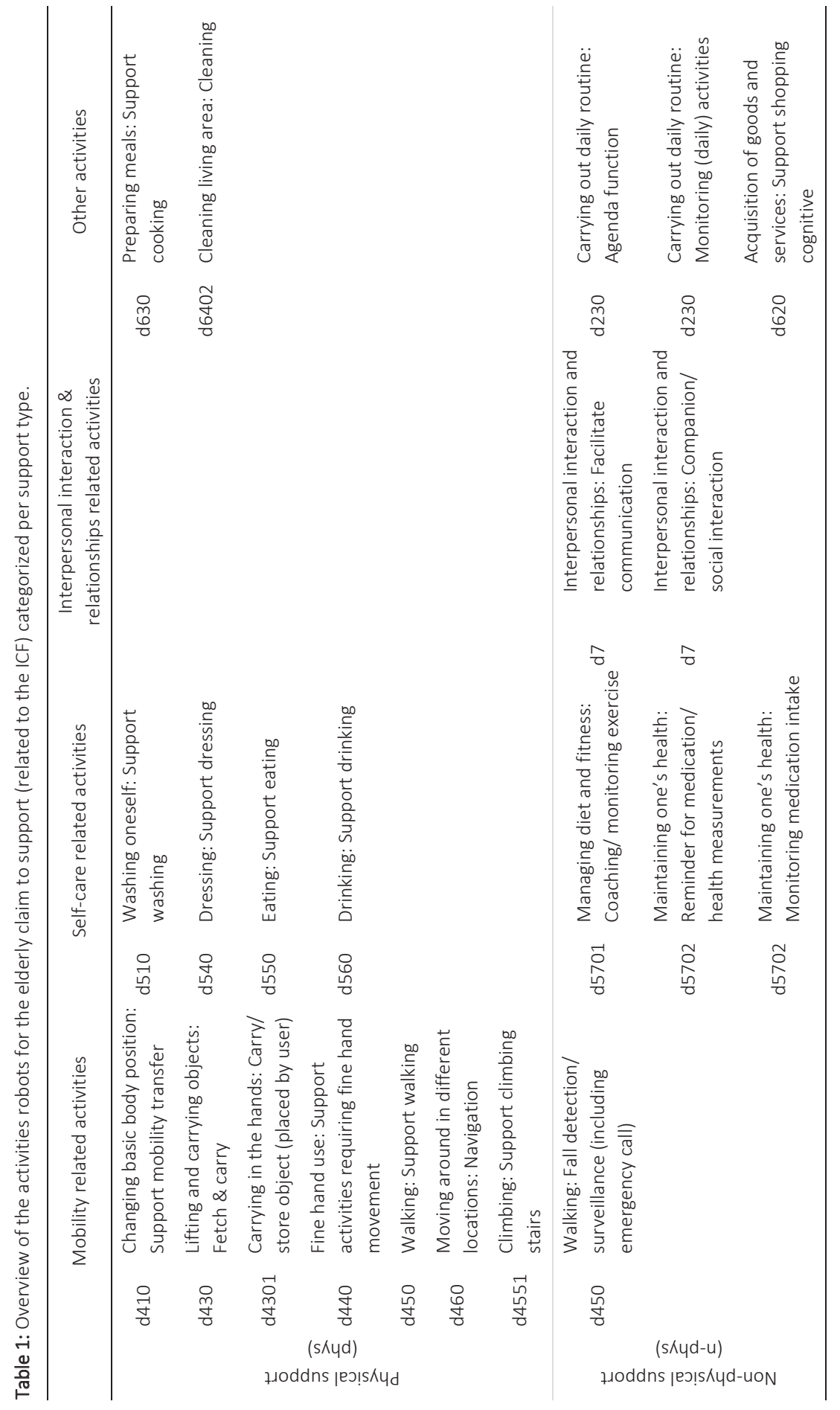




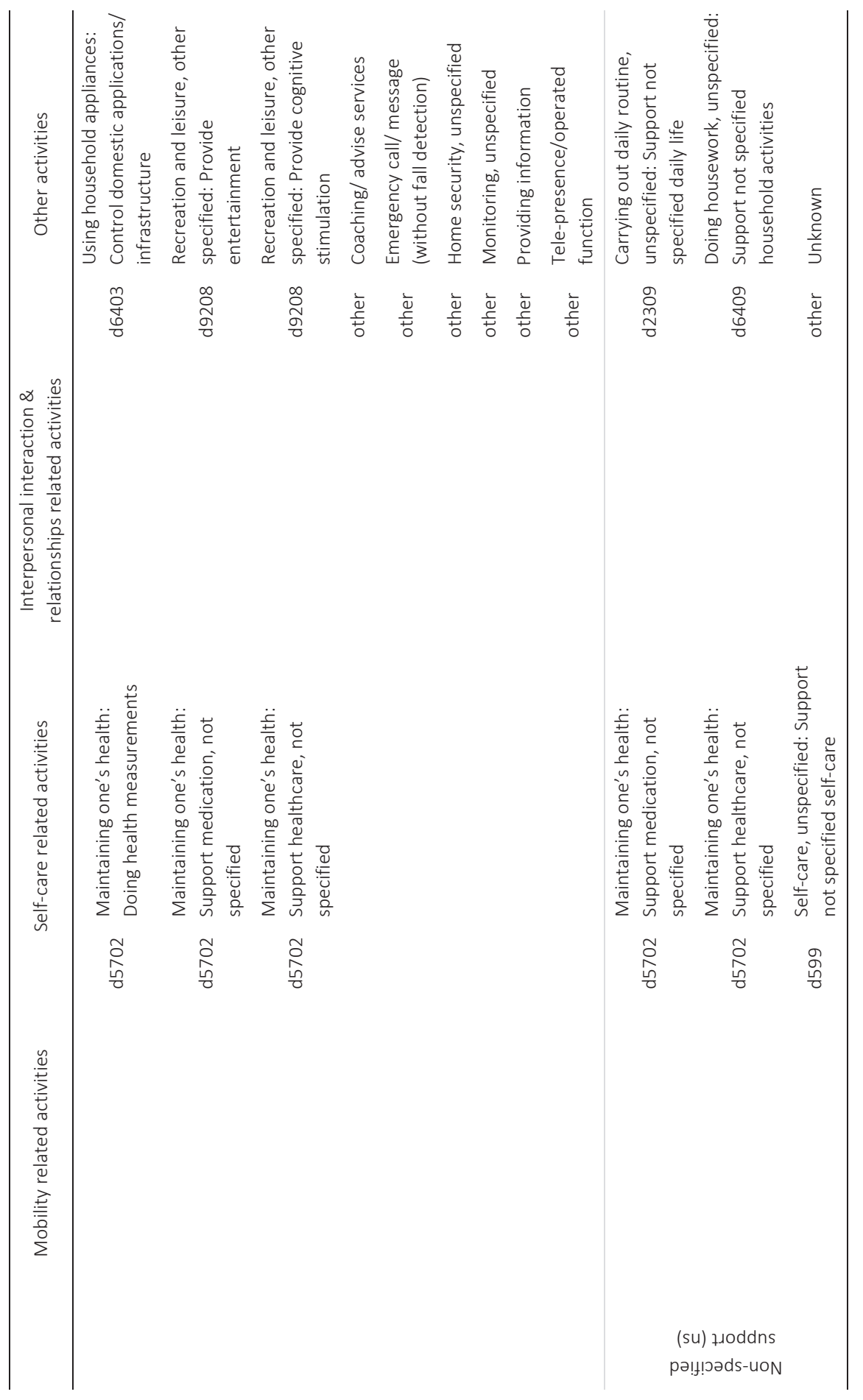


- Monitoring user/environment (i.e., carrying out daily routines: monitoring daily activities; walking: fall detection; managing diet and fitness: coaching/ monitoring exercise; maintaining one's health: reminder for medication/health measurements; maintaining one's health: monitoring medication intake; home security: unspecified, tele-presence).

- Providing information (i.e., coaching/advice services, providing information), control equipment (i.e., maintaining one's health: doing health measurements; using household appliances: control domestic applications/infrastructure, emergency call/message).

- Social interaction (i.e., interpersonal interaction and relationships: facilitate communication; interpersonal interaction and relationships: companion/social interaction).

- $\quad$ Providing entertainment (i.e., recreation and leisure: provide entertainment; recreation and leisure: provide cognitive stimulation).

- Non-specified support (i.e., support daily life, support medication, support healthcare, support self-care, doing housework) includes the activities for which it was not clear whether these were physically or non-physically supported by the robots.

When looking at the development stages of all robots three groups could be created. Group 1 consists of six robots that were still in their concept phase; no physical prototypes, only (computer) drawings and/or descriptions of these robots, could be found in the articles and web pages (see Table 2). Four out of these six robots are intended to physically support mobility related activities, none of the robots aim to physically support self-care.

Table 2. Group 1: Robots in their concept phase and the activity domains they aim to support. Phys refers to physical support, $n$-phys refers to non-physical support and $n s$ refers to non-specified support.

\begin{tabular}{|c|c|c|c|c|c|}
\hline No. & Robot & $\begin{array}{c}\text { Mobility } \\
\text { related } \\
\text { activities }\end{array}$ & $\begin{array}{c}\text { Self-care } \\
\text { related } \\
\text { activities }\end{array}$ & $\begin{array}{l}\text { Interpersonal } \\
\text { interaction \& } \\
\text { relationships related } \\
\text { activities }\end{array}$ & $\begin{array}{c}\text { Other } \\
\text { activities }\end{array}$ \\
\hline 1 & ASTRO [8] & phys & n-phys, ns & n-phys & n-phys, ns \\
\hline 2 & Combined Carrier [9] & phys & & & \\
\hline 3 & ComforTABLE [10] & & n-phys & & n-phys \\
\hline 4 & Movable Service Robot [11] & phys & & & ns \\
\hline 5 & $\begin{array}{l}\text { Robot Assistant For Housekeeping And } \\
\text { Home Care [12] }\end{array}$ & phys & & & phys, ns \\
\hline 6 & Robot For The Elderly [13] & & & & ns \\
\hline
\end{tabular}


Group 2 contains robots under development (see Table 3). These robots are not commercially available, only prototypes are available for research purposes (e.g., user evaluations or technical evaluations). This group includes ninety-five robots. The produced prototypes of these robots varied from basic mechanical prototypes up to partly/fully working visual prototypes. For eight robots in this group no specific information could be found on the activities it aimed to support (i.e., no. 20, no. 38, no. 46 , no. 72 , no. 75 , no. 84 , no. 85 and no. 94 ). Sixty-four robots aim to support mobilityrelated activities and most of these robots, fifty in total, aim to provide physical support to the user. The mobility-related activities that were most often claimed to be physically supported were fetch \& carry (d430) and walking (d450). When looking at the domain self-care it can be seen that only thirty-five robots claim to support activities in this domain. Of these thirty-five robots only five robots claim to physically support activities in this domain, namely Handy 1 (no. 28), MATS robot (no. 50), Meal assistance robot (no. 51), Robotic Bed (no. 67) and Robotic Food Feeder (no. 68). The Handy 1 claims to support the self-care activities washing (d510), eating (d550) and drinking (d560). The MATS robot claims to support washing (d510), dressing (d540), eating (d550) and drinking (d560). The Robotic Bed claims to support the self-care activity washing (d510) and the Meal Assistance Robot and the Robotic Food Feeder both claim to support eating (d550). Thirty-three robots in their development phase claimed to support interpersonal interaction \& relationships activities (d7) with non-physical support. Finally, fifty-four robots claimed to support activities other than mobility, self-care and interpersonal interaction \& relationships. Ten of these fifty-four robots claimed to support preparing meals (d630) and/or cleaning living area (d6402) in a physical manner. When looking in detail at the specific activities the robots in group 2 support, it appears that these robots often claim to support multiple activities. For example the Care-O-bot 3 in the ACCOMPANY project (no. 18). This robot claims to provide reminders to support daily routines, to monitor user activities, to provide entertainment, and to fetch \& carry objects for the user.

Table 3. Group 2: Robots under development and the activity domains they claim to support. Phys refers to physical support, $n$-phys refers to non-physical support and $n s$ refers to non-specified support.

\begin{tabular}{|c|c|c|c|c|c|}
\hline No. & Robot & $\begin{array}{c}\text { Mobility } \\
\text { related } \\
\text { activities }\end{array}$ & $\begin{array}{c}\text { Self-care } \\
\text { related } \\
\text { activities }\end{array}$ & $\begin{array}{l}\text { Interpersonal } \\
\text { interaction \& } \\
\text { relationships related } \\
\text { activities }\end{array}$ & $\begin{array}{c}\text { Other } \\
\text { activities }\end{array}$ \\
\hline 1 & Active Mobile Robotic Assistant [14] & n-phys & n-phys & & n-phys \\
\hline 2 & Adi [15] & & n-phys & & n-phys \\
\hline 3 & ALIAS Robot [16] & n-phys & & n-phys & n-phys \\
\hline 4 & Animaloid [17] & & & n-phys & n-phys \\
\hline 5 & Apripoco [18] & n-phys & n-phys & n-phys & n-phys \\
\hline 6 & Artificial Liferobot [19] & & & & ns \\
\hline
\end{tabular}




\begin{tabular}{|c|c|c|c|c|c|}
\hline No. & Robot & $\begin{array}{l}\text { Mobility } \\
\text { related } \\
\text { activities }\end{array}$ & $\begin{array}{l}\text { Self-care } \\
\text { related } \\
\text { activities }\end{array}$ & $\begin{array}{c}\text { Interpersonal } \\
\text { interaction \& } \\
\text { relationships related } \\
\text { activities }\end{array}$ & $\begin{array}{c}\text { Other } \\
\text { activities }\end{array}$ \\
\hline 7 & Artos [20] & n-phys & & n-phys & n-phys \\
\hline 8 & ARSD [21] & phys & & & \\
\hline 9 & Assistive Kitchen System [22] & phys & & & n-phys \\
\hline 10 & Bandit [23] & & & n-phys & n-phys \\
\hline 11 & Biron [24] & & & n-phys & \\
\hline 12 & Bobbie [25] & phys & & & ns \\
\hline 13 & Cafero Robot [26] & n-phys & n-phys & n-phys & n-phys \\
\hline 14 & Carebot [27] & n-phys & n-phys & n-phys & n-phys \\
\hline 15 & Care-O-Bot $1[28]$ & phys, n-phys & n-phys & n-phys & $\begin{array}{c}\text { phys, n-phys, } \\
\text { ns }\end{array}$ \\
\hline 16 & Care-O-Bot 2 [28] & phys & n-phys & n-phys & phys, n-phys \\
\hline 17 & Care-O-Bot $3[28]$ & phys, n-phys & & n-phys & n-phys \\
\hline 18 & Care-O-Bot 3, ACCOMPANY Project [29] & phys & n-phys & & n-phys \\
\hline 19 & Care-O-Bot 3, SRS Project [30] & phys & & n-phys & phys, n-phys \\
\hline 20 & $\begin{array}{l}\text { Context Aware Biomedical Robotic } \\
\text { Platform [31] }\end{array}$ & & n-phys & & \\
\hline 21 & $\begin{array}{l}\text { Elderly-Assistant \& Walking-Assistant } \\
\text { Robot [32] }\end{array}$ & phys & & & \\
\hline 22 & Flo Robot [33] & & & & ns \\
\hline 23 & Florence Robot [34] & n-phys & n-phys & n-phys & n-phys \\
\hline 24 & Gait Assistant Service Mobile Robot [35] & phys & & & \\
\hline 25 & Giraff - Excite Project [36] & & & n-phys & n-phys \\
\hline 26 & Giraffplus [37] & n-phys & n-phys & n-phys & n-phys \\
\hline 27 & Guido [38] & phys & & & \\
\hline 28 & Handy 1 [39] & phys & phys & & \\
\hline 29 & Health Care Robot [40] & & & & ns \\
\hline 30 & Hector [41] & n-phys & n-phys & n-phys & n-phys \\
\hline 31 & Hobbit [42] & phys, n-phys & n-phys & n-phys & phys, n-phys \\
\hline 32 & Home-Mate Robot [43] & phys & & n-phys & \\
\hline 33 & Household Surveillance Robot [44] & n-phys & & & \\
\hline 34 & Huggable [45] & & & n-phys & n-phys \\
\hline 35 & Icat [46] & & & & n-phys \\
\hline 36 & Ibrs [47] & phys & n-phys & & \\
\hline 37 & Intelligent Cane Robot [48] & phys & & & \\
\hline 38 & Intelligent Escort Robot [49] & & & & ns \\
\hline 39 & $\begin{array}{l}\text { Intelligent Home Service Robotic System } \\
{[50]}\end{array}$ & phys & & & \\
\hline 40 & Intelligent Walking-Aid Robot [51] & phys & & & \\
\hline
\end{tabular}




\begin{tabular}{|c|c|c|c|c|c|}
\hline No. & Robot & $\begin{array}{c}\text { Mobility } \\
\text { related } \\
\text { activities }\end{array}$ & $\begin{array}{c}\text { Self-care } \\
\text { related } \\
\text { activities }\end{array}$ & $\begin{array}{l}\text { Interpersonal } \\
\text { interaction \& } \\
\text { relationships related } \\
\text { activities }\end{array}$ & $\begin{array}{l}\text { Other } \\
\text { activities }\end{array}$ \\
\hline 41 & Ipadron [52] & & & & ns \\
\hline 42 & Iphonoid [52] & & & & ns \\
\hline 43 & Jarow [53] & phys & & & \\
\hline 44 & Johnnie [54] & phys & & & \\
\hline 45 & Kobian [55] & & & & ns \\
\hline 46 & Kompaï [56] & & ns & n-phys & n-phys \\
\hline 47 & Kompaï, MOBISERV Project [57] & n-phys & n-phys, ns & n-phys & n-phys \\
\hline 48 & Mamoru [58] & & n-phys & & n-phys \\
\hline 49 & Mary [59] & phys & & & \\
\hline 50 & MATS Robot [60] & phys & phys, ns & & phys, ns \\
\hline 51 & Meal Assistance Robot [61] & & phys & & \\
\hline 52 & Milo [62] & & ns & n-phys & n-phys \\
\hline 53 & Mobile Robot Assistant [63] & & & & ns \\
\hline 54 & Movaid [64] & phys & & & phys, ns \\
\hline 55 & Nancy [65] & & & n-phys & \\
\hline 56 & Nao, KSERA Project [66] & & n-phys & n-phys & n-phys, ns \\
\hline 57 & $\begin{array}{l}\text { Nao In Combination With Barrett WAM } \\
\text { [67] }\end{array}$ & & & & phys \\
\hline 58 & Necoro [68] & & & n-phys & \\
\hline 59 & Omni-Directional Mobile Robot [69] & n-phys & & & \\
\hline 60 & Omnidirectional Mobile Robot [70] & phys & & & \\
\hline 61 & Ortw-li [71] & phys & & & \\
\hline 62 & Overhead Robot Arm [72] & phys & & & \\
\hline 63 & PAMM Smart Walker [73] & phys & n-phys & & \\
\hline 64 & Pearl [33] & phys & n-phys & n-phys & n-phys \\
\hline 65 & Peoplebot [74] & phys & & & ns \\
\hline 66 & Personal Assistant Robot [75] & & & & n-phys, ns \\
\hline 67 & Robotic Bed [76] & phys & phys & & \\
\hline 68 & Robotic Food Feeder [77] & & phys & & \\
\hline 69 & Robotic Mobility Aid [78] & phys & & & \\
\hline 70 & Robotic Walker [79] & phys & & & \\
\hline 71 & Robotic Walker [80] & phys & & & \\
\hline 72 & Robumate [81] & n-phys & n-phys & n-phys & n-phys \\
\hline 73 & Robuwalker [81] & phys & n-phys & & \\
\hline 74 & Rola [82] & n-phys & & n-phys & \\
\hline 75 & Rose [83] & phys & n-phys & n-phys & $\begin{array}{c}\text { phys, n-phys, } \\
\text { ns }\end{array}$ \\
\hline
\end{tabular}




\begin{tabular}{|c|c|c|c|c|c|}
\hline No. & Robot & $\begin{array}{l}\text { Mobility } \\
\text { related } \\
\text { activities }\end{array}$ & $\begin{array}{c}\text { Self-care } \\
\text { related } \\
\text { activities }\end{array}$ & $\begin{array}{c}\text { Interpersonal } \\
\text { interaction \& } \\
\text { relationships related } \\
\text { activities }\end{array}$ & $\begin{array}{c}\text { Other } \\
\text { activities }\end{array}$ \\
\hline 76 & Rt Walker [84] & phys & & & \\
\hline 77 & SAM [85] & phys & & & \\
\hline 78 & Security Warrior [86] & phys, n-phys & n-phys & n-phys & n-phys, ns \\
\hline 79 & Self-Help Standing-Up Method [87] & phys & & & \\
\hline 80 & Service Mobile Robot [88] & phys & n-phys & n-phys & n-phys \\
\hline 81 & SIRA [89] & & n-phys & n-phys & n-phys \\
\hline 82 & Smart Mobile Walker [90] & phys & & & \\
\hline 83 & Smartpal [91] & phys & & & phys \\
\hline 84 & Stair Climbing Robot [92] & phys & & & \\
\hline 85 & Stair Climbing Robot [93] & & & & ns \\
\hline 86 & Taizo [94] & & n-phys & & \\
\hline 87 & Telecare Robotic System [95] & phys & n-phys & & phys, n-phys \\
\hline 88 & T-Rot [96] & & & & ns \\
\hline 89 & Turtlebot [97] & & & & ns \\
\hline 90 & Twendy-One [98] & phys & & & phys, n-phys \\
\hline 91 & Ubot-5 [99] & phys, n-phys & n-phys & n-phys & n-phys \\
\hline 92 & Uma [100] & phys & & & \\
\hline 93 & Walbot [101] & phys & & & \\
\hline 94 & Walk Assist Robot [102] & phys & & & \\
\hline 95 & WL-16RII Walkbot [103] & phys & & & \\
\hline
\end{tabular}

Group 3 contains the robots that are commercially available for consumers (see Table 4). Out of all robots found in this review only six were known to be available on the market. None of these robots support mobility-related activities. For the Japanese communication robot Ifbot, developed by Business Design Laboratory (no. 1), no clear information in English could be found concerning its commercial availability and the exact activities it supports. When taking a closer look at the specific activities of the other five robots, it appears that these support only a single activity: the Mealtime Partner (no. 2), My Spoon (no. 3), and Winsford Feeder (no. 6) all physically support the activity eating (d550). The Sanyo Bath Robot (no. 5) physically supports washing (d510) and the robot seal PARO is a robotic companion supporting interpersonal interaction \& relationships (d7). 
Table 4. Group 3: Commercially available robots and the activity domains they support. Phys refers to physical support, n-phys refers to non-physical support and ns refers to non-specified support.

\begin{tabular}{lllcl}
\hline No. $\quad$ Robot & $\begin{array}{c}\text { Mobility } \\
\text { related } \\
\text { activities }\end{array}$ & $\begin{array}{c}\text { Self-care } \\
\text { related } \\
\text { activities }\end{array}$ & $\begin{array}{c}\text { Interpersonal } \\
\text { interaction \& } \\
\text { relationships related } \\
\text { activities }\end{array}$ & $\begin{array}{c}\text { Other } \\
\text { activities }\end{array}$ \\
\hline 1 & Ifbot [104] & n-phys & n-phys & n-phys \\
3 & Mealtime Partner [105] & phys & n-phys \\
4 & Paro [107] & phys & \\
5 & Sanyo Bath Robot [108] & phys & \\
6 & Winsford Feeder [109] & phys & \\
\hline
\end{tabular}

\section{Discussion}

The aim of this review was to investigate which robots are being developed to support the elderly in their independent living and to categorize these robots based on their progression toward market readiness and the activities they claim to support. The overview provided gives an insight into the robots under development and those available on the market. The functionalities of the robots discussed in this paper are all functionalities claimed by the authors and were derived from articles and web pages. Note that these functionalities not have been verified. When looking at the division between the three different development stages (i.e., concept phase, under development, commercially available), we can see that most robotics are classified in the second group and only a very small number of robots were found to be commercially available. Probably the group of conceptual robots is much larger but no publications on this are available.

For the robots still in the conceptual phase no prototype is available, only (computer) drawings and/or descriptions, so no proof was given that these robots will be capable of performing the promised activities in the future. The robots under development claimed to support various activities. However, claiming to support an activity and actually delivering this support (in the home of an elderly user) are two different things. It is not certain that all robots in this group will eventually be capable to effectively providing the claimed support. And even so, were the robot to be made available to an individual user it is for the user to determine whether the robot provides support in such a way that it results in added value.

Many of the robots under development can be regarded as technology development platforms without a solid commitment to market introduction. These robots have a research purpose and aim primarily at a proof of principle solution. It goes without reasoning that such work is highly valuable even without a clear outlook on approaching 
market availability. In contrast to the robots under development, commercially available robots only support a single activity. It is unlikely this is a coincidence. Single functionality robots may be easier to produce such that they offer a robust and reliable performance. With increasing complexity (functionality) reliability and robustness are likely to deteriorate rapidly rendering the robot unsuitable for market introduction.

Activities concerning self-care, mobility and interpersonal interaction \& relationships are found to be the most problematic for the elderly [1]. Robots could obviously support a number of tasks within these domains, but for some robots it is more questionable whether they will be able to effectively support activities. For example, several activities within the domain self-care (e.g. washing, toileting, dressing, and eating) and the domain mobility (e.g. climbing stairs, lifting and carrying objects) involve physical movement and/or force exertion. A robotic system could therefore be interesting in attempting to support these activities. It can be argued that the need for physical support in the domain self-care also becomes visible when looking at the commercially available robots supporting self-care. The Sanyo Bath Robot supports washing in a physical manner and the Mealtime Partner, My Spoon and Winsford Feeder physically support the user with eating. Interestingly, almost none of the robots in the development phase focus on the physical support of self-care activities. The robots that do focus on supporting self-care activities most often focus on the provision of reminders, monitoring the user and doing health measurements. And while these tasks can be useful for the elderly, it seems questionable whether a robot-based solution is the best option as there is most likely no need for physical movement and/or force exertion. This is similar for fall detection and entertainment functions. It may be easier to place a tablet in every room than to create an expensive tablet on wheels that can navigate through the house without problems, providing non-physical support. The need for a robotic solution is also questionable in the domain of interpersonal interaction \& relationships as there are already several (low cost) non-robotic ICT technologies available to provide social interaction (e.g. mobile telephone, Skype, tele-homecare systems). Nevertheless, there are exceptions such as the commercially available social robot Paro [107, 110]. This also addresses social isolation and is a great success. A strong aspect of Paro, and maybe one of the reasons for its success, is that Paro is an embodiment robot and not a screen based robot. The user can hold and cuddle the seal robot. Its physical and motor aspects are essential to its functioning.

\section{Study limitations}

Scientific literature from 1997 until November 2013, the references of this scientific literature, and relevant European projects were searched in order to collect the results presented in this paper. It can safely be assumed there is more robot development going on that has been missed in this review. However, the amount of robot development that 
was considered is substantial and it is unlikely additional examples would have led to different conclusions. The agreement between the reviewers for title assessment and abstract assessment was respectively substantial and moderate., which implies that publications may have been unjustly rejected. However, the total score of 2 that was applied for inclusion, meaning one reviewer was sure or both reviewers were in doubt, implies a high acceptance rate, which gives more certainty that no relevant titles may have been falsely rejected.

For the robots selected in this review, elderly people needed to be the intended target group for the developers or the robot had to be used in elderly care. However some robots, not specifically designed for the elderly, could still have the potential to successfully support this target group. One such example is the robotic vacuum cleaner e.g., Roomba ${ }^{\circledR}$ [111]. Many elderly experience trouble with vacuum cleaning and although the Roomba ${ }^{\circledR}$ is capable of eliminating this problem, it was nevertheless excluded as the elderly were not specified as the intended target group of the developers. Robots designed for people with specific clinical conditions (e.g., stroke patients, Alzheimer's patients) were also excluded even though robots designed for people with a specific clinical condition can sometimes be beneficial for elderly persons as patients with a clinical condition may also be elderly. Some of the conditions may even be age related. Nevertheless, the intention of this search was to find robots matching the target group elderly and not to find robotics matching the functional limitations resulting from a specific clinical condition that the elderly can experience. This resulted for example in the exclusion of several smart wheelchairs.

To be included, robots needed to be designed for the home environment. A house, apartment or supported housing for the elderly were seen as home environments. Robots that were designed for a hospital or nursing home and robots that were not assigned to a single household (e.g., robots supporting care driving from apartment to apartment) were excluded. Tele-operated robotics were included when they were assigned to a single household. In several cases it was not explicitly mentioned if the robot was intended for the home environment. In those cases the researchers assessed, based on their experience, whether the robot was suitable for the home environment or not. During the assessment of the robot database consensus between all three researchers was needed, which sometimes resulted in discussion. Nevertheless, for all possible robots consensus was reached concerning their inclusion or exclusion. For several robots only a little information could be found. The lack of information or outdated information on these robots may have led to inappropriate classification.

\section{Conclusion}

Many attempts are being made to develop robots that claim to support the elderly in their independent living. In total 107 robots for the elderly were identified. These robots 
were categorized based on their development stage, the activities they support and the type of support they provide. Six robots were still in their concept phase, 95 robots were in the development phase, and six robots were commercially available. The commercially available robots focus on the physical support of self-care related activities and none of these robots support mobility-related activities. More than half of the robots in the development phase claim to physically support mobility-related activities and only a limited number of robots in the development phase focus on providing physical support for self-care related activities.

Technical ambitions seem to be guiding the development of many of the robots under development; while being successful in bringing robots to the market, it seems the needs of the elderly should be taken as a starting point. Not all problematic activities for the elderly are necessarily best-solved by robots. In general, the need of a robot is questionable for activities which do not require physical movement and/or force exertion. Robots only providing non-physical support for mobility and self-care related activities (e.g. fall detection, medication reminders, medication monitoring) will most likely fail to cost-effectively prolong independent living of elderly people as the problematic activities in these domains often require physical support (e.g. mobility transfers, dressing, showering, toileting). The step toward physical support is inevitable and needs to be taken. This brings with it many technical challenges, for example, robots being capable of handling and/or moving frail users. Nevertheless, these technical challenges need to be overcome in order to create successful robots. Additionally, the few robots that were commercially available for consumers only have the capability to support a single activity, while many of the robots under development claim to support many activities. And although robots may in principle have the capabilities to support complex activities for the elderly in their home environment, developing robotics for the elderly in the home environment faces many challenges. The more activities a robot claims to support, the more complex market introduction will be as complexity will rapidly deteriorate reliability and robustness. It should also be noted here that there is a big discrepancy between what the robots under development claim to be capable of and what is demonstrated in the publications. A robot that is capable of performing certain functionality in a lab is still a long way off from a robot that can perform this in the home of an elderly in a safe and robust manner. And although movies on the Internet show us smart robots capable of performing complex activities, it will be a long time before a single robot will be capable of supporting multiple activities in a physical manner in the home of an elderly person in order to enhance their independent living. 


\section{Appendix 1}

\begin{tabular}{|c|c|c|c|}
\hline Cinahl & IEEE & Pubmed & Psyclnfo \\
\hline MH "Robotics" & Assistive technology & "Robotics"[Mesh] & Self help device \\
\hline MH "Assistive & Self-help device & "Self-help devices"[Mesh] & Assistive technolog* \\
\hline technology" & Robot* & Assistive technology & Robot* \\
\hline Assistive technolog* & Gerontechnology & Robot* & Gerontechnology \\
\hline Robot* & "Healthcare & Assistive robot* & Robot assistance \\
\hline Assistive robot* & technology" & Service robot* & Healthcare Technolog* \\
\hline Service robot* & "Health technology" & Gerontechnology & Health technolog* \\
\hline Gerontechnology & "Health technologies" & Robot* assistance & Care provider \\
\hline Robot* assistance & Care Technology & Healthcare technolog* & technolog* \\
\hline Healthcare technology* & "Service robot*" & Health technolog* & Care technolog* \\
\hline Health technolog* & "Assistive robot*" & Care provider technolog* & \\
\hline Care technolog* & "Robot* support" & Independence technolog* & \\
\hline Robot* device* & & Care technolog* & \\
\hline Robot* support & & Human robot* interaction & \\
\hline & & Robot* device* & \\
\hline MM "Frail elderly" & "Old age" & "Aged"[Mesh] & "Frail elderly" \\
\hline MH "Aged, 80 and over" & "Old aged people" & "Frail elderly"[Mesh] & "Aged people" \\
\hline Frail elderly & "Old age people" & "Aged, 80 and over"[Mesh] & "Aging people" \\
\hline Aged, 80 and over & "Older person" & "Frail elderly"[Mesh] & Elderly \\
\hline Elderly & "Older people" & "Frail" AND "Elderly" & "Older population*" \\
\hline Aged people & "Ageing population" & "Frail elderly" & “Aged population*" \\
\hline Ageing people & "Aging population" & "Aged people" & "Aging population*" \\
\hline $65+$ & "Older adults" & "Ageing people" & "Older adult*" \\
\hline Older population* & "Aged population" & 65 & "Older people" \\
\hline Ageing population* & Elderly & "Aged"[Mesh] & "Old age" \\
\hline Older adults & $65+$ & "Elderly" & \\
\hline Older people & "Aging people" & Older population & \\
\hline \multirow[t]{11}{*}{ Old age } & "Ageing people" & Older populations & \\
\hline & & "Aged population*" & \\
\hline & & Aging population & \\
\hline & & Ageing populations & \\
\hline & & Older AND “Adult”[Mesh] & \\
\hline & & "Adult" & \\
\hline & & "Adults" & \\
\hline & & Older AND “Persons"[Mesh] & \\
\hline & & "Persons" & \\
\hline & & "People" & \\
\hline & & "Old age" & \\
\hline
\end{tabular}




\section{References}

[1] Bedaf, S., Gelderblom, G.J., Syrdal, D.S., Lehmann, H., Michel, H., Hewson, D., ... \& de Witte, L. (2014). Which activities threaten independent living of elderly when becoming problematic: inspiration for meaningful service robot functionality. Disability and Rehabilitation: Assistive Technology, 9(6), 445-452. doi: 10.3109/17483107.2013.840861

[2] Cameron, C., \& Moss, P. (2007). Care work in Europe: Current understandings and future directions. Oxford: Routledge.

[3] Vlaskamp, F., Soede, T., \& Gelderblom, G.J. (2011). History of assistive technology: 5000 years of technology development for human needs. Heerlen: Zuyd University of Applied Sciences.

[4] International Federation of Robotics. (2014, July 29). Retrieved from http://www.ifr.org

[5] Bekey, G., Ambrose, R., Kumar, V., Sanderson, A., Wilcox, B., \& Zheng, Y. (2006). WTEC Panel Report on International Assessment of Research and Development in Robotics. World Technology Evaluation Centre.

[6] Üstün, T.B. (2002). Towards a Common Language for Functioning, Disability and Health, ICF. World Health Organization Geneva, 23

[7] Landis, J.R., \& Koch, G. G. (1977). The measurement of observer agreement for categorical data. biometrics, 159-174. doi: 10.2307/2529310.

[8] Cavallo, F., Aquilano, M., Bonaccorsi, M., Mannari, I., Carrozza, M.C., \& Dario, P. (2011). Multidisciplinary approach for developing a new robotic system for domiciliary assistance to elderly people. In Engineering in Medicine and Biology Society (EMBC), 2011 Annual International Conference of the IEEE (pp. 5327-5330). IEEE. doi: 10.1109/IEMBS.2011.6091318.

[9] Kim, Y. J., Im, E., Ko, C. W., Kim, S. T., Chun, K. J., \& Kim, D. H. (2010). Design and control of actively combined carrier system for the elderly. In Control Automation and Systems (ICCAS) (pp. 143-146). IEEE.

[10] Green, K. E., Wakjer, I. D., Brooks, J. O., Mohktar, T., \& Smolentzov, L. (2009). comforTABLE: A robotic environment for aging in place. In Proceedings of the 4th ACM/IEEE International Conference on Human robot interaction (pp. 223-224). ACM. doi: 10.1145/1514095.1514147.

[11] Zhihua, Z., Jianyong, Z., Yang, L., \& Gang, L. (2009). Development of a movable service robot with double working arms for the elderly and the disabled. In 2009 International Conference on Electronic Computer Technology.

[12] Lay, K., Prassler, E., Dillmann, R., Grunwald, G., Hägele, M., Lawitzky, G., ... \& Von Seelen, W. (2001). MORPHA: Communication and interaction with intelligent, anthropomorphic robot assistants. Tagungsband Statustage Leitprojekte Mensch-Technik-Interaktion in der Wissensgesellschaft.

[13] Tian, L., Li, M., Chen, Z., \& Duan, H. (2012). Research of the robot for the elderly based on star positioning. In Intelligent Control and Automation (WCICA) (pp. 3639-3641). IEEE. doi: 10.1109/WCICA.2012.6359078.

[14] Tsai, C. C., Hsieh, S. M., Hsu, Y. P., \& Wang, Y. S. (2009, October). Human-robot interaction of an active mobile robotic assistant in intelligent space environments. In International Conference on Systems, Man and Cybernetics (pp. 1953-1958). IEEE. doi: 10.1109/ICSMC.2009.5346049.

[15] RoboCare. (2014, March 6). Retrieved from http://robocare.istc.cnr.it/robocup.htm

[16] European Commision. (2012). EU-funded research into robotics for rehabilitations and independent living. Retrieved from https://ec.europa.eu/digital-agenda/en/news/overview-eu-funded-running-researchprojects-robotics-rehabilitation-and-independent-living

[17] Woo, J., Wada, K., \& Kubota, N. (2012). Robot partner system for elderly people care by using sensor network. In 4th IEEE RAS \& EMBS International Conference on Biomedical Robotics and Biomechatronics (BioRob) (pp. 1329-1334). IEEE. doi: 10.1109/BioRob.2012.6290933.

[18] Toshiba. (2014, March 6). Retrieved from https://www.toshiba.co.jp/rdc/rd/fields/07_t15.htm

[19] Sugisaka, M. (2001). Development of Communication methods between artificial liferobot and human being. In Proceedings of IEEE Region 10 International Conference on Electrical and Electronic Technology (Vol. 2, pp. 894-898). IEEE. doi: 10.1109/TENCON.2001.949725. 


\section{Chapter 3}

[20] Berns, K., \& Mehdi, S.A. (2010). Use of an autonomous mobile robot for elderly care. In Advanced Technologies for Enhancing Quality of Life (AT-EQUAL) (pp. 121-126). IEEE. doi: 10.1109/ATEQUAL. 2010.30.

[21] Xiong, G., Gong, J., Zhuang, T., Zhao, T., Liu, D., \& Chen, X. (2007). Development of assistant robot with standing-up devices for paraplegic patients and elderly people. In IEEE/ICME International Conference on Complex Medical Engineering (CME 2007) (pp. 62-67). doi: 10.1109/ICCME.2007.4381693.

[22] Ficocelli, M., \& Nejat, G. (2012). The design of an interactive assistive kitchen system. Assistive Technology, 24(4), 246-258. doi: 10.1080/10400435.2012.659834.

[23] Fasola, J., \& Mataric, M. J. (2010). Robot exercise instructor: A socially assistive robot system to monitor and encourage physical exercise for the elderly. In RO-MAN, 2010 IEEE (pp. 416-421). doi: 10.1109/ ROMAN.2010.5598658.

[24] Cogniron. (2014, March 6). Retrieved from http://www.cogniron.org/final/Home.php

[25] Bobbie Robotics. (2014, March 6). Retrieved from http://www.bobbierobotics.nl/home

[26] HealthBots. (2014, March 6). Retrieved from https://wiki.auckland.ac.nz/display/csihealthbots/Home?src =contextnavchildmode

[27] GeckoSystems. ((2014, March 6). Retrieved from http://www.geckosystems.com/

[28] Fraunhofer IPA. (2014, March 6). Retrieved from http://www.care-o-bot.de/en/care-o-bot-3.html

[29] ACCOMPANY. (2014, March 6). Retrieved from http://accompanyproject.eu/

[30] SRS. (2014, March 6). Retrieved from http://srs-project.eu/

[31] Surendran, S., Rasamany, S., \& Megalingam, R.K. (2013). Context aware biomedical robotic platform for elderly health care. In 8th International Conference on Computer Science \& Education (ICCSE) (pp. 259263). IEEE. doi: 10.1109/ICCSE.2013.6553921.

[32] Wei, X., Zhang, X., \& Yi, P. (2012). Design of control system for elderly-assistant \& walking-assistant robot based on fuzzy adaptive method. In International Conference on Mechatronics and Automation (ICMA) (pp. 2083-2087). IEEE.

[33] Nursebot. (2014, March 6). Retrieved from http://www.cs.cmu.edu/ nursebot/

[34] Florence. (2014, March 6). Retrieved from http://www.florence-project.eu/

[35] Park, T.J., Han, C.S., Han, J.S., \& Lee, H.G. (2004). Development of the gait assistant mobile robot using ergonomic design. In Proceedings IEEE International Conference on Robotics and Automation (Vol. 2, pp. 2037-2042). IEEE.

[36] ExCITE. (2014, March 6). Retrieved from http://www.oru.se/ExCITE/

[37] GiraffPlus. (2014, March 6). Retrieved from http://giraffplus.eu/

[38] Rentschler, A.J., Simpson, R., Cooper, R.A., \& Boninger, M.L. (2008). Clinical evaluation of Guido robotic walker. Journal of rehabilitation research and development, 45(9), 1281-1293.

[39] RAIL. (2014, March 6). Retrieved from http://www.ftb-net.com/rail.html

[40] Fiorini, P., Ali, K., \& Seraji, H. (1997). Health care robotics: A progress report. In Proceedings IEEE International Conference Robotics and Automation (Vol. 2, pp. 1271-1276). IEEE. doi: 10.1109/ROBOT. 1997.614312.

[41] CompanionAble. (2014, March 6). Retrieved from http://www.companionable.net/

[42] Hobbit. (2014, March 6). Retrieved from http://hobbit.acin.tuwien.ac.at/

[43] Lee, S. (2011). Cognitive recognition and the homemate robot. In IEEE International Conference Systems, Man, and Cybernetics (SMC) (pp. 1-1). IEEE.

[44] Wu, X., Gong, H., Chen, P., Zhi, Z., \& Xu, Y. (2009). Intelligent household surveillance robot. In IEEE International Conference on Robotics and Biomimetics (pp. 1734-1739). IEEE.

[45] MIT Media Lab. (2014, March 6). Retrieved from http://robotic.media.mit.edu/projects/robots/huggable/ overview/overview.html

[46] Philips. (2014, March 7). Retrieved from http://www.research.philips.com/technologies/projects/ robotics/

[47] Seo, K.H., Oh, C., Choi, T.Y., \& Lee, J.J. (2005). Bed-type robotic system for the bedridden. In Proceedings IEEE/ASME International Conference on Advanced Intelligent Mechatronics (pp. 1170-1175). IEEE. 
[48] Nakagawa, S., Pei, D., Huang, J., Sekiyama, K., \& Fukuda, T. (2013). Control of intelligent cane robot considering usage of ordinary cane. In RO-MAN (pp. 762-767). IEEE. doi: 10.1109/ROMAN.2013.6628405.

[49] Ohya, A., \& Munekata, T. (2002). Intelligent escort robot moving together with human-interaction in accompanying behavior. In Proceedings 2002 FIRA Robot World Congress (pp. 31-35).

[50] Jia, S., Hada, Y., Gakuhari, H., Takase, K., Ohnishi, T., \& Nakamoto, H. (2006). Intelligent home service robotic system based on robot technology middleware. In IEEE/RSJ International Conference on Intelligent Robots and Systems (pp. 4478-4483). IEEE. doi: 10.1109/IROS.2006.282084.

[51] Ye, J., Huang, J., He, J., Tao, C., \& Wang, X. (2012). Development of a width-changeable intelligent walkingaid robot. In International Symposium on Micro-NanoMechatronics and Human Science (MHS), (pp. 358363). IEEE. doi: 10.1109/MHS.2012.6492438.

[52] Botzheim, J., \& Kubota, N. (2012). Growing neural gas for information extraction in gesture recognition and reproduction of robot partners. In International Symposium on Micro-NanoMechatronics and Human Science (MHS), (pp. 149-154). IEEE. doi: 10.1109/MHS.2012.6492471.

[53] Lee, G., Ohnuma, T., Chong, N.Y., \& Lee, S.G. (2014). Walking intent-based movement control for JAIST active robotic walker. IEEE Transactions on Systems, Man, and Cybernetics: Systems, 44(5), 665-672. doi: 10.1109/tsmc.2013.2270225.

[54] Yu, K.T., Lam, C.P., Chang, M.F., Mou, W.H., Tseng, S.H., \& Fu, L.C. (2010). An interactive robotic walker for assisting elderly mobility in senior care unit. In IEEE Workshop on Advanced Robotics and its Social Impacts (ARSO) (pp. 24-29). IEEE.

[55] Zecca, M., Endo, N., Momoki, S., Itoh, K., \& Takanishi, A. (2008). Design of the humanoid robot KOBIANpreliminary analysis of facial and whole body emotion expression capabilities. In 8th IEEE-RAS International Conference on Humanoid Robots (pp. 487-492). IEEE. doi: 10.1109/ICHR.2008.4755969.

[56] Robotsoft. (2014, March 7). Retrieved from from http://www.robosoft.com/

[57] Mobiserv. (2014, March 7). Retrieved from http://www.mobiserv.info/

[58] JSK. (2014, March 7). Retrieved from http://www.jsk.t.u-tokyo.ac.jp/index.html

[59] Taipalus, T., \& Kosuge, K. (2005). Development of service robot for fetching objects in home environment. In Proceedings IEEE International Symposium on Computational Intelligence in Robotics and Automation (CIRA) (pp. 451-456). IEEE. doi: 10.1109/CIRA.2005.1554318.

[60] Balaguer, C., Gimenez, A., Huete, A.J., Sabatini, A.M., Topping, M., \& Bolmsjo, G. (2006). The MATS robot: service climbing robot for personal assistance. IEEE Robotics \& Automation Magazine, 13(1), 51-58. doi: 10.1109/mra.2006.1598053.

[61] Yamazaki, A., \& Masuda, R. (2012). Autonomous foods handling by chopsticks for meal assistant robot. In Proceedings of 7th German Conference on Robotics (ROBOTIK) (pp. 1-6). VDE.

[62] Salemi, B., Reis, J., Saifhashemi, A., \& Nikgohar, F. (2005). Milo: Personal robot platform. In IEEE/RSJ International Conference on Intelligent Robots and Systems (IROS 2005) (pp. 4089-4094). IEEE. doi: 10.1109/IROS.2005.1545566.

[63] Lin, H.H., Tsai, C.C., Hu, S.M., \& Chang, H.Y. (2007). Automatic mapping for an indoor mobile robot assistant using RFID and laser scanner. In Annual Conference SICE (pp. 2102-2108). IEEE.

[64] Dario, P., Guglielmelli, E., Laschi, C., \& Teti, G. (1999). MOVAID: a personal robot in everyday life of disabled and elderly people. Technology and Disability, 10(2), 77-93.

[65] Ge, S. S., Safizadeh, M. R., \& Li, Y. (2011). Mechanical design of social robot Nancy. In IEEE/SICE International Symposium on System Integration (SII) (pp. 324-329). IEEE. doi: 10.1109/SII.2011.6147468.

[66] KSERA. (2014, March 7). Retrieved from http://www.ksera-project.eu/

[67] Liu, T., \& Meng, M.Q.H. (2012). Study on cooperation between humanoid robot Nao and Barrett WAM. In IEEE International Conference on Robotics and Biomimetics (ROBIO) (pp. 980-983). IEEE. doi: 10.1109/ROBIO.2012.6491096.

[68] Nakashima, T., Fukutome, G., \& Ishii, N. (2010). Healing effects of pet robots at an elderly-care facility. In IEEE/ACIS 9th International Conference on Computer and Information Science (ICIS) (pp. 407-412). IEEE. doi: 10.1109/ICIS.2010.53. 
[69] Kuo, Y.P., Pai, N.S., Hsieh, H.H., \& Kuo, C.L. (2013). The application of CMAC-based fall detection in Omnidirectional mobile robot. In International Conference on Advanced Robotics and Intelligent Systems (ARIS) (pp. 64-69). IEEE. doi: 10.1109/ARIS.2013.6573536.

[70] Zhu, C., Oda, M., Luo, X., Watanabe, H., \& Yan, Y. (2009). Platform development of an omnidirectional mobile robot for the elderly's walking support and the caregiver's power assistance. In IEEE International Conference on Robotics and Biomimetics (ROBIO) (pp. 1900-1905). IEEE.

[71] Nejatbakhsh, N., \& Kosuge, K. (2005). User-environment based navigation algorithm for an omnidirectional passive walking aid system. In 9th International Conference on Rehabilitation Robotics, 2005 (ICORR) (pp. 178-181). IEEE. doi: 10.1109/ICORR.2005.1501079.

[72] Suzuki, N., Masamune, K., Sakuma, I., Suzuki, M., Yahagi, N., Tuji, T., ... \& Dohi, T. (2000). System assisting walking and carrying daily necessities with an overhead robot arm for in-home elderlies. In Proceedings of the 22nd Annual International Conference of the IEEE on Engineering in Medicine and Biology Society (Vol. 3, pp. 2271-2274). IEEE. doi: 10.1109/IEMBS.2000.900593.

[73] Henry, J.S., \& Aharonson, V. (2010). Gait monitoring for the elderly using a robotic walking aid. In IEEE 26th Convention of Electrical and Electronics Engineers in Israel (IEEEI) (pp. 000392-000394). IEEE. doi: 10.1109/EEEI.2010.5662196.

[74] Filipescu, A., Susnea, I., \& Stamatescu, G. (2009). Distributed system of mobile platform obstacle avoidance and control as robotic assistant for disabled and elderly. In IEEE International Conference on Control and Automation (ICCA) (pp. 1886-1891). IEEE.

[75] Alexan, A.I., Osan, A.R., \& Oniga, S. (2012). Personal assistant robot. In IEEE 18th International Symposium for Design and Technology in Electronic Packaging (SIITME) (pp. 69-72). IEEE. doi: 10.1109/SIITME.2012. 6384348.

[76] Panasonic. (2014, March 21). Retrieved from http://panasonic.co.jp/corp/news/official.data/data.dir/ en090918-2/en090918-2.html

[77] Takahashi, Y., Kikuchi, Y., Ibaraki, T., \& Ogawa, S. (1999). Robotic food feeder. In 38th Annual Conference Proceedings of the SICE Annual (pp. 979-982). IEEE. doi: 10.1109/SICE.1999.788683.

[78] Chuy, O., Hirata, Y., \& Kosuge, K. (2007). Active type robotic mobility aid control based on passive behavior. In IEEE/RSJ International Conference on Intelligent Robots and Systems (IROS) (pp. 165-170). IEEE. doi: 10.1109/IROS.2007.4399408.

[79] Morris, A., Donamukkala, R., Kapuria, A., Steinfeld, A., Matthews, J.T., Dunbar-Jacob, J., \& Thrun, S. (2003). A robotic walker that provides guidance. In Proceedings of the IEEE International Conference on Robotics and Automation (ICRA) (Vol. 1, pp. 25-30). IEEE. doi: 10.1109/ROBOT.2003.1241568.

[80] Chugo, D., Asawa, T., Kitamura, T., Songmin, J., \& Takase, K. (2009). A motion control of a robotic walker for continuous assistance during standing, walking and seating operation. In IEEE/RSJ International Conference on Intelligent Robots and Systems (IROS) (pp. 4487-4492). IEEE.

[81] DOMEO. (2014, March 21). Retrieved from http://www.aal-domeo.eu/

[82] Song, K. T., Tsai, C. Y., Huang, F. S., Hong, J. W., Lin, C. Y., Chen, C. W., \& Lin, Z. S. (2008). Development of the robot of living aid: RoLA. In IEEE International Conference on Automation and Logistics(ICAL) (pp. 443448). IEEE.

[83] ROSE. (2014, March 21). Retrieved from http://robot-rose.com/nc/home/

[84] Hirata, Y., Wang, Z.D., \& Kosuge, K. (2006). Human-robot interaction based on passive robotics. In International Joint Conference SICE-ICASE (pp. 4206-4209). IEEE. doi: 10.1109/SICE.2006.314771.

[85] Lebec, O., Ghezala, M.W.B., Leynart, V., Laffont, I., Fattal, C., Devilliers, L., ... \& Dupourque, V. (2013). High level functions for the intuitive use of an assistive robot. In IEEE International Conference on Rehabilitation Robotics (ICORR) (pp. 1-6). IEEE. doi: 10.1109/ICORR.2013.6650374.

[86] Luo, R.C., Chen, C.T., \& Pu, Y.J. (2009). Internet based remote supervisory system for Tele-medicine robot application. In IEEE Workshop on Advanced Robotics and its Social Impacts (ARSO) (pp. 153-158). IEEE. doi: 10.1109/ARSO.2009.5587057.

[87] Hatsukari, T., Kuroko, S., Miyake, N., Higuchi, J.I., Kawazoe, R., Hirata, Y., \& Kosuge, K. (2009). Self-help standing-up method based on quasi-static motion. In IEEE International Conference on Robotics and Biomimetics (ROBIO) (pp. 342-347). IEEE. doi: 10.1109/ROBIO.2009.4913027. 
[88] Tzou, J.H., \& Chiang, F.C. (2009). The development of the mobile robot for taking care of elderly people. In Fourth International Conference on Innovative Computing, Information and Control (ICICIC) (pp. 540543). IEEE. doi: 10.1109/ICICIC.2009.352.

[89] Barea, R., Bergasa, L.M., López, E., Escudero, M.S., Hernández, J.A., \& Willemaers, Y. (2004). Tele-medicine system based on a personal robotic assistant. In 10th IEEE International Conference on Methods and Models in Automation and Robotics MMAR (Vol. 4, pp. 909-915).

[90] Yuk, G.H., Park, H.S., Jun, H.G., Dan, B.J., \& Jo, B.R. (2012). Posture balancing control of smart mobile walker for uneven terrain. In 9th International Conference on Ubiquitous Robots and Ambient Intelligence (URAI) (pp. 63-64). IEEE.

[91] Yaskawa Electric. (2014, March 21). Retrieved from http://www.yaskawa.co.jp/newsrelease/2007/25.htm

[92] Chen, C.T., \& Pham, H.V. (2008). Enhanced development and stability analysis of a new stair-climbing robotic wheelchair. In IEEE Workshop on Advanced robotics and Its Social Impacts (ARSO) (pp. 1-6). IEEE.

[93] Wang, M.S., \& Tu, Y.M. (2008). Design and implementation of a stair-climbing robot. In IEEE Workshop on Advanced robotics and Its Social Impacts (ARSO) (pp. 1-6). IEEE.

[94] AIST. (2014, March 21). Retrieved from http://www.aist.go.jp/aist_e/aist_today/2010_36/hot_line/ hot_line_19_2.html

[95] Jia, S., \& Takase, K. (2003). Development of a human-assist robotic system using distributed computing technology. In Proceedings IEEE International Symposium on Computational Intelligence in Robotics and Automation (Vol. 1, pp. 241-246). IEEE. doi: 10.1109/CIRA.2003.1222096.

[96] Kim, M., Kim, S., Park, S., Choi, M.T., Kim, M., \& Gomaa, H. (2009). Service robot for the elderly. IEEE robotics \& automation magazine, 16(1), 34-45. doi: 10.1109/mra.2008.931636.

[97] Georgoulas, C., Linner, T., Kasatkin, A., \& Bock, T. (2012). An Aml environment implementation: Embedding TurtleBot into a novel robotic service wall. In Proceedings of 7 th German Conference on Robotics (ROBOTIK) (pp. 1-6). VDE.

[98] Iwata, H., \& Sugano, S. (2009). Design of human symbiotic robot TWENDY-ONE. In IEEE International Conference on Robotics and Automation (ICRA) (pp. 580-586). IEEE. doi: 10.1109/ROBOT.2009.5152702.

[99] LPR. (2014, March 21). Retrieved from http://www-robotics.cs.umass.edu/index.php/Robots/UBot-5

[100] Takagi, M., Takahashi, Y., \& Komeda, T. (2009). A Universal Mobile robot for assistive tasks. In IEEE International Conference on Rehabilitation Robotics (ICORR) (pp. 524-528). IEEE. doi: 10.1109/ICORR.2009.5209602.

[101]Jiang, S.Y., Hung, S.C., \& Song, K.T. (2011). A call-to-service design for mobile robots using Zigbee sensor networks. In 8th Asian Control Conference (ASCC) (pp. 317-322). IEEE.

[102]Ko, C.H., Young, K.Y., Huang, Y.C., \& Agrawal, S.K. (2013). Active and passive control of walk-assist robot for outdoor guidance. IEEE/ASME Transactions on Mechatronics, 18(3), 1211-1220. doi: 10.1109/tmech. 2012.2201736

[103]Sugahara, Y., Ohta, A., Hashimoto, K., Sunazuka, H., Kawase, M., Tanaka, C., ... \& Takanishi, A. (2005). Walking up and down stairs carrying a human by a biped locomotor with parallel mechanism. In IEEE/RSJ International Conference on Intelligent Robots and Systems (IROS) (pp. 1489-1494). IEEE. doi: 10.1109/ IROS.2005.1545500.

[104]Kato, S., Ohshiro, S., Itoh, H., \& Kimura, K. (2004). Development of a communication robot Ifbot. In Proceedings of IEEE International Conference on Robotics and Automation (ICRA) (Vol. 1, pp. 697-702). IEEE. doi: 10.1109/ROBOT.2004.1307230.

[105]Assistive Innovations. (2014, March 21). Retrieved from http://www.assistive-innovations.eu/

[106]SECOM. (2014, March 21). Retrieved from http://www.secom.co.jp/english/myspoon/

[107]AIST. (2014, March 21). Retrieved from http://www. parorobots.com/

[108]Panasonic. (2014, March 20). Retrieved from http://ctlg.panasonic.co.jp/sanyo/products/biz/care/ products/care/index.html

[109]North Coast Medical. (2014, March 21). Retrieved from https://www.ncmedical.com/

[110]Gelderblom, G.J., Bemelmans, R., Spierts, N., Jonker, P., \& De Witte, L. (2010). Development of PARO interventions for dementia patients in Dutch psycho-geriatric care. In International Conference on Social Robotics (pp. 253-258). Springer Berlin Heidelberg. doi: 10.1007/978-3-642-17248-9_26.

[111]iRobot. (2014, March 21). Retrieved from http://www.roomba.nl/Roomba/iRobot.html 


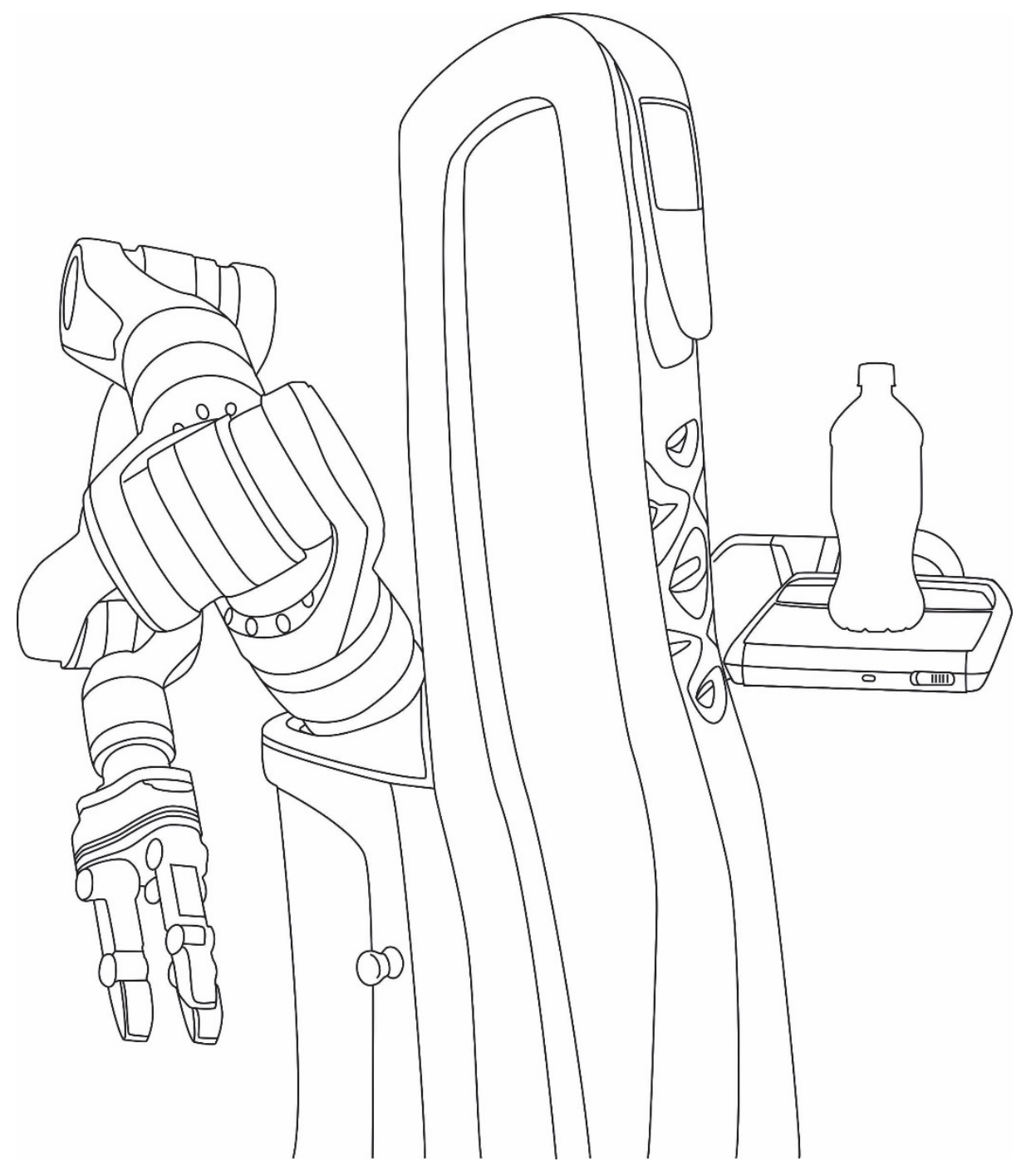




\section{CHAPTER 4}

\section{Which Activities Threaten Independent Living of Elderly when Becoming Problematic; Inspiration for Meaningful Service Robot}

Functionality

This chapter was published as:

Bedaf, S., Gelderblom, G. J., Syrdal, D. S., Lehmann, H., Michel, H., Hewson, D., ... \& de Witte, L. (2014). Which Activities Threaten Independent Living of Elderly when Becoming Problematic: Inspiration for Meaningful Service Robot Functionality. Disability and Rehabilitation: Assistive Technology, 9(6), 445-452. doi: 10.3109/17483107. 2013.840861. 


\section{Abstract}

Purpose: In light of the increasing elderly population and the growing demand for home care, the potential of robot support is given increasing attention. In this paper an inventory of activities was made that threaten independent living of elderly when becoming problematic. Results will guide the further development of an existing service robot, the Care-O-bot ${ }^{\circledR} 3$.

Method: A systematic literature search of Pubmed was performed, focused on the risk factors for institutionalization. Additionally, focus group sessions were conducted in the Netherlands, United Kingdom, and France. In these focus group sessions problematic activities threatening the independence of elderly people were discussed. Three separate target groups were included in the focus group sessions: 1$)$ elderly persons $(n=41), 2)$ formal caregivers $(n=40)$, and 3 ) informal caregivers $(n=32)$.

Results: Activities within the ICF domains mobility, self-care, and interpersonal interaction $\&$ relationships were found to be the most problematic.

Conclusions: A distinct set of daily activities was identified that may threaten independent living, but no single activity could be selected as the main activity causing a loss of independence as it is often a combination of problematic activities which is personspecific. Supporting the problematic activities need not involve a robotic solution. 


\section{Introduction}

In western societies sustaining independent living of elderly is preferred by most citizens and a target for societal policies. Nonetheless, when people age, they are faced with the negative consequences of their decreasing abilities which, among other factors, can threaten their independent living. Age-related changes to mental and physical abilities can make the performance of everyday tasks difficult or challenging. For those who are not able to maintain their independence, societies seek different kinds of solutions towards regaining or sustaining independence, or alternatively offer an institutional arrangement for dependent living. Risk profiles for institutionalization are very useful for developing interventions to prevent the need for nursing home admission and designing non-institutional alternatives to costly long-term institutional care. However, the causes of the institutionalization of an elderly person are certainly complex [1]. Regardless of the housing situation, care is traditionally provided either informally by those from the direct social environment (e.g. family) or more formally by professionals funded by either public or private means. However, social structures have changed, which have resulted in family members being less inclined and/or able to provide care. Due to this change and the increasing shortage of care staff [2] alternative solutions are being given increasing attention, with technology as the alternative with the highest potential. Of course, technology is already being used to support independence. Assistive technology (AT), such as wheelchairs, stair lifts, patient hoists, smart home technologies, and in general accessibility adaptations of the home, has come a long way in supporting individuals in their independence [3]. But with the ongoing development of technology new possibilities emerge for supporting independent living. A new emerging field in AT is robotics. Robotics has the potential to support care and independence in many ways [4]. Although there is still only limited application of robotics in care, substantial effort is being taken to develop applications [5]. The envisioned role of the robots in these developments, and the type of tasks the robots perform, are primarily guided by technical feasibility and to a lesser degree by the target users' needs [5]. Over the past decades several projects have developed a range of functionalities. Nevertheless, only a small number of robot systems have actually been brought to the market and made available to support care for individuals in their daily lives. This raises questions concerning the suitability of the robots to actually answer the needs of users.

In the ACCOMPANY project (Acceptable robotiCs COMPanions for AgeiNg Years) an existing service robot's functionality will be further developed to support older citizens to sustain independent living [6]. This robot should be able to assist elderly persons in being able to carry out problematic daily tasks on his/her own. The type of robot pursued in the ACCOMPANY project, the Care-O-bot ${ }^{\circledR} 3$ (Fraunhofer IPA, Stuttgart, Germany), aims to support activities and is not aimed at replacing lost or declined human abilities as such. The focus of this study is therefore on the activities older people perform and not on their abilities. Humans perform a very wide range of activities, any of which could potentially 
become difficult for older people to perform, thereby threatening independent living. The first goal of the ACCOMPANY project is to understand the needs of future users, regardless of perspectives related to availability of technological solutions.

This paper presents the results of a systematic literature search in PUBMED and the results obtained during focus group sessions conducted with elderly persons, formal caregivers, and informal caregivers in the Netherlands, the United Kingdom, and France, surveying the problematic daily activities which result in elderly persons dependency. This survey process was guided by the following question: Which problematic activities in daily life are most threatening the independence of elderly persons? The idea is that the answer to this question might subsequent be leading for the development of robot functionalities.

\section{Method}

First a systematic literature search was conducted followed by focus group sessions. To deal with the variety of pertinent activities, the International Classification of Functioning (ICF) of the World Health Organization (WHO) was adopted to group activities human perform. The ICF provides a structured taxonomy for the description of human functioning [7]. Within the ICF the subgroups of section d, Activities and Participation, were especially considered to be relevant as the focus here is on the activities people perform and not on their ability which is also the focus of this paper.

\section{Literature}

The data collection process to find articles, concerning risk factors (related to daily activities) for the institutionalization of elderly persons, consisted of two tracks: a systematic search in Pubmed and a hand search (see Figure 1). First, a systematic literature search of Pubmed was performed for records through September 2012 to identify articles of all studies which aimed to assess activity related risk factors for institutionalization of elderly persons. Pubmed was searched using the following search terms: risk factors, predictors, determinants, daily activities, activities of daily living, and instrumental activities of daily living combined in all possible ways with institutionalization. There were no limitations on dates of publication or venue. This resulted in an initial list of 688 titles. Secondly, the author and two other researchers independently screened and scored the initial set of titles (score 0 when not relevant, 1 point when maybe relevant and 2 points when expected to be highly relevant). Studies were selected as relevant if they reported risk factors for the institutionalization of elderly persons. Studies concerning rehabilitation, fall risks, cognitive decline or clinical conditions (e.g. stroke, dementia, Alzheimer) were excluded. Studies were selected for inclusion if they received a total score of minimal 2 points (the kappa for scoring titles between reviewer 1 and 2 was 0.56, between reviewer 1 and 30.49 , and between 
reviewer 2 and 3 0.55, which are all moderate). This second step in the data collection process resulted in a list of 116 abstract. Thirdly, the author and the same two researchers independently screened and scored all abstracts given the same in- and exclusion criteria for scoring the titles. Studies were selected for inclusion if they received a total score of 3 points or more (the kappa for scoring abstracts between reviewer 1 and 2 was 0.48, between reviewer 1 and 3 0.44, and between reviewer 2 and 30.62 , which are again all moderate). This resulted, after the exclusion of 4 non-English articles, in 60 full-text articles. In addition, a hand search was adopted to retrieve data. Efforts in these searches led to 2 additional studies on the problems of independently living elderly people with no cognitive decline. Finally, these 62 full-text studies were reviewed by the author, according to the aim of this literature study: creating an overview of articles that studied the possibility of daily activities being risk factors for the institutionalization of an elderly person. This led to the final number of 51 papers.

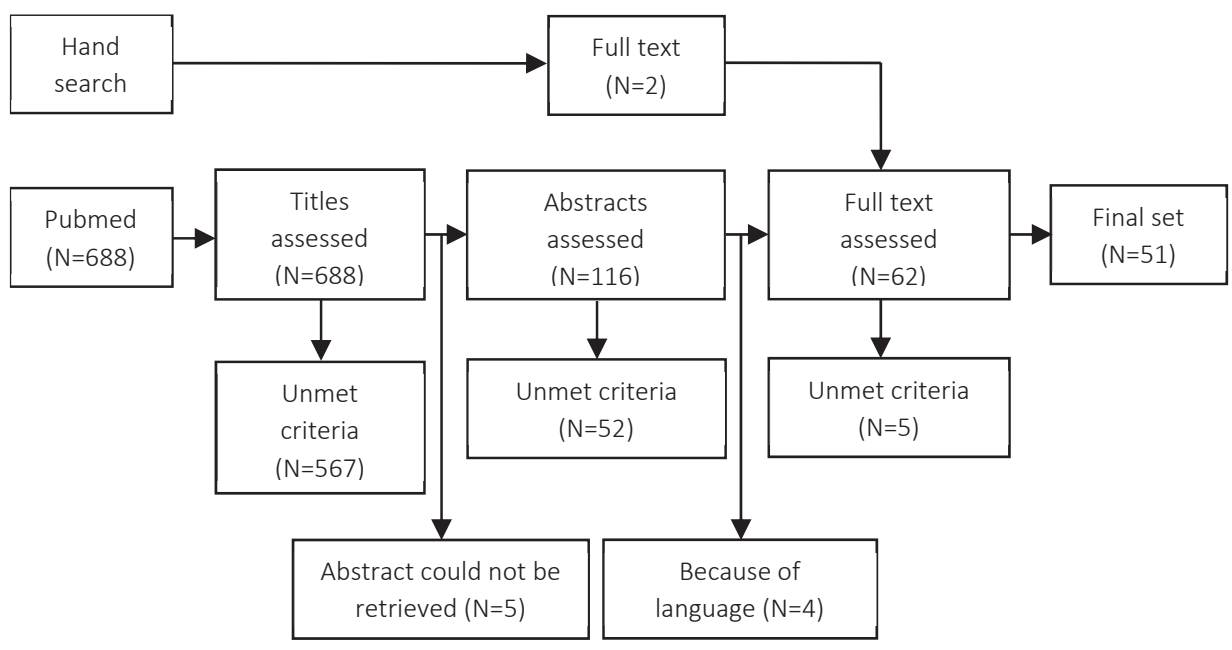

Figure 1: Overview in and exclusion titles, abstracts, and full text of the literature study process.

\section{Focus Groups}

Different focus group meetings were held in the Netherlands, United Kingdom, and France. For these focus group meetings the viewpoints of the individual participants as well as the group consensus were found to be important. Therefore the Metaplan method was used for the data collection [8]. This method ensured that all participants contributed to the outcome of the meeting, whilst the group discussion provided deeper understanding of the issues discussed. Three separate target groups were included: 1) elderly persons, 2) formal caregivers, and 3) informal caregivers. Separate focus groups were held for each of the three target groups, so that perspectives of the different groups could be captured. 


\section{Participants}

Elderly persons and formal caregivers were contacted through care organizations. Informal caregivers were contacted through personal networks and through care organizations. Elderly persons were selected based on four criteria: 1) aged 60+, 2) living at home, 3) no cognitive decline, and 4) receiving home care. The selection of formal caregivers was based on their work activities/profession. It was required that they worked closely with independently living elderly persons on at least a weekly basis. Informal caregivers had to meet one of the two criteria: 1 ) take care of an independently living elderly person on at least a weekly basis, or 2) to have taken care of an independently living elderly person on a weekly basis in the last year. During the recruitment the term robotics was mentioned, as well as the goal of the ACCOMPANY project. However it was clearly stated that the particular emphasis of this focus group would not be on the use of robots. In total 113 persons participated in the study:

- Forty-one elderly persons (12 male, 29 female) with a mean age of 78.0 years (60 to 95) participated in focus group meetings in the Netherlands (11), United Kingdom (5) and France (25). All elderly persons were still living at home and receiving some form of care assistance (e.g. home care, tele-homecare system).

- Forty professional caregivers (2 male, 38 female) participated in focus group meetings in the Netherlands (14), United Kingdom (4) and France (22). Caregivers' professions varied from care workers, nurses, psychologists to managers. All professional caregivers worked closely with the elderly.

- Thirty-two informal caregivers (2 male and 30 female) participated in focus group meetings in the Netherlands (7), United Kingdom (5) and France (20). Informal caregivers took care of (one of) their parents, their spouse, neighbour, or their aunt. In two cases the elderly person taken care of was recently institutionalized and in one case the elderly person had recently passed away.

\section{Procedure}

The focus groups were carried out in separate groups of 4-10 participants in a room with a round table formation. Every participant received a marker pen and sticky notes. After the introduction and signing of the informed consent, participants were given one of the following questions (one for each group type):

- Elderly persons: Which problematic activities in (your) daily life are threatening (your) independent living?

- Formal caregivers: Which problematic activities in the daily lives of your clients are threatening their independent living?

- Informal caregivers: Which problematic activities in the daily lives of the person you care for are threatening his/her independent living? 
The first assignment given to all participants was to individually write down as many activities they could think of on sticky notes answering the given question (one activity per sticky note). They were asked to stick their notes (randomly) on one surface when finished writing. Secondly, the participants were asked, as a group, to cluster all the gathered material per topic. During this clustering phase, discussion among participants was encouraged and more clarification was asked when needed. After clustering, all subgroups/topics were again discussed in the group. Finally participants were asked which group/topic they thought was the most important for independent living. Participants who had difficulty picking just one problem at the end of the focus group meeting, were given the following question: If we are going to create something to solve one of these problems, which problem should we solve first? The duration of the focus groups varied between 1.5 and 2 hours.

Data analysis

Pictures were taken of the final clustered notes and all activities written on the notes were copied per group/topic. A short summary of every group/topic was compiled, as well as a general description of the whole session. A final list was composed for every focus group of those activities participants felt needed solving first.

\section{Results}

\section{Literature}

In the literature different variables related to nursing home admission could be identified. Nonetheless, only articles that studied the possibility of daily activities being risk factors were found to be interesting and will be discussed in this chapter. The systematic literature search led to 50 non-robotic-related studies and 1 robot-related study on the problems of independently living elderly people. This robot-related study concerns the European Multi-Role Shadow Robotic System for Independent Living (SRS) project [9], which produced a list of activities that make independent living challenging for elderly persons. This list was created without reference to robotics or technologies and therefore suitable for this literature search.

Within the final set of 51 studies a distinction was made between articles studying clustered activities and articles studying single activities (see Figure 2). Articles could also be grouped in both sub-groups when one or more single activity was studied besides a clustered activity. Within the clustered activities group, three different clustered activities could be identified: activities of daily living (ADL), instrumental activities of daily 


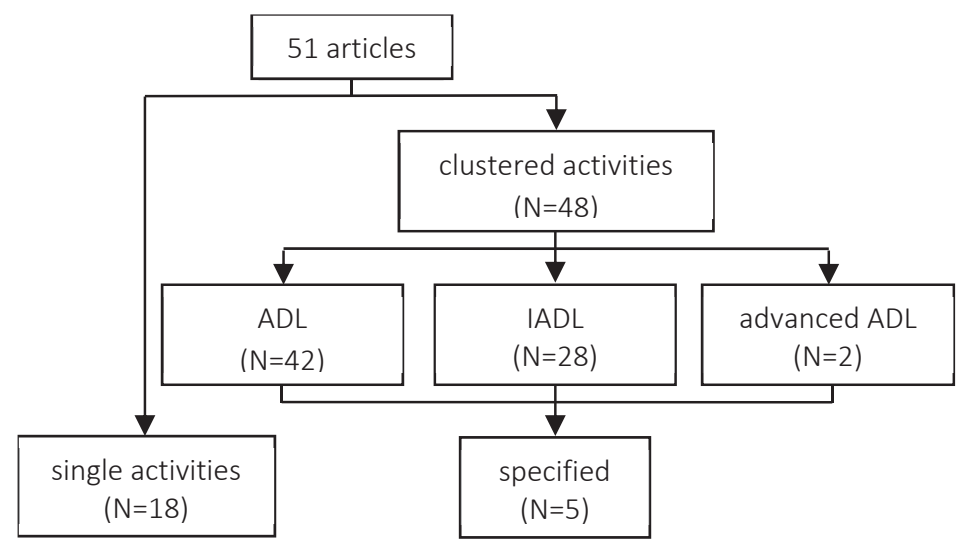

Figure 2: Classification of the final set of 51 articles. An article can appear in more than one group/sub-group.

living (IADL), and advanced activities of daily living (advanced ADL). ADL includes activities such as bathing, dressing, toileting, transfer, and eating. IADL includes the activities cooking, shopping, and cleaning. And finally, advanced ADL includes managing money and using the telephone. Out of the 48 articles studying the effect of one or more clustered activity on the institutionalization of elderly, 42 studies investigated ADL. From these 42 studies, 35 highlighted ADL as a risk factor (see Table 1). Out of the 28 studies that included IADL, 17 concluded that IADL was a risk factor for institutional. And out of the 2 studies investigating advanced ADL, 1 study found it to be a risk factor. Overall, ADL and IADL are seen as risk factors for the institutionalization of an elderly person. However, this does not provide sufficient insight in which activities specific are responsible for losing one's independence. Therefore we took it one step further and looked at the studies which specified the clustered activities. This resulted in 5 studies out of the clustered activities group [10-14].

Table 1. Overview of the number of article in which $A D L / I A D L / a d v a n c e d ~ A D L$ is mentioned as a risk factor for institutionalization.

\begin{tabular}{lcc}
\hline & Number of articles & Risk factor \\
\hline ADL & 42 & 35 \\
IADL & 28 & 17 \\
Advanced ADL & 2 & 1 \\
\hline
\end{tabular}

These 5 studies were added to the 18 studies from the single activities domain group (see figure 2) [9, 11, 15-30]. One article [11] was present in the single activities group as well as in the specified group; this therefore resulted in a total of 22 studies. Within these 22 articles a distinguish could be made between three different types of studies. The articles 
of the first type conducted risk factor analysis in order to investigate if activities could be seen as risk factors for the institutionalization of an elderly person. The second type includes one article that is focused on the characteristics of new entrants of nursing homes and the third type on the problematic activities mentioned by (still independent living) elderly persons without a risk factor analysis.

\section{Type 1 - Risk factor analysis of activities}

Nineteen studies [11-29] investigated if one or more single activities were risk factors for the institutionalization of an elderly person through a risk factor analysis. An overview of these studies can be found in Table 2 . From this table it can be said that mobility $-d 4$, changing body position (e.g. sitting and getting up) - d410, walking - d450, washing oneself - d510, toileting - d530, dressing - d540, feeding - d550/d560, taking medication - d570, preparing meals - d630, and interpersonal interaction \& relationship - d7 were considered to be a risk factor by at least one study.

Table 2. Overview of activities addressed in the literature. Shading indicates activities identified as risk factor.

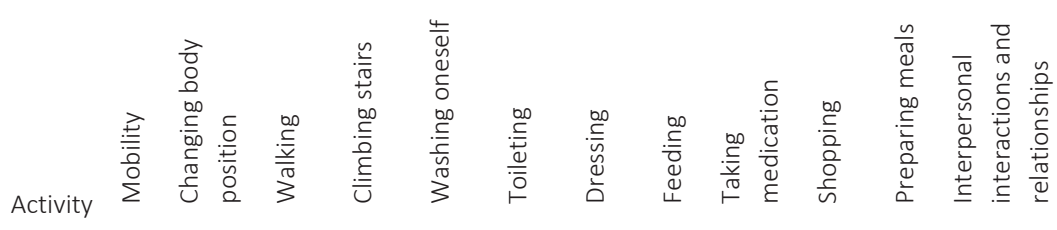

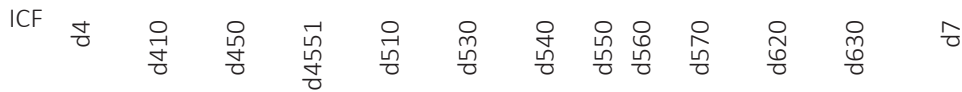

\begin{tabular}{|c|c|c|c|c|c|c|c|c|c|c|}
\hline Greenberg (1979) [11] & & $x$ & & $x$ & $x$ & $x$ & $x$ & $x$ & & $x$ \\
\hline Lee (2001) [12] & & $x$ & & $x$ & $x$ & & $x$ & & & \\
\hline Hancock (2002) [13] & & $x$ & & & $x$ & $x$ & $x$ & & & \\
\hline Matsumoto (2007) [14] & & $x$ & & $x$ & $x$ & & $x$ & & & \\
\hline Cohen (1986) [15] & $x$ & & & & & & & & & \\
\hline Newman (1990) [16] & & & & & $x$ & & $x$ & & & \\
\hline Jette (1992) [17] & $x$ & & & & & & & & & \\
\hline Nygaard (1992) [18] & & & & & & $x$ & $x$ & & & \\
\hline Black (1999) [19] & $x$ & & & & & & & & & \\
\hline Jylhä (1999) [20] & $x$ & & & & & & & & $x$ & \\
\hline Hays (2003) [21] & $x$ & & & & & & & & & \\
\hline Schur (2003) [22] & & & $x$ & & & & & & & \\
\hline Weatherall (2004) [23] & $x$ & & & & & & & & & \\
\hline Gill (2006) [24] & & & & $x$ & & & & & & \\
\hline $\begin{array}{l}\text { Cohen-Mansfield } \\
\text { (2007) [25] }\end{array}$ & & & & & & & & & & \\
\hline
\end{tabular}




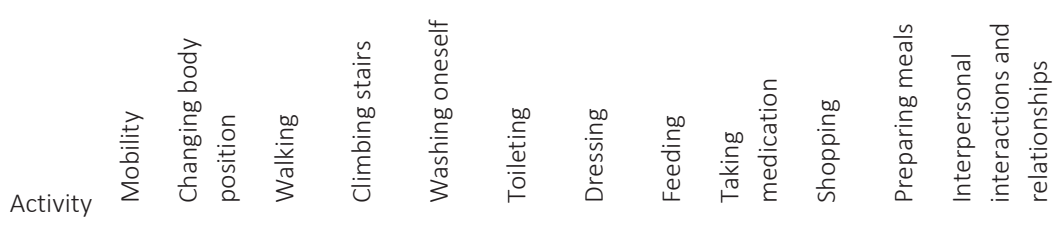

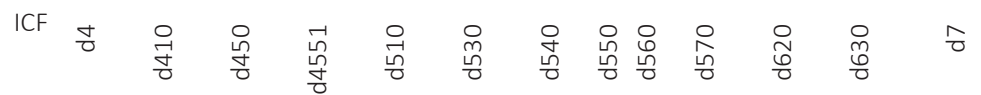

Meijer (2009) [26] X

Kendig (2010) [27]

Cohen-Mansfield

(2011) [28]

Type 2 - Characteristics of new entrants nursing home

From the 22 studies, one study [10] looked at the characteristics of a sample ( $N=125)$ of new entrants in four nursing homes. The majority of these new entrants were, concerning $A D L$, the most dependent in washing - d510 (50.4\%), followed by dressing - d540 (48.8\%), toileting - d530 (28.8\%), mobility - d4 (26.4\%), and eating - d550 (10.4\%). Concerning IADL, new entrants were most dependent in cleaning - d6401/d6402 (87.2\%), followed by cooking - d630 (81.6\%), laundry/ironing - d6400 (75.4\%), outside mobility d4602 (66.4\%), and administration - d860 (68.0\%). None of these specified activities were individually included in a risk factor analysis.

\section{Type 3 - List of challenging activities}

The European Multi-Role Shadow Robotic System for Independent Living (SRS) project [9], together with the Dutch study into The most recurrent problems of the independently living elderly: recommended assistive devices and solutions [30] form the third group type. Both produced a list of activities that make independent living challenging for elderly persons. The SRS study used qualitative and quantitative methodologies. First they included in focus group sessions a direct question about difficulties of daily living and some complementary questions about degree of difficulty and its causes. Elderly persons as well as family cares, professional caregivers, and health professionals participated in both the focus group session as the questionnaire. The Dutch study [30] only conducted a qualitative study which resulted in a list of the 10 most mentioned problems of independent living elderly. The prioritized difficulties with daily tasks mentioned in the studies were reading - d166, mobility-related ones (walking inside/outside - d450/d4602, climbing up stairs - d4551, reaching for objects - d4452, sitting \& getting up - d410, carrying heavy objects - d430, and bending - d4105), selfcare related (washing oneself - d510, caring for body parts - d520, toileting - d530, 
dressing - d540, feeding - d550/d560, taking medication - d570), domestic life (shopping - d620, preparing meals - d630, doing housework - d640), and loneliness - d7.

\section{Focus groups}

From the focus group meetings a total of 43 different problems were gathered (see Figure 3). Not all 43 problems were mentioned in every focus group. The majority of the collected problematic activities raised during the focus group meetings could be grouped into section d, Activities and Participation, of the ICF. The other types of problems mentioned were not specifically activities of individuals but more of the environment (e.g. being looked after). For the second step of the session, participants of each focus group were asked to cluster the problems per topic. Although not all 43 problems were mentioned in every group, the topics created after clustering showed great overlap. For example: The Dutch elderly people, the formal caregivers, as well as the informal caregivers all mentioned one topic in their focus group Self-care. However, this topic contained different problems for every focus group (see Table 3). This was similar for the other overlapping clustered topics. To complete the problem assessment session in the focus group meetings, participants were asked to rank the problems. Problems that were often mentioned during the group session were not ranked as most problematic per se, as current solutions sometimes were found to be sufficient. One such example is the problem of preparing meals, which was mentioned multiple times in most focus group meetings. Current solutions (e.g. meal delivery services, microwave meals) meant that this problem was no longer perceived as a severe threat for the independence of elderly persons.

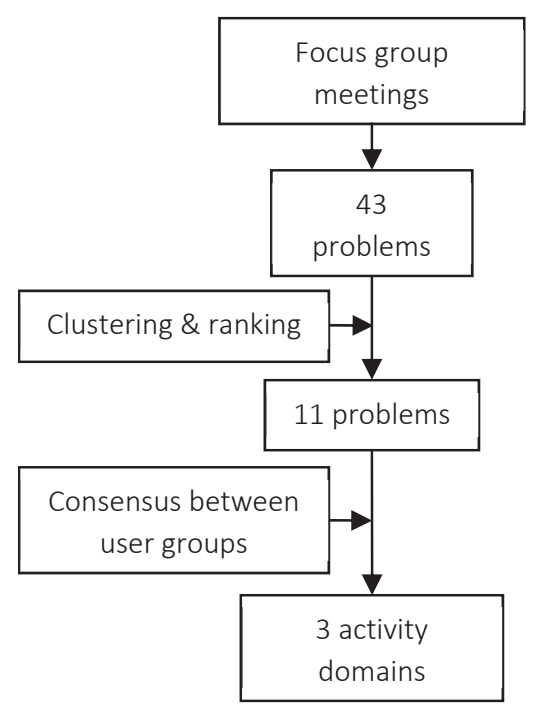

Figure 3: Steps in the analysis of focus group results. 
Table 3. Decomposition of the Self-care cluster for 3 Dutch focus groups.

\begin{tabular}{lll}
\hline Elderly & Formal caregivers & Informal caregivers \\
\hline Getting (un)dressed & ADL care & Getting (un)dressed (2x) \\
Putting shoes on/off & Combing hair & Personal care \\
Showering & Getting (un)dressed (2x) & Toileting \\
& Washing hair & Showering \\
& Putting cream on legs & \\
& Washing back & \\
& Toileting (3x) & \\
& Putting stockings on/off (3x) \\
& Putting shoes on/of & \\
& Showering & \\
& Cutting nails (2x) & \\
& Eating & \\
& Making sandwiches & \\
\hline
\end{tabular}

Table 4. Overview of the prioritised (shaded) clustered problems expressed in the focus group meetings in the Netherlands, the UK, and France.

\begin{tabular}{|c|c|c|c|}
\hline Clustered problems & Elderly & Formal caregivers & Informal caregivers \\
\hline \multicolumn{4}{|l|}{$\begin{array}{l}\text { Communication support for the hearing } \\
\text { impaired }\end{array}$} \\
\hline \multicolumn{4}{|l|}{ Costs (e.g. poverty) } \\
\hline \multicolumn{4}{|l|}{ Housing adaptations } \\
\hline \multicolumn{4}{|l|}{ Social isolation } \\
\hline \multicolumn{4}{|l|}{ Lack of hobbies } \\
\hline \multicolumn{4}{|l|}{ Mobility } \\
\hline \multicolumn{4}{|l|}{ Monitoring } \\
\hline \multicolumn{4}{|l|}{ Opening the front door } \\
\hline \multicolumn{4}{|l|}{ Self-care activities } \\
\hline \multicolumn{4}{|l|}{ Shopping } \\
\hline Specific information about health problems & & & \\
\hline
\end{tabular}

The clustering and ranking of the problems resulted in eleven main problems, which are shown in Table 4. All clustered activities contain a number of problems that differed per focus group session (similar to the example of Self-care in Table 3). In table 4 also an overview is given to the combined priorities over the three countries, specified per type of user. Most of these problems were multi-dimension and became a threat for several reasons; e.g. opening the front door presents a mobility issue, but also poses the problem that it is difficult for the elderly to know if it is safe to open the door. Table 4 also visualizes the consensus between the three different groups. Following this consensus a priority list 
could be created. The three activities described below received the highest priority, as they were seen as most threatening for the independence of elderly by participants from all the three target groups. Additionally, the problematic activities for these three overall activities written by the participants on the sticky notes are added, categorized by ICF number:

1. Self-care activities: When an elderly person is not able to take care of their personal hygiene, then he or she becomes dependent, especially when getting up in the morning or going to bed in the evening. Consequently, people have to adapt their daily schedule to the schedule of their caregiver. Self-care problems mentioned by the focus group participants were: Washing oneself $-d 510$, caring for body parts - d520, toileting - d530, dressing - d540, eating - d550, drinking - d560, and taking medication - d570.

2. Mobility: Living independently at home becomes extremely difficult as one is not mobile any more. Mobility problems mentioned in the focus group session were: Walking inside - d450, climbing stairs - d4551, sitting \& getting up - d410, lifting and carrying objects $-\mathrm{d} 430$, and bending - d4105. Mobility problems can also make other activities problematic (e.g. opening the front door or shopping).

3. Social isolation: Social isolation is caused by the decrease or even lack of activities concerning interpersonal interaction and relationships. Problems mentioned by elderly people, formal caregivers, and informal caregivers in the focus group session were: Loneliness, lack of family/friends, going outside, keeping in touch with family/friends, safety (being alone at night), isolation, and lack of hobbies.

The next step was to combine the results derived from the literature with the results of the focus group meetings. Therefore the results from the 22 studies and the focus group meetings were combined in one table (see Table 5). The activities mentioned in the second column of the table are not all on the same level; e.g. mobility - d4 (no. 2) includes the 7 sub-activities listed below (no. 3 - no. 9). This is similar for the activity doing household - d640 (no. 19): this activity also includes the 3 sub-activities listed below (no. 20 and no. 21). The numbers in the column of type 1 represent the number of studies concluded the activity to be a risk factor and the total number of studies investigated the activity; e.g. changing basic body position - d410 (no. 3) was found to be a significant risk factor by 3 out of the 4 studies investigating this activity. The numbers in the column of type 2 represent the percentage of new entrants in nursing homes having difficulties with the specific activity. 
Table 5. Overview of activities identified in the focus groups and in the three different types of literature (i.e. type 1: Risk factor analysis of activities, type 2: Characteristics of new entrants nursing home, and type 3: List of challenging activities) threatening the independent living of elderly persons in order of ICF number.

\begin{tabular}{|c|c|c|c|c|c|c|}
\hline \multirow{2}{*}{ No. } & \multirow{2}{*}{ Activity } & \multirow{2}{*}{ ICF } & \multirow{2}{*}{ Focus groups } & \multicolumn{3}{|c|}{ Literature } \\
\hline & & & & Type 1 & Type 2s & Type 3 \\
\hline 1 & Reading & d166 & & & & \\
\hline 2 & Mobility & d4 & & $7 / 7$ & $26.4 \%$ & \\
\hline 3 & Changing basic body position & $\mathrm{d} 410$ & & $3 / 4$ & & \\
\hline 4 & Bending & d4105 & & & & \\
\hline 5 & Lifting and carrying objects & $d 430$ & & & & \\
\hline 6 & Reaching & $d 4452$ & & & & \\
\hline 7 & Walking & $d 450$ & & & & \\
\hline 8 & Climbing stairs & $d 4551$ & & & & \\
\hline 9 & Outside mobility & d4602 & & & $66.4 \%$ & \\
\hline 10 & Washing oneself & d510 & & $3 / 4$ & $50.4 \%$ & \\
\hline 11 & Caring for body parts & d520 & & & & \\
\hline 12 & Toileting & d530 & & $3 / 5$ & $28.8 \%$ & \\
\hline 13 & Dressing & d540 & & $2 / 3$ & $48.8 \%$ & \\
\hline 14 & Eating & d550 & & 210 & $10.4 \%$ & \\
\hline 15 & Drinking & $d 560$ & & & & \\
\hline 16 & Taking medication & d570 & & $1 / 1$ & & \\
\hline 17 & Shopping & $d 620$ & & & & \\
\hline 18 & Preparing meals & $d 630$ & & $1 / 1$ & $81.6 \%$ & \\
\hline 19 & Doing household & $d 640$ & & & & \\
\hline 20 & $\begin{array}{l}\text { Washing and drying clothes and } \\
\text { garments }\end{array}$ & $d 6400$ & & & $75.4 \%$ & \\
\hline 21 & $\begin{array}{l}\text { Cleaning cooking area and utensils } \\
\text { Cleaning living area }\end{array}$ & $\begin{array}{l}d 6401 \\
d 6402\end{array}$ & & & $87.2 \%$ & \\
\hline 22 & $\begin{array}{l}\text { Interpersonal interaction and } \\
\text { relationships }\end{array}$ & d7 & & $3 / 3$ & & \\
\hline 23 & Basic economic transactions & $\mathrm{d} 860$ & & & $68.0 \%$ & \\
\hline
\end{tabular}

When looking at the overlap between the literature and the focus group meeting results, it can be seen that there is an overlap for the activities within the domains mobility $-\mathrm{d} 4$ (no. 2 - no. 9), self-care - d5 (no. 10 - no. 16), and interpersonal interaction and relationships $-d 7$ (no. 23). The relevance of problematic domestic activities - d6 (no. 17 - no. 22) found in the literature was not confirmed by the results of the focus group meetings. However, these domestic activity problems were mentioned in the focus group sessions, but were not highlighted as most problematic. 


\section{Discussion}

The goal of this study was to find an answer to the following question: Which problematic activities in daily life most threaten the independence of elderly persons? This study showed that activities concerning the ICF domains mobility - d4, self-care activities $-d 5$, and social isolation - $d 7$ were regarded both in literature and by the participants of the focus group sessions as the most problematic and threatening for the independence of elderly persons. However, it has also become clear there is no single activity that can be selected as the main activity causing a loss of independence. Some participants of the focus groups had difficulty picking just one problem at the end of the focus group meeting, resulting in an underlining of the multidimensional nature of the problems. It is often a combination of problematic activities which is person-specific. This is understandable in light of the diversity in age related loss of abilities between individuals and the diversity in living environments between individuals.

In principle, the elderly age in much the same way everywhere, as they face similar problems resulting from physical and mental decline. The perspective of the three countries was introduced as there are differences in the way care is provided and the range of activities supported by public care provision. The assumption was that this would significantly differ between countries and was expected to influence the problems experienced and/or reported by the participants. The difference in the results between the countries did not reflect this. There were some small differences: in France the problem concerning the coordination of care was quite prominent, while this was not mentioned in the Netherlands or the United Kingdom. But regarding the problematic activities, the overlap between the three countries was obvious.

The correspondence between the countries was notable high, however in the United Kingdom the focus was somewhat more on disabilities (e.g. physical and psychological limitations) rather than activities. This may be influenced by the fact that the focus groups in the three countries were all moderated by different facilitators, resulting in some variations in the adopted method. This introduced some difficulty in performing the final step in prioritizing the activities between the countries. Nonetheless, the results between the three countries were in line and therefore one list of problems could be created. The group sizes also varied considerably between the three countries. However, this was of no concern in analyzing the data as the results between the countries showed great overlap to integrate the list of problems. The inclusion criteria selections were not particularly specific (e.g. elderly persons only had to meet three criteria and informal caregivers only one) and there were no inclusion criteria concerning the gender balance of the sample. This resulted in an unbalanced sample size between genders, as $86 \%$ of all the participants were female. When looking at the balance between male-female for all three user groups it can be found that $71 \%$ of the elderly people, $95 \%$ of the professional caregivers, and $94 \%$ of the informal caregivers were female. Overall, females have a higher life expectancy, however the percentage of female elderly persons in the focus 
group session is still higher compared to the European average in 2011. According to Eurostat [31] $62 \%$ of the European population aged $75+$ was female. The overrepresentation of females among the professional caregivers and informal caregivers may be explained by the fact that care professions/tasks these days are still mainly executed by females. Further, people with cognitive difficulties, who form a large and growing group, were excluded. For this group a different set of activities will prove to be a threat to independent living. Although the inclusion criteria resulted in an overrepresentation of females, we included a broad group of participants and we think these participants can be seen as representative for the general population.

The aim of this paper was to identify meaningful tasks for robot support of elderly persons. For this we analyzed critical activities supporting independent living. The results do not imply that all these task should be performed by robotic systems. When tasks can be solved as effectively by parsimonious or cheaper technology, robots should be discarded. The added value of a robotic system developed should be made clear over alternative (simpler) technology or human care solution. This will be essential to use in practice sooner or later.

In general a robot is an embodied system that is able to perform automated tasks, involving physical movement and/or force exertion. Looking at the three problematic activity domains (i.e. self-care activities, mobility, and social isolation), it is clear that robots could obviously support a number of these tasks, but for other tasks it is more questionable. For example: several activities within the domain self-care (e.g. washing, toileting, dressing, and eating) and the domain mobility (e.g. climbing stairs, lifting and carrying objects) involve physical movement and/or force exertion. These activities could therefore be interesting for a robotic system. The third problematic domain, social isolation, may be less suitable to be solved by a robotic system as there is most likely no need for physical movement and/or force exertion. There are already several (low cost) non-robotic ICT technologies available to support social interaction (e.g. Skype, telehomecare systems) and it is easier to place a tablet in every room than to create an expensive tablet on wheels that can navigate through the house without problems. Nevertheless, there are exceptions such as the social robot Paro [32], which also addresses social isolation and is a great success.

Further research should address the issues mentioned above and take the next step towards the development of a successful service robot and investigate which of the activities are best continued with. In making this selection the technical feasibility and the expected market potential will be decisive. Therefore, also the current care support available for elderly persons per country should be taken into account in assessing the potential of the outcomes of the ACCOMPANY project. Developing a solution in the ACCOMPANY project for a subset of this list of activities will result in a wish list for the remaining activities. 


\section{Conclusion}

To conclude, this study explored the problematic activities threatening independent living of elderly persons through literature and focus group meetings. What became apparent is that a clear set of activities could be identified. Nonetheless it was impossible of finding one single activity that, once becoming problematic, leads to a decision of having to leave home. It is most often a combination of problems that leads to such a decision, based on the abilities of the person (patient) in relation to their own perception, their wishes and the environment of independent living (in a social, physical and financial sense). From the literature and the focus group meetings we found the most important activities threatening the independence of elderly persons concern the activity domains mobility $-d 4$, self-care activities $-d 5$, and social isolation $-d 7$. However, the combination of problems can differ between individuals. A future service robot could therefore be designed to support a diverse need of activities. Further, the needs of future users is only one variable to consider in the development of a robot for elderly people. In order to create a successful robot, the influence of the current care support available for elderly persons (e.g. home care support, the supply of institutional services) must be considered, too. Further, it should also be noted that not all the problems mentioned in this article are necessarily best-solved by robotics.

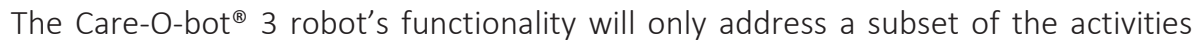
identified in this study and selected the basic fetch and carry task as functionality (related to the domains mobility - d4 and self-care - d5). During this project robot behaviour, both functional and social, will be developed to effectively deliver this functionality. The set of prioritized activities for which people need support is hoped to function as both as an inspiration and as a wish list for future robot development. 


\section{References}

[1] Miller, E. A., \& Weissert, W. G. (2000). Predicting elderly people's risk for nursing home placement, hospitalization, functional impairment, and mortality: a synthesis. Medical care research and review, 57 (3), 259-297. doi: 10.1097/00005110-200202000-00005.

[2] Cameron, C., \& Moss, P. (2007). Care work in Europe: Current understandings and future directions. Oxford: Routledge.

[3] Vlaskamp, F., Soede, T., \& Gelderblom, G.J. (2011). History of assistive technology: 5000 years of technology development for human needs. Heerlen: Zuyd University of Applied Sciences.

[4] Bekey, G., Ambrose, R., Kumar, V., Sanderson, A., Wilcox, B., \& Zheng, Y. (2006). WTEC Panel Report on International Assessment of Research and Development in Robotics. World Technology Evaluation Centre.

[5] Butter, M., Rensma, A., Boxsel, J. V., Kalisingh, S., Schoone, M., Leis, M., ... \& Thielmaan, A. (2008). Robotics for healthcare: final report. DG Information Society, European Commission, Brussels.

[6] ACCOMPANY. (2012, December 12). Retrieved from www.accompanyproject.eu

[7] Üstün, T.B. (2002). Towards a Common Language for Functioning, Disability and Health, ICF. World Health Organization Geneva, 23.

[8] Schnelle, E., \& Thiersch, M. (1979). The Metaplan-Method: Communication tools for planning \& learning groups. Metaplan $\mathrm{GmbH}$.

[9] Cavallaro, F.I., Facal, D., Pigini, L., Mast, M., Blasi, L., \& Fdcgo, H.D.M. (2013). Detailed user requirements, environment definition, general guidelines on ethical concerns and SRS scenario report.

[10] Van Rensbergen, G., \& Pacolet, J. (2012). Instrumental Activities of Daily Living (I-ADL) trigger an urgent request for nursing home admission. Archives of Public Health, 70(1), 2. doi: 10.1186/0778-7367-70-2.

[11] Greenberg, J.N., \& Ginn, A. (1979). A multivariate analysis of the predictors of long-term care placement. Home Health Care Services Quarterly, 1(1), 75-99. doi: 10.1300/J027v01n01_04.

[12] Lee, T., Kovner, C.T., Mezey, M.D., \& Ko, I.S. (2001). Factors Influencing Long-Term Home Care Utilization by the Older Population: Implications for Targeting. Public Health Nursing, 18(6), 443-449. doi: 10.1046/j. 1525-1446.2001.00443.x.

[13] Hancock, R., Arthur, A., Jagger, C., \& Matthews, R. (2002). The effect of older people's economic resources on care home entry under the United Kingdom's long-term care financing system. The Journals of Gerontology Series B: Psychological Sciences and Social Sciences, 57(5), S285-S293.

[14] Matsumoto, M., \& Inoue, K. (2007). Predictors of institutionalization in elderly people living at home: the impact of incontinence and commode use in rural Japan. Journal of cross-cultural gerontology, 22(4), 421432. doi: 10.1007/s10823-007-9046-2.

[15] Cohen, M.A., Tell, E.J., \& Wallack, S.S. (1986). Client-related risk factors of nursing home entry among elderly adults. Journal of Gerontology, 41(6), 785-792. doi: 10.1093/geronj/41.6.785.

[16] Newman, S. J., Struyk, R., Wright, P., \& Rice, M. (1990). Overwhelming odds: Caregiving and the risk of institutionalization. Journal of gerontology, 45(5), S173-S183. doi: 10.1093/geronj/45.5.S173.

[17] Jette, A.M., Branch, L.G., Sleeper, L.A., Feldman, H., \& Sullivan, L.M. (1992). High-risk profiles for nursing home admission. The Gerontologist, 32(5), 634-640. doi: 10.1093/geront/32.5.634.

[18] Nygaard, H.A., \& Albrektsen, G. (1992). Risk factors for admission to a nursing home: a study of elderly people receiving home nursing. Scandinavian Journal of Primary Health Care, 10(2), 128-133. doi: 10.3109/ 02813439209014049.

[19] Black, B. S., Rabins, P. V., \& German, P. S. (1999). Predictors of nursing home placement among elderly public housing residents. The Gerontologist, 39(5), 559-568. doi: 10.1093/geront/39.5.559.

[20] Jylhä, M., \& Hervonen, A. (1999). Functional status and need of help among people aged 90 or over: a mailed survey with a total home-dwelling population. Scandinavian journal of public health, 27(2), 106111. doi: 10.1177/14034948990270021001.

[21] Hays, J.C., Pieper, C.F., \& Purser, J.L. (2003). Competing risk of household expansion or institutionalization in late life. The journals of gerontology series B: psychological Sciences and Social Sciences, 58(1), S11-S20. doi: 10.1093/geronb/58.1.S11. 
[22] Schur, D., \& Whitlatch, C.J. (2003). Circumstances leading to placement: a difficult caregiving decision. Professional Case Management, 8(5), 187-195. doi: 10.1097/00129234-200309000-00002.

[23] Weatherall, M., Slow, T., \& Wiltshire, K. (2004). Risk factors for entry into residential care after a supportneeds assessment. The New Zealand Medical Journal (Online), 117(1202). Retrieved on January 4, 2013 from http://journal.nzma.org.nz/journal/117-1202/1075/.

[24] Gill, T.M., Allore, H.G., \& Han, L. (2006). Bathing disability and the risk of long-term admission to a nursing home. The Journals of Gerontology Series A: Biological Sciences and Medical Sciences, 61(8), 821-825. doi: 10.1093/gerona/61.8.821.

[25] Cohen-Mansfield, J., \& Wirtz, P.W. (2007). Characteristics of adult day care participants who enter a nursing home. Psychology and aging, 22(2), 354. doi: 10.1037/0882-7974.22.2.354.

[26] de Meijer, C.A., Koopmanschap, M.A., Koolman, X.H., \& van Doorslaer, E.K. (2009). The role of disability in explaining long-term care utilization. Medical Care, 47(11), 1156-1163. doi: 10.1097/MLR.0b013e3181b69fa8.

[27] Kendig, H., Browning, C., Pedlow, R., Wells, Y., \& Thomas, S. (2010). Health, social and lifestyle factors in entry to residential aged care: an Australian longitudinal analysis. Age and ageing, 39(3), 342-349. doi: 10. 1093/ageing/afq016.

[28] Cohen-Mansfield, J., \& Wirtz, P.W. (2011). Predictors of entry to the nursing home: Does length of followup matter?. Archives of gerontology and geriatrics, 53(3), 309-315. doi: 10.1016/j.archger.2010.12.009.

[29] Braunseis, F., Deutsch, T., Frese, T., \& Sandholzer, H. (2012). The risk for nursing home admission (NHA) did not change in ten years-A prospective cohort study with five-year follow-up. Archives of gerontology and geriatrics, 54(2), e63-e67. doi: 10.1016/j.archger.2011.06.023.

[30] Crützen, C., Dhome ,C., Smits, Y., \& Spierts N. (2012). Meest voorkomende problemen bij zelfstandig wonende ouderen en aanbevolen hulpmiddelen en oplossingen. Heerlen: Zuyd University of Applied Sciences.

[31] Population on 1 January by broad age group and sex. (2013, January 11). Retrieved from http://epp.eurostat.ec.europa.eu/portal/page/portal/eurostat/home

[32] Gelderblom, G.J., Bemelmans, R., Spierts, N., Jonker, P., \& De Witte, L. (2010). Development of PARO interventions for dementia patients in Dutch psycho-geriatric care. In International Conference on Social Robotics (pp. 253-258). Springer Berlin Heidelberg. doi: 10.1007/978-3-642-17248-9_26. 


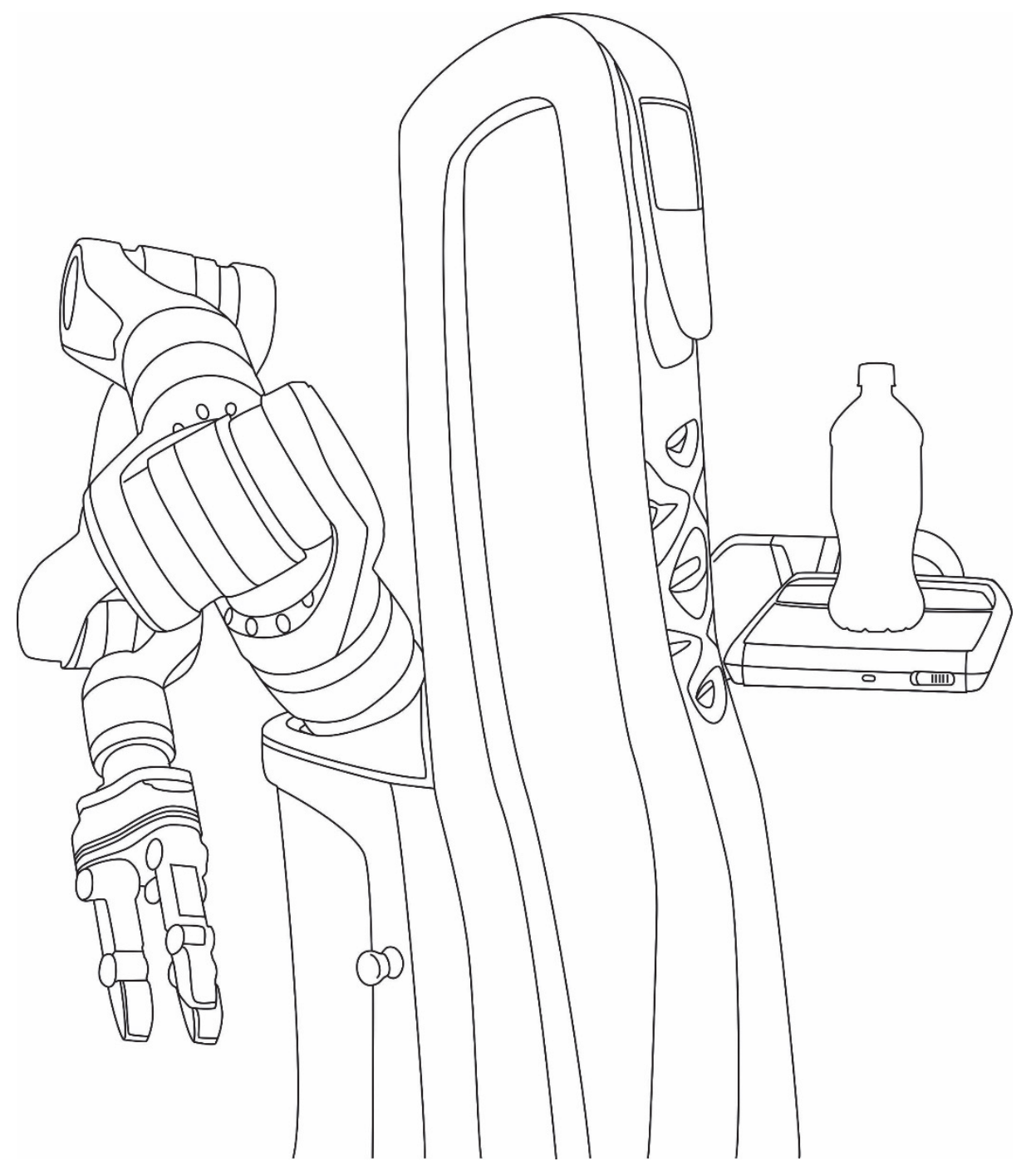




\section{CHAPTER 5}

Can a Service Robot which Supports Independent Living of Older People Disobey a Command? The Views of Older People, Informal Carers and Professional Caregivers on the Acceptability of Robots

This chapter was published as:

Bedaf, S., Draper, H., Gelderblom, G.J., Sorell, T., \& de Witte, L. (2016). Can a service robot which supports independent living of older people disobey a command? The views of older people, informal carers and professional caregivers on the acceptability of robots. International Journal of Social Robotics, 8(3), 409-420. doi: 10.1007/s12369-016-0336-0. 


\begin{abstract}
Sustaining independent living for elderly people in their own homes is desirable for various reasons. As older people become frail or disabled, a 'gap' appears between the abilities they still have and the abilities that are required for independent living. To a certain extent robots may close this gap by providing functionality lost through frailty or disability. A scenario was created involving a re-enablement coach robot. This scenario was discussed with older people, informal carers, and care professionals in focus groups in the Netherlands, United Kingdom and France. The results provided insights into the acceptability of robots and showed that older people were open to the idea of having a robot supporting them in their daily life. Participants were also willing to have a robot perform higher level coordinating tasks while playing the role of the re-enablement coach. However, participants wanted the robot to operate at the same level of intelligence as a human carer. This implies that more attention needs to be given to the development of the social skills and behaviour of such robots. Additionally, participants acknowledged that such a robot would create tension between respecting the autonomy of the user (i.e. robot obeys all commands given by the user) and the promotion of independence in the long term (i.e. robot is programmed to maintain the abilities the user still has). Our results indicate that people preferred to resolve this tension in favour of autonomy. This choice, however, may decrease the user's abilities in the longer term and thereby undermine users' ability to live independently.
\end{abstract}




\section{Introduction}

Older people generally prefer to remain in their own homes for as long as possible, and may be reluctant to move to care institutions. At the same time, at societal level, keeping older people in their homes for as long as possible is desirable: institutionalised care is expensive, and providing good care can be labour-intensive. Promoting independence, then, may reduce calls on services provided by the welfare state.

Being able to stay in one's own home depends upon one's ability to wash, go to the toilet, prepare and consume food and drinks - in short, to meet one's own needs [1]. The practical problems older people face are person-specific due to variation in age-related loss of abilities and the diversity of their home environments and personal preferences. Self-care, mobility, and interpersonal interaction \& relationships are most important for independent living of older people [1]. As older people become frail or disabled their ability to function in these domains diminishes, opening up a space where care must be provided. We will describe this as the 'care- gap', the gap between the abilities one still has to care for oneself, and the abilities that are required for independent living.

Traditionally, this gap has been bridged with human care, either informally - by friends and family - or by care professionals. Changing social structures, however, have resulted in family members being less inclined or available to provide care. These changes and the increasing shortage of care staff [2] has led to technology - and more specifically robotics - being given increasing attention. Robots, particularly service robots, have the potential to support care and independence in many ways [3]. According to the International Federation of Robotics, a personal service robot can be defined as an actuated mechanism that is programmable in two or more axes with a degree of autonomy (i.e. the ability to perform intended tasks based on current state and sensing, without human intervention), can move within its environment, is able to perform useful tasks for humans excluding industrial automation application, is used for non-commercial tasks, and is usually used by lay persons (e.g. domestic servant robot, personal mobility assist robot) [4]. A possible advantage of a service robot is that it helps people to help themselves rather than doing it for the user. This is comparable to the use of a white cane: a white cane for the blind does not remove obstacles, but it enables the user to overcome these obstacles.

The ACCOMPANY (Acceptable robotiCs COMPanions for AgeiNg Years) project aimed to develop the functionalities of an existing service robot, the Care-O-bot ${ }^{\circledR} 3[5]$, in order to support older people to continue to live independently [6]. A service robot should be able to assist older people to carry out relatively difficult daily tasks on their own. ACCOMPANY distinguishes three types of potential users for its experimental platform: 1) cognitively unimpaired older persons who need some support to remain independent in their own homes, 2) informal carers, and 3) professional caregivers.

Current developments in service robotics for older people at home are mainly focused on the technical feasibility and functional performance [7]. ACCOMPANY aimed also to 
develop flexible as well as appropriate robot behaviour. For example: one older person may need support to overcome temporary difficulties; in this case the support of the robot should be aimed at facilitating the rehabilitation process. Another user may need the same robot functionality because he/she is permanently unable to perform the activity him/herself. A third may sometimes need the support but on other occasions may benefit from being encouraged not to use this support so as to maintain existing functional abilities.

One of the aspects ACCOMPANY seeks to promote is re-enablement. A re-enablement coach needs to motivate and stimulate; whenever someone is still capable of performing a task themselves, a re-enablement coach should stimulate the person to do so rather than performing the task for them. When developing a service robot capable of functioning as a coach, one must bear in mind that this service robot should be able to do more than just execute functional tasks; it should for example also have the qualities to monitor, to interpret a situation and to make decisions. This introduces the issue of whether it is the service robot or the user who should make certain decisions. For example, is it acceptable for a service robot to 'decide' to refuse to execute a task given by the user, in order to get the user to exercise abilities they might otherwise lose?

In order to explore these areas of tensions a scenario was created to discuss whether the presence of a service robot in an older person's house could be used to change his/her behaviour in some way. The scenario made it possible to ask what the limits of robot intervention should be if the intervention was to be acceptable to older people, informal carers and care professionals in the Netherlands, United Kingdom and France. This paper presents their views and thoughts concerning the potential tension between autonomy and independence, and what these might mean for future robot development.

\section{Method}

Focus group sessions with older people, informal carers, and care professionals were conducted in the Netherlands, United Kingdom and France. During these focus group sessions the following scenario was discussed:

Marie, who is 78 years old, has lived alone since her husband died ten years ago. She has ulcers on her leg, the dressings for which are changed by a nurse once a week. It is important for the healing of these ulcers that she moves around as much as possible to encourage circulation to her legs and avoid further swelling. Her Care-O-bot ${ }^{\circledR}$ knows that she should be encouraged to move about, and suggests several times a day that she walks with it to look out of the window at either the garden or the street below. Marie is reluctant to get up from her chair because she is afraid of falling and walking is uncomfortable. She also uses the Care-O-bot ${ }^{\circledR}$ to get drinks for her from the kitchen, even though the nurse has 
suggested that she should go to the kitchen with the Care-O-bot ${ }^{\circledR}$ but let it carry the drinks back to her chair for her. Also the Care-O-bot ${ }^{\circledR}$ can only bring bottles of water to her and the nurse suggests that she would feel warmer if she made herself hot drinks. The Care-O-bot ${ }^{\circledR}$ reminds her to take her antibiotics and to keep her leg up on a stool when she returns to her chair after, for example, going to the toilet. She is grateful for the reminders about the antibiotics but feels irritated about the reminders to elevate her leg as she hardly ever forgets to do this but she likes to get comfortable first. She sometimes put her leg down so that her cat can sit on her lap more comfortably. Her ulcers are slow to heal but when the nurse asks if Marie is moving around more she always says that she is, even though she ignores the prompts to come to the window and doesn't go to the kitchen with the robot.

As the focus groups were hosted by four different facilitators at four different parties in three European countries (i.e. the Netherlands - Zuyd University of Applied Sciences (ZUYD), UK - University of Birmingham (UB) and University of Hertfordshire (UH), and France - Maintien en Autonomie a'Domicile des Personnes Agees (MADoPA)). A detailed topic guide was produced to ensure consistency based on a shared understanding of the purpose and goals of the scenarios.

\section{Participants}

Older persons were contacted through care organizations, except for the older participants recruited by UB using the Birmingham 1000 Elders [8]. The older people recruited from the Birmingham 1000 Elders, unlike those at others sites ${ }^{2}$, had no previous experience of working with ACCOMPANY or exposure to the robot being developed. Older persons were selected based on four criteria: 1) aged 60+, 2) living at home, 3) no cognitive decline, and 4) receiving home care. Informal carers were contacted through care organizations and personal networks. Informal carers either 1) looked after an independent older person on at least a weekly basis, or 2) had taken care of an independently older person on a weekly basis in the last year. Professional caregivers were contacted through care organizations. Their selection was based on their work activities/profession. It was required that they worked closely at least weekly with older persons who live independently.

\section{Procedure}

The focus groups were convened in separate groups of 3-8 participants in a room with a round table formation. Interactions were conducted in native languages. After signing the

${ }^{2}$ All other participants either participated in previous focus groups or in user tests of the ACCOMPANY project. 
consent forms the scenario was explained and discussed. As the older participants at UB had no experience with the Care-O-bot ${ }^{\circledR} 3$, they were shown a short video clip of the robot under development before discussing the scenarios. After the explanation of the scenario, participants were asked for their thoughts. Follow-up questions and prompts from the topic guide were then applied. All data was audio and/or video recorded.

\section{Data analysis}

All focus group meetings were transcribed verbatim. The two sites not using English (i.e. ZUYD and MADoPA) selected a representative transcript of each of the three user types (i.e. older persons, informal carers and professional caregivers) and translated this into English. Two researchers (HD and TS) then independently coded all six of the translated transcripts and all those from UB and UH, using a combination of directed analysis and Ritchie \& Spencer's Framework Analysis [9]. This permitted the data to be searched for views supporting and/or rejecting the proposed tentative framework, whilst also being open to the expression of additional values/principles by participants. The resulting coding was then discussed by the two researchers (HD and TS) until agreement was reached. These final codes were then roughly worked into general themes by one researcher (HD) and presented to all the researchers who had facilitated focus group meetings. After consensus on the codes and general themes was reached, the researchers from ZUYD (SB) and MADoPA (CR) coded the remaining transcripts. Quotations were selected to illustrate the general themes and translated into English. Additional reports were produced summarising the data and providing information about the focus group meetings at each site. All of the data was then combined into a single report by HD and circulated to all facilitators for comment. Finally, one researcher (SB) analysed the final report looking for areas of tensions a re-enablement coach robot could cause and to what extent such a robot could be used to change the behaviour of older people. The results of this analysis were discussed with a second researcher (HD), which resulted in 7 topics.

\section{Results}

In total twenty-one focus group sessions were conducted in the Netherlands (6), UK - UB (3), UK - UH (3) and France (9). A total of 122 persons participated in these meetings (see Table 1). Older participants were $>62$ years of $a^{3} e^{3}$. The mean age of the older participants of ZUYD and MADoPA was 78.5 years ( 42 to 95 ). The age of the participants

${ }^{3}$ With the exception of one Dutch participant who was 42 years old, but due to her illness faced similar problems to those of older people. 
of UH and UB was unknown, except that they were aged 65+. Informal carers took care of (one of) their parents, their spouse, neighbour, or their aunt. In one case the older person had recently passed away and in two cases the older person taken care of was recently institutionalized. The profession of the care professionals varied from care worker, nurses, psychologists to managers of elderly care facilities.

Table 1: Overview of number of participants divided per research site.

\begin{tabular}{lccccr}
\hline \multirow{2}{*}{$\begin{array}{l}\text { Participants } \\
\text { Netherlands }\end{array}$} & UH & UB & France & Total \\
\hline Older adults & 10 & 5 & 21 & 19 & $55(19$ male, 36 female $)$ \\
Informal carers & 11 & 4 & - & 15 & 30 (6 male, 24 female) \\
Professional caregivers & 13 & 6 & - & 18 & 37 (1 male, 36 female) \\
Total & 34 & 15 & 21 & 52 & 122 \\
\hline
\end{tabular}

Different topics and areas of tension were discussed during the focus group sessions (see Figure 1-3).

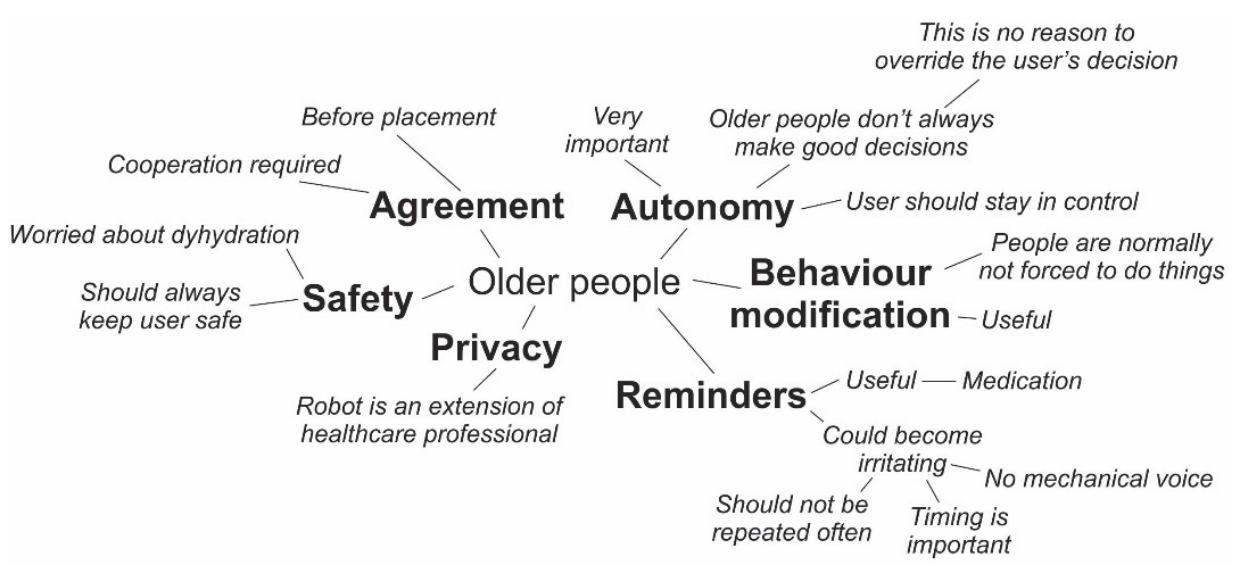

Figure 1: Overview of the different topics (in bold) that were discussed during the older participants' focus group sessions. 


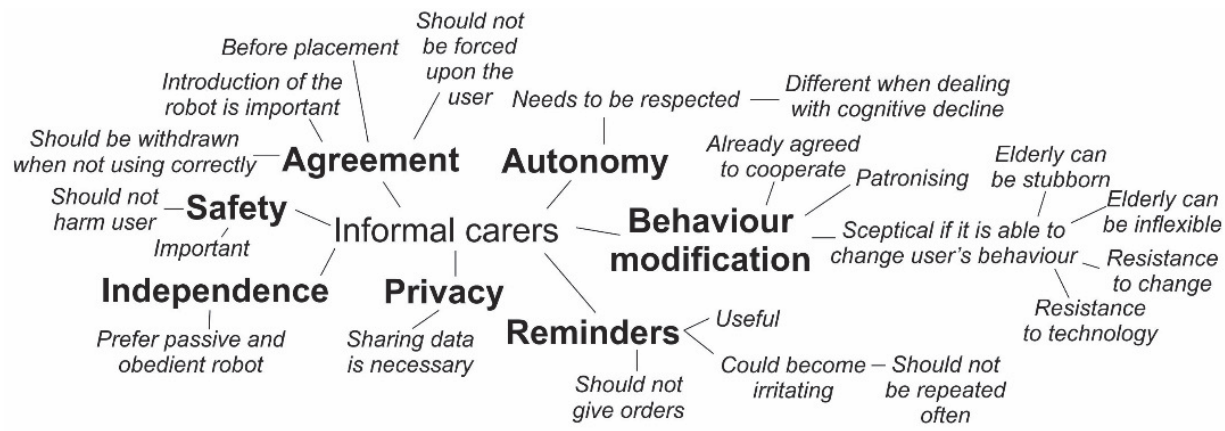

Figure 2: Overview of the different topics (in bold) that were discussed during the informal carers' focus group sessions.

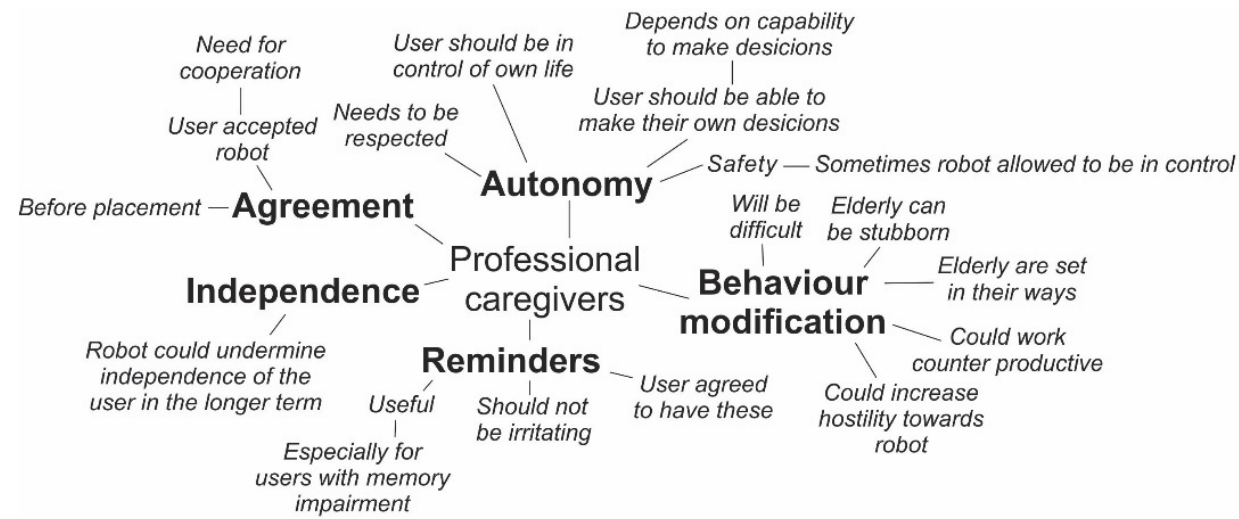

Figure 3: Overview of the different topics (in bold) that were discussed during the professional caregivers' focus group sessions.

A total of seven different areas of tension were discussed: 1) Autonomy, 2) Agreement, 3) Reminders, 4) Behaviour modification, 5) Independence, 6) Safety and 7) Privacy. No structured questionnaire was used, which resulted in not all topics being discussed in every session (see Table 2). For example: the topic "independence" was not mentioned during any session of the older participants groups, but it was mentioned during the sessions of the informal carers as well as the professional caregivers.

Table 2: Topics emerged from the focus groups session per group type.

\begin{tabular}{lccc}
\hline Participants & Older persons & Informal carers & $\begin{array}{c}\text { Professional } \\
\text { caregivers }\end{array}$ \\
\hline Autonomy & $\mathrm{X}$ & $\mathrm{X}$ & $\mathrm{X}$ \\
Agreement & $\mathrm{X}$ & $\mathrm{X}$ & $\mathrm{X}$ \\
Reminders & $\mathrm{X}$ & $\mathrm{X}$ & $\mathrm{X}$ \\
\hline
\end{tabular}




\begin{tabular}{lccc}
\hline Participants & Older persons & Informal carers & $\begin{array}{c}\text { Professional } \\
\text { caregivers }\end{array}$ \\
\hline Behaviour modification & $\mathrm{X}$ & $\mathrm{X}$ & $\mathrm{X}$ \\
Independence & $\mathrm{X}$ & $\mathrm{X}$ & \\
Safety & $\mathrm{X}$ & $\mathrm{X}$ & \\
Privacy & & \\
\hline
\end{tabular}

\section{Autonomy}

Older people were able to relate to the scenario of Marie. This group acknowledged that (older) people do not always make good decisions (defined as those that best promote their own health or other kinds of well-being). Nevertheless, the majority of these older participants stated that the user should always stay in control of their own life and several participants were very explicit that making a decision about which others would disapprove was not a sufficient reason to let the robot override the user's decision. Autonomy of the user was seen as most important and the user's view about how the robot should behave must always be respected.

"I'm also such a person, so I can tell you that I don't always do what they tell me to do." (ZUYD OPFG2 E3)

"Older people still have their personal freedom and if they say 'no' it should be 'no', shouldn't it?" (MADoPA OPFG1 P1)

"I dislike it and I think it's a bit (stronger) than dislike, that the idea that because you've reached a certain age...you have to have something, or you're put in a position where someone's telling you what to do all the time... You have a right to decide I don't want, I don't care what I'm being told to do. I have a right...as any adult does not to do it. And not to put up with being nagged at." (UB OPFG1 P5)

Informal carers were also able to relate to the scenario, and provided similar examples from their own experience. They likewise thought that the autonomy of older people in general needs to be respected, except when dealing with older people who are cognitively impaired. Allowing this group to make their own decisions was seen as less important.

The professional caregiver's group shared the same opinion as the older people's and informal carer's groups, as they agreed older people need to be in control of their own lives. This group also stated that the autonomy of the user needs to be respected and older people should be able to make their own decisions.

"It always comes back to the fact that what the professional care worker needs or wants is not necessarily what the user needs or wants. Our priority is the user's need or want and we have to take it into account. We aren't going to do anything 
without the user; if he or she doesn't want to do something, we can't force them to do so against their wishes." (MADoPA PC1 P6)

"I suppose what you want with people is for them to take control as much as possible themselves." (UH PC B)

Some professional caregivers, however, disagreed that older persons always should to be in charge of the robot as they could envisage circumstances, usually associated with safety, when they would want the robot to be programmed to act in ways that are not in line with the wishes of the user (and which would therefore undermine the autonomy of the householder). Professional caregivers made a similar distinction between older people who are still capable to make their own decisions and those who are not.

"We deal with people who are mentally fit and able, unless their health has deteriorated and they have cognitive problems, but for as long as a person is in full possession of their mental faculties, they are free to do whatever they want at home." (MADoPA PC1 P7)

A: "And some people like decisions to be laid for them whereas stronger people prefer to make their decisions themselves."

F: "Rights of choices versus health and safety."

B: "And the capacity. The capacity of the individual isn't it? The capability and capacity, you know." (UH PC)

\section{Agreement}

Participants in the older person groups tended to think that the robot would not have been placed in the home of the user against his/her wishes and that some agreement about the tasks the robot would perform had been reached prior to its placement. Cooperation with the robot was therefore seen as a reasonable requirement deriving from the initial agreement to accept the robot. Thus, respect for autonomy of the user starts even before the robot is installed in the user's home. Some of these participants referred to this assumed prior agreement when discussing whether it was acceptable for the robot to be programmed not to comply with all the commands and preferences of the user.

"To begin with, if someone wants a robot in their home, if they decide to get one, then what's the point if afterwards they actually don't listen to it? ... To my way of thinking, with the robot it's as when you go to see a doctor. If you don't take the mediation he prescribed for you, why bother going in the first place?" (MADoPA OPFG1 P7)

"You have chosen yourself to have that thing in your house, so you also have to accept the things it does." (ZUYD OPFG1 E2) 
"What is the point of people having a robot, who are going to provide facilities, you are going to accept it or not? And if you're going to ignore anything and everything it does, except get you your drink of water you might as well save the money and get her one!" (UB OPFG1 P1)

The informal carers also expected that the placement of the robot would have been discussed and agreed in advanced with the user and that older people should not be forced to have a robot. Some informal carers added to this that if the user would not follow its instructions and would not make good use of it (which in part meant cooperating with it in ways that would be beneficial to them) the robot could be withdrawn and placed with someone else. Further, the informal carer group participants mentioned the importance of how the robot would be introduced into someone's home. Each group had ideas how this should be done.

"But when you take the benefits, see the advantages of this right away and it is introduced stressing the benefits then I think it is possible." (ZUYD IF2 M1)

"I think you should take something as an starting point. And with that you should also have a certain policy in which you state: If this is your care need and this is your situation we can help you, but you should also be motivated. I think you need to evaluate the situation after a certain period. You should take a look at what it brought to the user, but this doesn't need to be in the controlling way, because you're still dealing with humans." (ZUYD IF1 M1)

"They're signing away their privacy for certain things. [...] That they actually sign that they agree to having this robot instead of going into a care home because the function of this robot is not just to be useful but also for health and safety." (UH IF P4)

Some professional caregiver participants agreed with the informal carers and suggested that if the user agreed to accept the robot, it was reasonable to expect the user to cooperate with and use it.

"You of course need to judge certain things in an objective way, and when you say at every occasion oh well, people should do it themselves hoping people will be honest in their reporting, then I say there is no point in bringing in the robot. You must of course have certain registrations, information. You need to be able to access that otherwise there is no point in all this." (ZUYD PC1 P4)

\section{Reminders}

In the scenario the robot reminds Marie to take her medication, to keep her leg elevated and to move around to increase her circulation. Overall, the older people group participants thought these reminders were useful. They were aware that memories might begin to fail as people become older. Reminding people to take their medication was 
therefore regarded as useful. However, these participants also had some concerns regarding the reminders: they were afraid these reminders could become irritating if repeated often, if the reminders were issued by a mechanical voice and/or by the timing of the reminders (e.g. being interrupted when doing something the user particularly enjoyed).

"Yes, but if it is programmed to push you every 30 minutes and you're watching a thrilling movie. You don't want to get up and then it stands next to your chair: You have to get up, you have to walk." (ZUYD OPFG1 E3)

"Perhaps there's the way it's said too. Perhaps the robot should say it gently and kindly rather than as an order." (MADoPA OPFG1 P3)

In the informal carers' groups similar contrary views were expressed about the reminder provision: some thought it would be useful, but other participants also thought that they could become annoying.

"And look at my mother, every day she asks what day it is. The robot can remind her. Reminders are automatic things, it could do that without any difficulty." (MADoPA IF3 P3)

"If it senses that she has taken the legs down for a given period of time. Say 40 minutes has elapsed and the robot has sensed that she hasn't put it back up again it could give her a gentle reminder, not something every 5 minutes like when you are in the care and you haven't put the seatbelt on." (UH IF P3)

R1: "So the role of the robot should be more passive? Something that gives reminder but no orders. An inferior."

M several: "Yes."

M2: "For instance a signal for activities and nothing like: You should go to the toilet now, or anything like that."

R1: "And what about user that need to do exercises for physical therapy. Also only a reminder for that and nothing more?"

M2: "Nothing more." (ZUYD IF1)

The professional caregivers also thought the reminder function of the robot was useful, especially for clients with memory impairments. And again there were some professional caregiver participants who mentioned that reminders issued by the robot should not become irritating. Professional caregivers often associated the reminders with what people wanted and thought being reminded of something/to do something was something people should agree to.

"If you're the type that watches television in the evening that will become a pattern for the robot. So than you should be able to receive the signal half an hour or an hour before." (ZUYD PC2 P4)

"Reminders and helpful reminders and actually wanting to be signed up to this." (UH PC B) 


\section{Behaviour modification}

The robot prompting health-promoting behaviour (e.g. telling Marie to move around to increase her circulation) evoked mixed responses from the older participants. Some thought it would be useful, while others felt sympathy for the discomfort that physical therapies can cause. Another factor influencing the participants' views was that people are not normally forced or cajoled into cooperating with health-promoting behaviours. People are, for instance, free to smoke tobacco and drink too much alcohol. No clear boundary emerged in these discussions between adherence to 'prescribed' actions (recommendations of the 'do this in order to recover more quickly' kind) and adherence to health-promotions messages (advice of the 'do this to avoid damaging your future health' kind).

"I think the robot could sort of be more forthright if you say. Sort of tell to do it more often. Because I know sitting in a chair as I have been for 4 months that you need a lot of persuasion to get up from that chair to do something... It's very difficult, you really got to have somebody to prompt you to make you get up and do something. If you are comfortable in the chair and you know it is gonna hurt when you get up." (UH OPFG P2)

"The robot doesn't know whether she's having a good day, bad day, if she's had other problems, is the leg feeling more painful today, or has she got an upset stomach or a hangover." (UB OPFG2 P1)

The views of the informal carers concerning prompting health-promoting behaviour were also mixed. These groups assumed the user already agreed to cooperate with the robot, at least in health-related interventions. It was also mentioned several times that trying to make people change was patronising. Additionally, informal carers reported that, in their experience, older people could be quite stubborn and inflexible in their views and attitudes. Informal carers were therefore sceptical that the robot would be able to change older people's behaviour. Some even thought that it was not worth trying to change the minds of some older people, so great was their resistance to change. Some participants in the informal carers groups also thought that older people in general might be resistant to technology. There was less evidence of this reluctance in the views expressed by the participants from the older people's group.

"I think these older people, they will not go with the robot, really! From the experience with my father... He would not say something like: Ok, I will walk. More like: Switch that device off." (ZUYD IF2 M3)

"No, he really is very set in his ways. He can't see things from a broader perspective, not anymore, and there are things that he cannot accept anymore. He has become very backward-looking recently, since the illness set in and he lives in his past." (MADoPA IF1 P5) 
"If someone doesn't want to take their doctor's orders on board, they're not going to take much notice of a robot either." (MADoPA IF1 P6)

Some care professional participants shared the view that older people can be very stubborn or set in their ways. It could therefore be really difficult to get them to change their minds and to change their behaviour for their own benefit.

"But you know what it's like with people as well, when they are in their armchairs and you say to them: Come on, let's go and do this, and they say: Oh no, I don't want to." (MADoPA PC1 P5)

P5: "Yes but they are non-compliant eh..."

P4: "They do what they themselves seem right." (ZUYD PC1)

"They don't like changes well, older people are resistant to change." (UH PC PD)

Professional caregivers also believed that forcing older people to change their behaviour could be counter-productive. Forcing older people to change their behaviour could also lead to resentment according to these participants, which would also increase hostility to the robot.

"She is very interested in something and then it gets turned off in the middle of something that she is very interested in, that would really annoy her." (UH PC PD) P6: "But rather like: We agreed to watch television till 6 o'clock and then we will walk for 5 minutes, but not like: Bang, 6 o'clock television is switched off."

P4: "I think this would have an adverse effect, that the resentment against exercise would only grow." (ZUYD PC1)

\section{Independence}

Some informal carer participants preferred a passive and obedient robot. Some care professionals noted that having a robot that does things for the user might undermine the independence of the user in the longer term. They had experience of clients developing a "why should I?" attitude to doing things for themselves, because the carers themselves were at hand to do it for them. And these participants thought this attitude could be transferred to the robot.

"Why make the effort if there's someone here to do it for me? It's an attitude we're all familiar with and expect to see on a fairly regular bases. It's part of our job as well, as is often said, not to do things instead of people but to help them when they can't manage. But people, especially when it comes to services where they have to pay contribution, tend to say if I've paid, they should do it for me." (MADoPA PC1 P7)

P4: "What I tend to hear is: I pay to have someone do things for me. My response is: Yes you pay, but you pay to have someone help you do things, which people 
don't like hearing because for them it's a case of: I pay therefore you do it instead of me."

P5: "That's even the way it is for us and we're not even a service that's paid for, I mean the person doesn't pay us directly, which is the same thing." (MADoPA PC1)

\section{Safety}

Some of the older people group participants of UB were worried about dehydration if the robot refused to get drinks. The robot should keep the user safe.

"I think that if the robot wasn't giving her the water and she was left to herself she'd just not have the water, she would dehydrate probably and that would be another problem." (UoB OPFG3 P7)

Most participants in the informal carers group regarded the safety of the user as important. They were therefore more resistant to the robot behaving in ways that could put the user at any risk of harm (e.g. refusing to fetch Marie drinks that she could fetch for herself).

"The problem with letting others decide for the person is the loss of that individual's personal freedom, and the fact that different parties have different interests and motivations: the family wants to be reassured, and care workers want to care and keep the patient safe even though the patient may not necessarily want to be kept safe." (MADoPA IF1 P7)

$\mathrm{R}$ : "Should the robot be programmed to refuse to get these drinks for Marie unless she goes to the kitchen with the robot?"

P3: "No, she might be incapacitated."

P4: "It might be a bit dangerous to do." (UH IF)

\section{Privacy}

Older participants were open to the possibilities that the robot could be an extension of the healthcare professional in the home.

R1: "And concerning the data the home carer could get from the robot. [...] Isn't it personal?

E7: "No. Home carers do the same." (ZUYD OPFG1)

The robot's sharing data was regarded as necessary by the informal carers when professional caregivers or other paid carers are involved. They thought this was necessary to ensure effective care. The robot may have been regarded as an extension of the care team and therefore to be governed by the usual norms for sharing information between members of such teams. 
"If you say that the robot is going to replace a home-help, if the home help learns that the lady never raises her foot, she will take that back to the nurses or the doctor saying that there's a problem. If something is medically prescribed, which she hasn't complied with, that has to be reported - perhaps confidentially - to the doctor. But that has to be reported, otherwise it's not much use." (MADoPA IF3 P1) "Yes, that the robot does something. That it notes things down, just like we do. For instance the number of times she got out of her chair." (ZUYD IF1 M6)

\section{Discussion}

This study enabled us to explore the areas of tension that a re-enablement coach robot can cause, and to discuss with different potential user groups the limits that should be set on the extent to which a robot in an older person's house could be used to change their behaviour. Focus groups session were conducted in three different countries (i.e. the Netherlands, UK, and France). No major differences could be found among the views of the participants of the three countries.

Participants' previous experience with technology plays a role in the acceptance of robotics [10]. This could imply that the informal carers and professional caregivers would have a more positive attitude towards the acceptance of robot as they are likely to have more experience with technology. Some of the informal carers also mentioned that they thought older people in general might be resistant to technology, however the results did not reflect this. A robot providing reminders was generally regarded as useful and acceptable by all target groups. This is in line with the study of Smarr et al. [11] in which being reminded by a robot to take medication was a preferred activity by older adults. However the tasks a robot needs to carry out in order to be useful are often more difficult than first appears [12].Participants in our study expected that a robot providing reminders was also capable of responding to the user's habitual behaviour and to provide useful reminders depending on the situation. For example, if the user watches the 8 o'clock news every evening, the robot should learn not to interrupt this activity with a reminder to do a different activity. Without this level of intelligence the robot could easily become annoying. Prompting health-promoting behaviour was not as acceptable as providing reminders. Our results from the informal carers and professional caregivers also suggest that changing health-related behaviour of older people may be challenging, as they can be quite stubborn and set in their ways. These participants tended to consider that a robot forcing older people to change their behaviour could be counter-productive and could lead to resentment, which would increase hostility/rejection to the robot. Thus in order to be accepted by this user-group, the robot must in some real sense be within their control. This was also acknowledged in all focus groups. Sharkey \& Sharkey [13] also state that a robot that is under the control of an elderly person could empower them and increase their independence. For our participants older people have the right to be in 
control of their own lives and therefore the robot should respect their wishes. This raises the question of how much control an elderly person should be allowed [13]. Some older participants were very clear that the robot should always obey the householder and should never been allowed to refuse tasks given by the user. Nevertheless, such a robot may actually erode the quality of life of older people, because when the robot does too much it can de-skill, de-motivate and/or otherwise erode the abilities the user actually still has, risking decreasing the user's ability in the longer term. In this event the robot would become a 'wedge' that widens the care gap. This tension between "respecting the autonomy of the user" and "the promotion of the independence of the user on the longer term" was discussed in every focus group.

Participants were also not always consistent in their responses. Even though participants in the older person groups thought the user should always be in control of the robot, they also stated that when a robot is installed with permission of the householder and agreements are made about certain aspects, the user should honour these agreements even when the robot appears to nag. Care professional participants were also not consistent concerning who should be in control of the robot, as they could also envisage circumstances where the robot would refuse to execute a given task, often related to safety. However, restraining a person to avoid harm could be a slippery slope towards authoritarian robotics [13]. Additionally, participants also envisioned situation in which the robot in trying to promote good behaviour could harm the user: by refusing to fetch Marie a drinks to encourage her to get her own, the robot may cause Marie to eventually become dehydrated. Care professionals agreed that a robot should never behave in such a way that it could harm the user. In the situation described here, the robot would eventually have to give in and fetch the drink for Marie. The right balance needs to be found between promoting good behaviour and protecting the user from dangerous situations. In the same situation there is also tension between "respect for autonomy" and "promotion of independence": for the promotion of independence it is best if Marie gets the drink herself, but a robot refusing to execute the command to get her a drink does not respect the autonomy of the user.

Overall, it can be said that the participants had high expectations and demands concerning the capabilities and intelligence of an acceptable robot. The robot was expected to recognize the circumstances, interpret these and make decisions depending on the situation. These qualities are similar to those of a human carer. This comparison to a human carers, who in their turn are expected to behave in certain ways, resonates with the outcomes of a study concerning the client's perspective on current clientcentred care in the Netherlands [14]. According to this study recognition of the client's values by the caregivers is the central element in tailored care. This means that the client must be seen as a unique, comprehensive, autonomous human being, and the life of the client and fairness needs to be central in care, and that the client needs to be treated as an equal, interdependent partner in care [14]. This underlines the importance of personalizing the robot, making it sensitive to the emotions and difficulties of the user; 
enabling the robot to be flexible in the timing and extent of care; and designing the robot to respect the decisions of the user.

Designing a robot that is sufficiently flexible to bridge the gap between one's abilities and the abilities required for independent living will be difficult to achieve as this not only involves technical challenges, but also ethical ones. Further research is needed to address the issues and tensions mentioned above and to take the next step towards the development of acceptable robots for supporting independent living of older people. In this study only the acceptability of the robot as a re-enablement coach was explored. For future research it is important to study the influences of other behaviour types on the acceptance of robots by the target user group.

\section{Limitations}

This study reflects the limitations of qualitative research in general. Some of the focus groups contained a dominant speaker, who drowned out the potentially interesting and relevant views of other participants. Sampling involves elements of both convenience and self-selection, which means that there is a possibility that the data is influenced because a certain group or type of people was attracted to participate in the study. The inclusion criteria were also not particularly specific (e.g. older people only had to meet three criteria and informal caregivers only one) and there were no inclusion criteria concerning the gender balance of the sample. This resulted in an unbalanced sample size between genders, as $79 \%$ of all the participants were female. When looking at the balance between male - female for all three user groups it can be found that $65 \%$ of the older people, $80 \%$ of the informal carers, and $97 \%$ professional caregivers of the were female. Overall, females have a higher life expectancy, and according to Eurostat $62 \%$ of the European population aged $75+$ was female [15]. The overrepresentation of females among the professional caregivers and informal carers may be explained by the fact that care professions/tasks these days are still mainly executed by females. Although the inclusion criteria resulted in an overrepresentation of females, a broad group of 122 participants was included and we think these participants can be seen as representative for the general population. One Dutch participant in the older user focus group was significantly younger than other participants at age 42 . She was deemed to face similar problems to older people receiving home care and therefore included. The older participants who participated in the focus group sessions facilitated by UB had no previous experience of working with ACCOMPANY or previous exposure to the robot, while other participants did. This may have affected their views. Nevertheless, no major differences between these older participants and the older participants from UH, ZUYD and MADoPA could be found. There was also some overlap between the types of groups: many of the people in the older people groups were themselves caring for (or had previous experience - both informal as professional or giving care to) older people. The informal carers spoke also about the care that they would themselves hope to receive 
and some of the professional caregivers referred to experiences they had when providing care to their own family members. It is not clear this limited the variety of views expressed.

Additionally, this study was conducted by various researchers in three different countries (i.e. the Netherlands, France, and UK). The team met regularly to discuss progress and to attempt to standardise the conduct of the research. In spite of this, the data may be influenced by the fact that the focus groups in the three countries were all moderated by different facilitators. Similarly, the research was coded by more than one member of the research team, so the analysis was subject to the same potential variation, even though attempts were made to standardise the coding and to get agreement on the themes. The focus groups were also conducted in the local languages (i.e. Dutch, French, and English). The non-English data was, after transcription, translated into English. In this process the meaning of some of the quotations may have been subtly altered or distorted. Given the international character and the sample size of this study, the disadvantages of using three different sites was found to be of minor importance compared to the advantages.

\section{Conclusion}

In this paper we explored the areas of tension and the boundaries of a re-enablement robot coach for older people through focus group meetings. What became apparent is that potential users are open to the idea of having a robot to support them in their daily life. Moreover the concept of a robot performing higher level coordinating tasks within the role of a re-enablement coach was acceptable.

Participants recognized that a re-enablement robot coach introduces a tension between two different values: 'respect for autonomy' and 'promotion of independence'. For example, a robot that respects the autonomy of the user will obey all commands given, even the ones that may harm the independence of the user in the longer term (i.e. when the robot does too much it can de-skill, de-motivate and/or otherwise erode the abilities the user actually still has, risking decreasing the user's ability in the longer term). In this event the robot would become a 'wedge' that widens the care gap. On the other hand, a robot that refuses to execute a task given by the user, in order to promote independence of the user, seems not to respect the autonomy of the user.

Older people at their most rational probably know that it would be best to do as much as possible for themselves. However, older people, informal carers and care professionals also acknowledged that older persons do not always do what is best for them. And our data suggests that potential users may prefer to resolve the tension between 'respect for autonomy' and 'promotion of independence' in favour of autonomy, making it unacceptable for robots to be programmed to resist commands. However, this dilemma is rather an ethical dilemma as such robots do not permit the user to choose 


\section{Chapter 5}

inappropriately help from the robot. This can drive the user's ability and need further apart and can even create dependence or can encourage passiveness which undermines the ultimate independence of the user as the robot may no longer be able to fill the caregap that emerges.

It is also important for the acceptance of a re-enablement robot that such a robot be more than just a helper. Since the gap between the abilities one still has and the abilities that are required for independent living is likely to differ between people, and over time for the same person, a robot needs to be flexible in order to be effective and efficient; one size does not fit all. A re-enablement coach robot therefore will need to be extremely smart and must be able to perform tasks with the similar qualities and intelligence of human caregivers in order to be found acceptable. To function at such a high level of intelligence robots are required to become more advanced than current available robotics permits. Developing the functional features to perform activities is not the only challenge in robot development; even more challenging will be the development of social behaviour and skills that will enable a re-enablement robot to win acceptance from users. 


\section{References}

[1] Bedaf, S., Gelderblom, G.J., Syrdal, D.S., Lehmann, H., Michel, H., Hewson, D., ... \& de Witte, L. (2014). Which activities threaten independent living of elderly when becoming problematic: inspiration for meaningful service robot functionality. Disability and Rehabilitation: Assistive Technology, 9(6), 445-452. doi: 10.3109/17483107.2013.840861.

[2] Cameron, C., \& Moss, P. (2007). Care work in Europe: Current understandings and future directions. Oxford: Routledge.

[3] Bekey, G., Ambrose, R., Kumar, V., Sanderson, A., Wilcox, B., \& Zheng, Y. (2006). WTEC Panel Report on International Assessment of Research and Development in Robotics. World Technology Evaluation Centre.

[4] International Federation of Robotics. (2014, July 29). Retrieved from http://www.ifr.org

[5] Fraunhofer IPA. (2014, July 6). Retrieved from http://www.care-o-bot.de/en/care-o-bot-3.html

[6] ACCOMPANY. (2014, June 1). Retrieved from www.accompanyproject.eu

[7] Butter, M., Rensma, A., Boxsel, J. V., Kalisingh, S., Schoone, M., Leis, M., ... \& Thielmaan, A. (2008). Robotics for healthcare: final report. DG Information Society, European Commission, Brussels.

[8] The Birmingham 1000 elders group (2014, January 18). Retrieved from http://www.birmingham.ac.uk/ research/activity/mds/centres/healthy-ageing/elders.aspx

[9] Ritchie, J., \& Spencer, L. (2002). Qualitative data analysis for applied policy research. The qualitative researcher's companion, 573(2002), 305-329. doi: 10.4324/9780203413081_chapter_9.

[10] Flandorfer, P. (2012). Population ageing and socially assistive robots for elderly persons: the importance of sociodemographic factors for user acceptance. International Journal of Population Research. doi: 10. 1155/2012/829835.

[11] Smarr, C.A., Prakash, A., Beer, J.M., Mitzner, T.L., Kemp, C.C., \& Rogers, W.A. (2012). Older adults' preferences for and acceptance of robot assistance for everyday living tasks. In Proceedings of the Human Factors and Ergonomics Society Annual Meeting (Vol. 56, No. 1, pp. 153-157). Sage CA: Los Angeles, CA: SAGE Publications. doi: 10.1177/1071181312561009.

[12] Sparrow, R., \& Sparrow, L. (2006). In the hands of machines? The future of aged care. Minds and Machines, 16(2), 141-161. doi:10.1007/s11023-006-9030-6.

[13] Sharkey, A., \& Sharkey, N. (2012). Granny and the robots: ethical issues in robot care for the elderly. Ethics and information technology, 14(1), 27-40. doi:10.1007/s10676-010-9234-6.

[14] Schoot, C. M. (2006). Client-centred care: balancing between perspectives of clients and nurses in home care. Dissertation. Maastricht: Maastricht University.

[15] Eurostat (2013, December 13). Retrieved from http://epp.eurostat.ec.europa.eu/portal/page/portal/ eurostat/home 


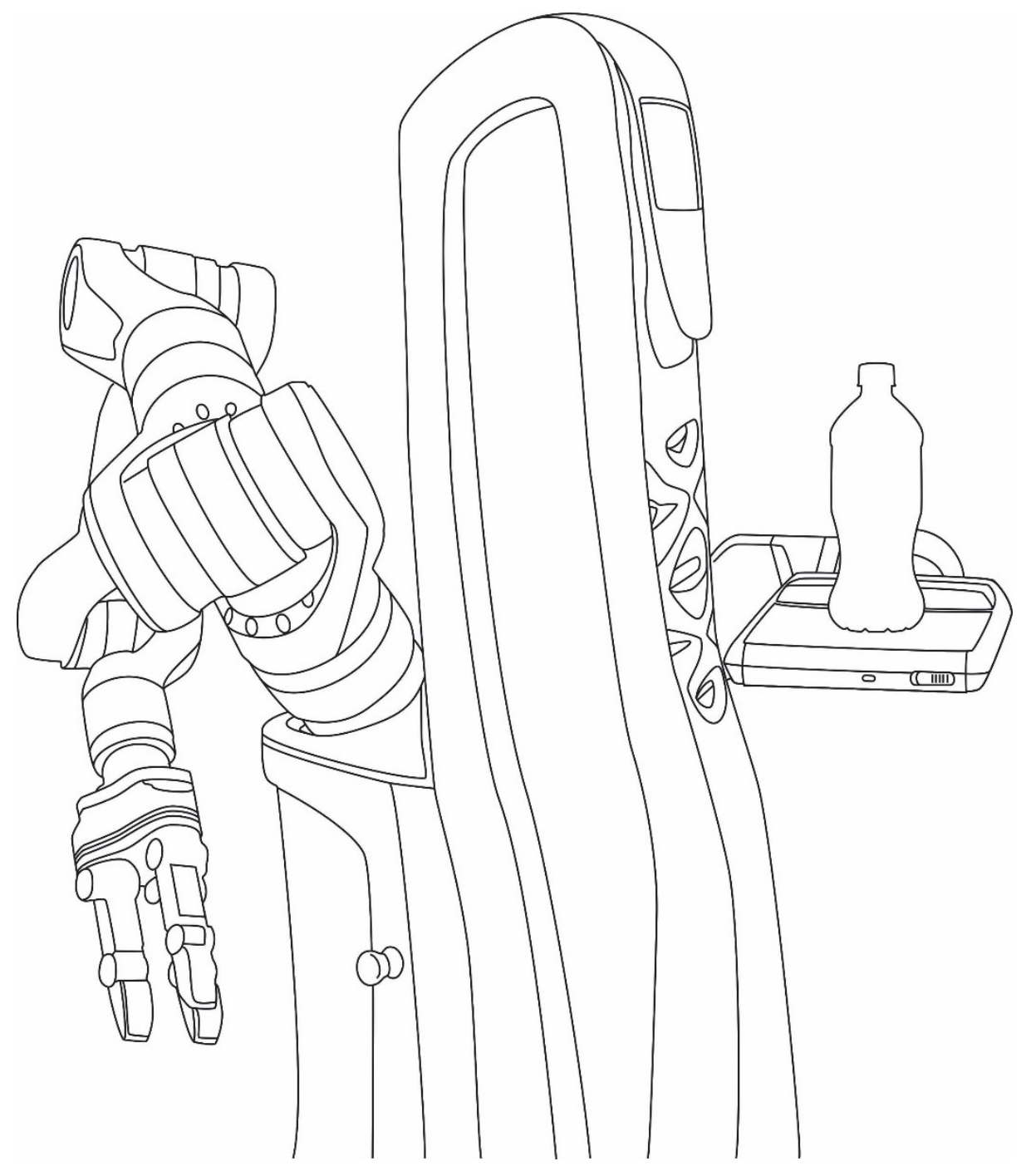




\section{CHAPJFR 6 (}

What are the Preferred Characteristics of a Service Robot for the Elderly? A MultiCountry Focus Group Study with Older Adults and Caregivers

This chapter was submitted as:

Bedaf, S., Marti, P., \& de Witte, L. What Are The Preferred Characteristics Of A Service Robot For The Elderly? A Multi-Country Focus Group Study With Older Adults And Caregivers. Revised version submitted at Assistive Technology: The Official Journal of RESNA. 
CHAPTER 7

\section{A Multiperspective Evaluation of a Service Robot for Seniors: The Voice of Different Stakeholders}

This chapter was published as:

Bedaf, S., Marti, P., \& de Witte, L. (2017). A Multiperspective Evaluation of a Service Robot for Seniors: The Voice of Different Stakeholders (2017). Disability \& Rehabilitation: Assistive Technology, 1-8. doi: 10.1080/17483107.2017.1358300. 


\section{Abstract}

Purpose: The potential of service robots for seniors is given increasing attention as the aging population in Western countries will continue to grow as well as the demand for home care. In order to capture the experience of living with a robot at home, a multiperspective evaluation was conducted.

Methods: Older adults $(n=10)$ were invited to execute an actual interaction scenario with the Care-O-Bot ${ }^{\circledR} 3$ robot in a home-like environment and were questioned about their experiences. Additionally interviews were conducted with the elderly participants, informal carers $(n=7)$, and professional caregivers $(n=11)$.

Results: Seniors showed to be more keen to accept the robot than their caregivers and relatives. However, the robot in its current form was found to be too limited and participants wished the robot could perform more complex tasks. In order to be acceptable a future robot should execute these complex tasks based on the personal preferences of the user which would require the robot to be flexible and extremely smart, comparable to the care that is delivered by a human carer.

Conclusions: Developing the functional features to perform activities is not the only challenge in robot development that deserves the attention of robot developers. The development of social behaviour and skills should be addressed as well. This is possible adopting a person-centred design approach, which relies on validation activities with actual users in realistic environments, similar to those described in this paper. 


\section{Introduction}

The population of Western countries is aging and will continue to grow the upcoming years [1-3]. With this prospect more attention is given to the development of assistive technology (AT). Ongoing technological developments made it possible for the AT domain to evolve over the past decades [4] and many ATs became commercially available to support individuals in their independence, such as wheelchairs, smart home technologies, and accessibility adaptations of the home. Ongoing technological developments also resulted in a new emerging field within the AT domain: robotics. Robots have the potential to support care and independence in many ways [5]. But even though the technological developments are promising, the majority of robotic developments do not reach the market and only a limited number of robots designed for older adults become commercially available [6]. There are various reasons for not reaching the market. One may be that robot developments often seem to be guided by the technical feasibility, the type and tasks a robot can perform and often too little attention is given to the actual needs and wishes of the targeted users $[6,7]$.

The European Acceptable robotiCs COMPanions for Ageing Years (ACCOMPANY) project was a robotic project that aimed to provide services to older adults in an acceptable manner to facilitate independent living at home $[8,9]$. In this project, a state of the art service robot platform, the Care-O-bot ${ }^{\circledR} 3$ (Picture 1), was used to assess user requirements throughout the project [10]. The wishes and needs of potential users (i.e., older adults with no cognitive decline who need some support to remain independent in their own homes, informal carers, and professional caregivers) were used as a starting point and focus group sessions with potential users were conducted during different stages of the project $[11,12]$. This led to a realistic user scenario that was realised at Zuyd University of Applied Sciences in Heerlen, the Netherlands. The scenario was designed from a socio-technical viewpoint, that is focusing on robot's functionality as well as the quality of interaction with the final user. During the technical implementation of this scenario, different technological components were integrated within the action sequence described in the scenario, such as the interacting robot, the use of the robotic arm, the user localisation, the user identification, and the user interface. This scenario allowed us to test the robot in a home environment.

In order to capture the experience of performing the realised scenario and to reflect on the interaction with the robot a multi-perspective evaluation was conducted with older adults, informal caregivers and professional caregivers. We call this kind of evaluation "multi-perspective" since different stakeholders, with different role in the use of the robotic platform, confronted their point of views giving birth to a rich and complex set of "desiderata" and insights for the development of a next generation of social robots for domestic use. This article presents how different stakeholders evaluate the role of a robotic assistant at home, what this means for future robot developments and functions as an inspiration on how other scenarios can be designed and implemented. 


\section{The Care-O-bot ${ }^{\circledR} 3$}

The Care-O-bot ${ }^{\circledR} 3$ (see Picture 1 ) is a high-tech research platform that can be used as a robust, close-to-product research and development platform [10]. It is equipped with omnidirectional drives, a seven degrees-of-freedom manipulator, a three-finger gripper and a tray that can be used to carry objects. The 'head' of the Care-O-bot ${ }^{\circledR} 3$ contains range and image sensors enabling object learning and detection and 3-dimensional supervision of the environment in real time. The robot can move autonomously and can fetch, carry and manipulate objects.

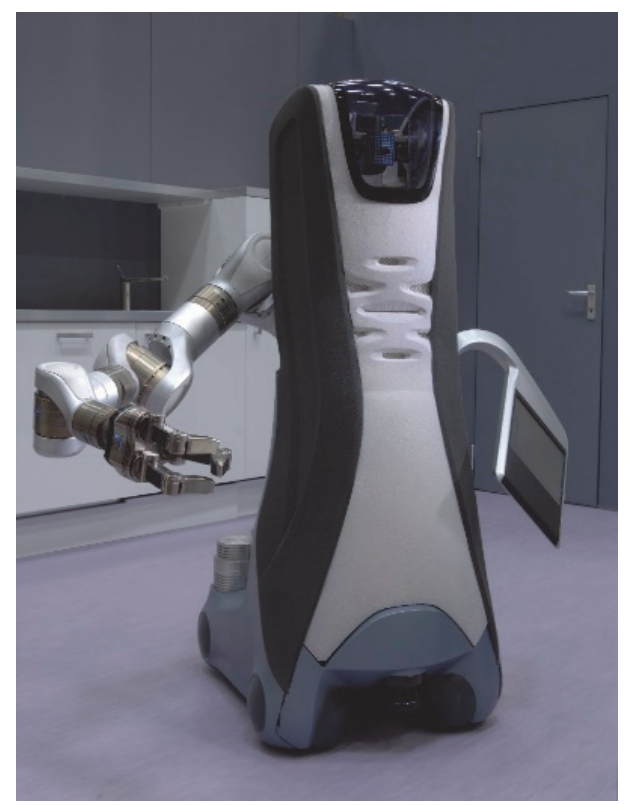

Picture 1: Care-O-bot ${ }^{\circledR} 3$.

\section{Method}

In order to evaluate the scenario individual user tests were conducted with older adults at Zuyd University of Applied Sciences in Heerlen, the Netherlands. This scenario consisted of two parts (see Figure 1) [13]. During the first part of the scenario the user needed to use the robot to get a parcel at the front door of the apartment. During the second part of the scenario the robot noticed the user has not drunk in 3 hours. The robot therefore reminded the user to have a drink, accompanied the user to the kitchen to get the drink, carried the drink back to the sofa and served it to the person by gently placing 
the drink on the table in front of the user. Additionally, the robot also observed if the user would drink from the cup. If not, the robot gently reminded the user to drink.

Part 1

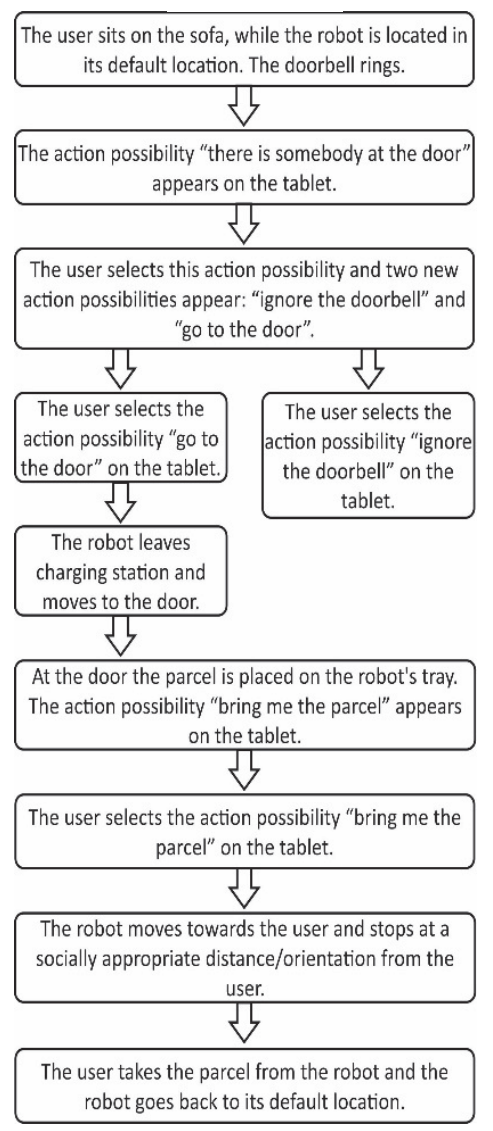

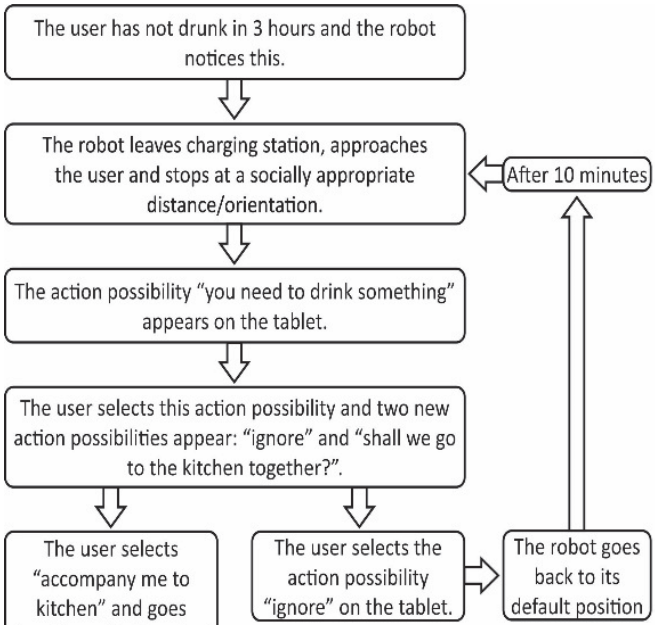

together with the robot

to kitchen.

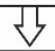

When arriving in the kitchen the user fetches a drink from the fridge and places it on robot's tray.

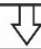

Both robot and user move back to the sofa, while the robot is carrying the drink. The robot places the drink on sofa table and goes back to its default position.<smiles>C1=C2CC2C1</smiles>

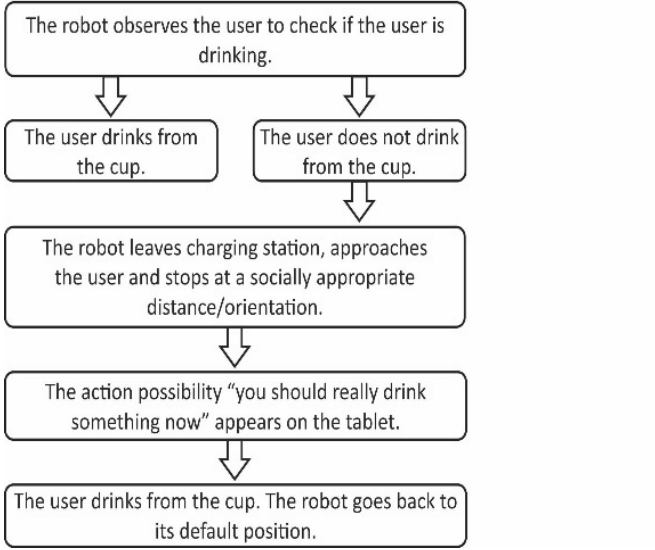

Figure 1: The realised scenario. 
During the whole scenario the robot made use of two different colours lighting in its torso: blue and yellow. The standard blue lighting turned yellow when the robot started moving to a different position, for example when moving towards the front door or kitchen.

The robot could be operated with a remote control (i.e. tablet). A graphical user interface (GUI) on this remote control was used to interact with the robot (see Picture 2). This GUI was developed following a person-centred approach based on the concept of action-possibility. This means the robot has the possibility to execute tasks in a context dependent way [14]. For example: if the environment gets dark, the action-possibility "Switch the light on" appears in the form of a button on the screen. Or if the person did not drink for a long while, the action possibility button "Bring me the water" pops up. The GUI is dynamic since the action possibilities change according to the interplay between the specific configuration of the environment, the potential need/desire of the user and the likelihood for the robot to execute a task.

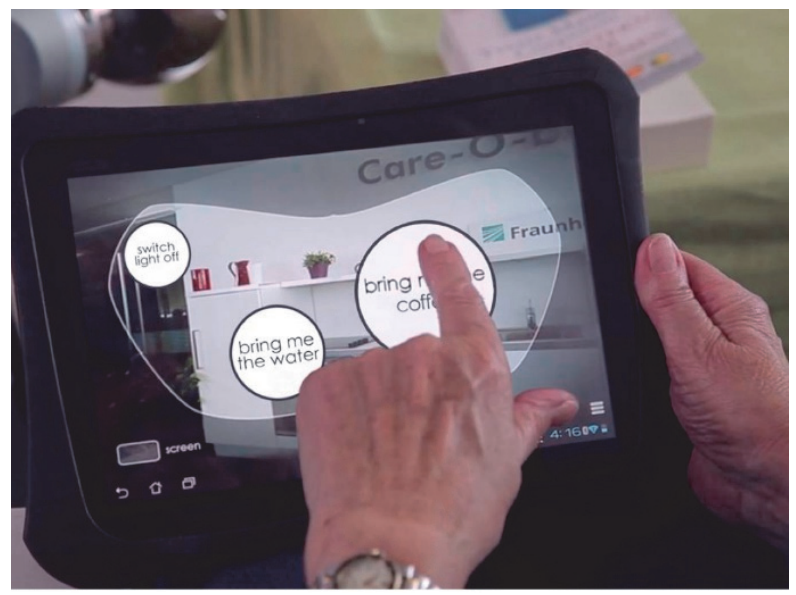

Picture 2: GUI on the tablet..

\section{Participants}

Older adults were contacted through two elderly care organizations in the south of the Netherlands. Their selection took place based on four criteria: aged 60+; living at home; no cognitive decline; receiving home care. Informal caregivers were contacted through the older adults and personal network. Professional caregivers were contacted through the care organizations. Informal caregivers either looked after an independently living older adult on at least a weekly basis, or had taken care of an independently living older adult on a weekly basis in the past year. The selection of professional caregivers was based on their work activities/profession. It was required that they worked closely at least weekly with older adults who live independently. 


\section{Setting}

The Care-O-Bot ${ }^{\circledR} 3$ was part of a smart environment installed in the premises of Zuyd University of Applied Sciences to carry out the evaluation (see Figure 2). The space was enhanced with a multi-angle camera fusion system and sensor network providing information about the living patterns of the older adult and current states of objects in the environment.

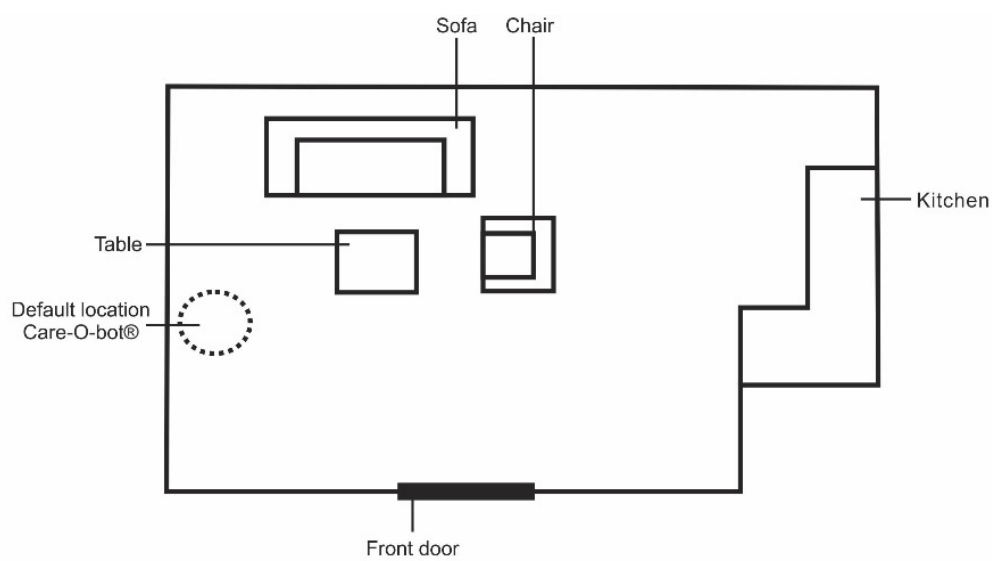

Figure 2: Lab setting

\section{Data collection and analysis}

Individual user tests were conducted with older adults. A researcher (SB) was present during all user tests. Before executing the realised scenario, participants were given the opportunity to practise the scenario once with the robot in order to become familiar with operating and interacting with the robot. During the practise session the participant was free to ask questions concerning the execution of the scenario. After this practise session the participants had to execute the scenario by themselves. After performing the scenario, participants were asked to fill in a questionnaire assisted by the researcher to capture their experience. This questionnaire consisted of 27 Likert-scale questions covering the following 8 topics: 1) Picking up parcel from the front door, 2) Reminder to drink part 1, 3) Getting a bottle of water from the kitchen, 4) Reminder to drink part 2, 5) Operating the remote control, 6) The understanding of the changing patterns of coloured lights on the robot's torso, 7) Performance and 8) Being in charge (see Table 1). The user test sessions were video recorded. The total duration per session was 1.5 hours.

Older adults who participated in the user tests were also invited for an additional semi-structured interview to reflect on the interaction with the robot and to discuss the possible role of the robot in the daily living situation. Older adults were asked to also 
invite their informal caregiver(s). At the start of the interview a video of the executed scenario was shown. The interview guide included questions regarding the experience of performing the scenario together with the robot and the usage of such a robot in daily living. All interviews were audio recorded and the total duration of the interview varied between 45 and 90 minutes. These semi-structured interviews were summarized in written form. All data were analysed by two researchers (SB and LH) using directed content analysis [15].

\section{Results}

\section{Participants}

A total of 10 older adults ( 7 females and 3 males) with the average age of 79,3 years (62 - 93) participated in the user tests. After performing the scenario with the robot, all participants filled in the questionnaire assisted by the researcher. All participants were also invited for the additional interview. Due to illness one female participant dropped out, which resulted in a total number of 9 older adults ( 6 females and 3 males) with the average age of 78,9 years $(62-93)$ who participated in the interviews.

Only one informal caregiver (male) was able be present at the interview of the older adult (female) he was taking care of. For this reason an additional group session was organized with 6 informal caregivers. All were taking care of (one of) their parents. Also, two group sessions with care professionals were organized. This resulted in a total number of 7 informal caregivers ( 5 females and 2 males) and 11 professional caregivers (10 females and 1 male). Three out of the 7 informal caregivers and 9 out of the 11 professional caregivers also visited Zuyd University of Applied Sciences and experienced the scenario live.

\section{Questionnaire}

Overall, elderly participants were positive about performing the scenario (see Table 1). They had a positive attitude towards the two tasks and how the ACCOMPANY robot executed them. Participants also did not mind that the robot reminded them to drink, and found the way the robot did this appropriate. The speed of the robot was most often commented as most participants found the robot to be too slow, especially when placing the drink on the table. Also the place the robot stopped and the spot where the robot placed the drink evoked a mixed response as the different participants had different personal preferences about the best place for both actions. All older adults understood they had to operate the robot with the remote control. Also the use of the touch screen based interface was rated as pleasant, even though none of the participants had previous experience with touch screens. The majority stated it was clear how to select an option 
on the interface. Only half of the participants noticed the changing colours on the robot's torso, but it was not clear to them what these changing colours meant and some even thought it had no meaning. This suggests that colours should never be used arbitrarily in design.

Table 1. Number of participant response per question after performing the scenario.

\begin{tabular}{|c|c|c|c|c|c|c|c|}
\hline No. & Topic & Question & 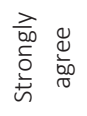 & 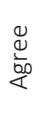 & $\begin{array}{l}\bar{\pi} \\
\stackrel{0}{ \pm} \\
\frac{0}{2}\end{array}$ & 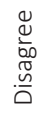 & 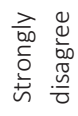 \\
\hline \multirow{7}{*}{1} & \multirow{7}{*}{$\begin{array}{l}\text { Picking up } \\
\text { parcel from the } \\
\text { front door }\end{array}$} & $\begin{array}{l}\text { The way the robot approached me, when bringing the } \\
\text { parcel, was pleasant. }\end{array}$ & 3 & 4 & 2 & 1 & - \\
\hline & & $\begin{array}{l}\text { The robot approached me, when bringing the parcel, } \\
\text { with a pleasant speed. }\end{array}$ & 2 & 6 & 1 & 1 & - \\
\hline & & $\begin{array}{l}\text { The robot approached me, when bringing the parcel, } \\
\text { from a pleasant direction. }\end{array}$ & 4 & 6 & - & - & - \\
\hline & & $\begin{array}{l}\text { The robot stopped at a pleasant distance from me, } \\
\text { when bringing the parcel. }\end{array}$ & 1 & 7 & - & 2 & - \\
\hline & & $\begin{array}{l}\text { It was clear to me when I could take the parcel of the } \\
\text { tray. }\end{array}$ & 2 & 4 & 2 & 2 & - \\
\hline & & The way the robot handed me the parcel was pleasant. & 5 & 3 & 2 & - & - \\
\hline & & $\begin{array}{l}\text { It was clear when the robot was finished with the first } \\
\text { task. }\end{array}$ & 2 & 8 & - & - & - \\
\hline \multirow[b]{2}{*}{2} & \multirow{2}{*}{$\begin{array}{l}\text { Reminder to } \\
\text { drink part } 1\end{array}$} & It was pleasant that the robot reminded me to drink. & 4 & 5 & 1 & - & - \\
\hline & & $\begin{array}{l}\text { The way the robot reminded me to drink was } \\
\text { appropriate. }\end{array}$ & 2 & 6 & - & 2 & - \\
\hline \multirow{8}{*}{3} & \multirow{8}{*}{$\begin{array}{l}\text { Getting a bottle } \\
\text { of water from } \\
\text { the kitchen }\end{array}$} & $\begin{array}{l}\text { It was clear that I needed to walk to the kitchen } \\
\text { together with the robot. }\end{array}$ & - & 7 & 1 & 2 & - \\
\hline & & $\begin{array}{l}\text { It was pleasant to walk to the kitchen together with } \\
\text { the robot. }\end{array}$ & 2 & 8 & - & - & - \\
\hline & & Standing in the kitchen with the robot was pleasant. & 2 & 8 & - & - & - \\
\hline & & The way the robot unfolded the tray was pleasant. & 3 & 5 & 2 & - & - \\
\hline & & $\begin{array}{l}\text { Walking back to the couch with the robot was similar } \\
\text { as walking to the kitchen. }\end{array}$ & 3 & 3 & 3 & 1 & - \\
\hline & & $\begin{array}{l}\text { The place where the robot stopped with the drink was } \\
\text { pleasant. }\end{array}$ & 2 & 5 & 1 & 2 & - \\
\hline & & $\begin{array}{l}\text { The way the robot placed the bottle on the table was } \\
\text { pleasant. }\end{array}$ & 1 & 3 & 5 & 1 & - \\
\hline & & $\begin{array}{l}\text { The robot placed the bottle on the best spot on the } \\
\text { table. }\end{array}$ & 1 & 5 & 1 & 2 & 1 \\
\hline \multirow{2}{*}{4} & \multirow{2}{*}{$\begin{array}{l}\text { Reminder to } \\
\text { drink part } 2\end{array}$} & It was pleasant that the robot monitored if I drank. & 4 & 5 & 1 & - & - \\
\hline & & The robot used the best manner to remind me to drink & - & 5 & 2 & 3 & - \\
\hline
\end{tabular}




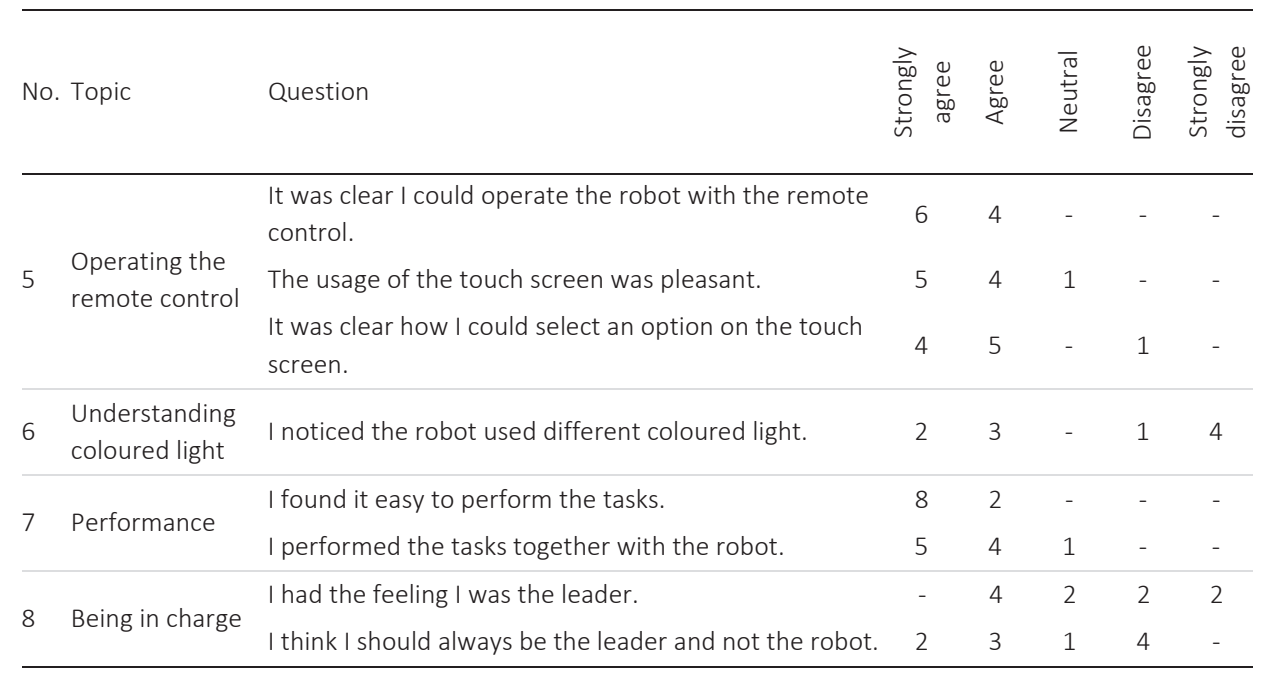

Participants found it easy to perform both tasks and almost all participants had the feeling they executed these tasks together with the robot. Finally, some statements were given about being in charge. This topic evoked mixed responses and three opinions could be distinguished. One group of elderly participants argued that they operated the robot by pushing the buttons and without them the robot would not do anything. They therefore stated they were in control. The second group of elderly participants thought neither they nor the robot were the leaders. They evaluated the interaction as a cooperative effort between them and the robot. The third group had the feeling that the robot was the leader since it suggested to drink and they just executed what the robot proposed them to do. When asking if they would prefer to always be the leader the majority thought it would depend on the situation and again on the personal preferences of the user.

\section{Interview}

Although the participants were in general positive about the current scenario, older adults, informal caregivers and professional caregivers all acknowledged during the interviews that the robot in its current form was too limited. They all stated the robot should perform more complex tasks in order to support independent living at home successfully. When discussing the type of tasks the robot should support in the future, tasks such as fetching \& carrying of objects, contacting others in case of a fall or other emergency, opening door and cooking were mentioned by the participants. Tasks that required the robot to be more delicate (e.g. touching a human being) such as supporting showering, toileting and getting dressed were often mentioned as not allowed and/or impossible as participants foresaw problems related to technical limitations of the future robot and/or the level of intelligence required. 
Participants also stated that a future robot should execute tasks based on the personal preferences of the user. "One size does not fit all" applies here. Especially the informal caregivers agreed that the robot should be able to support the user in a personal manner comparable to the support provided by a human carer. They stated that caring for someone requires having an eye for details. For example: a human caregiver can see if someone's skin is dry or if one has a wound that requires special care. Informal caregivers recommended that a future robot should be able to do this as well in order to be acceptable. This would require the robot to be extremely smart and its behaviour should be adapted to the specific needs of the seniors. For this reason some of the professional caregivers preferred a robot acting like an assistant of the caregiver; such a robot would never perform any tasks by itself. It would just support the caregiver in executing tasks (e.g. with the robot only one caregiver, instead of two, would be sufficient to take care of a bedridden senior).

How to introduce the robot was a topic that was intensively discussed during both sessions with the professional caregivers. This topic did not appear during the session with the informal caregivers or during the interviews with the older adults. Professional caregivers stated that introducing the robot required more than just placing it in the home of the end user. They were worried that older adults would need time to get familiar with the robot and thought it would be best if a human caregiver would introduce the robot step by step. In this case the robot could start with executing (simple) tasks together with the caregiver and after a while the robot could perform more (complex) tasks until it would execute (complex) tasks by itself without the presence of a caregiver. Professional caregivers expected that this type of introduction would help the senior to get used to receiving care from a robot and to accept the robot.

Informal caregivers were worried that older adults would not be capable to operate the robot as older adults have limited experience with 'new' technologies (e.g. computers). Other professional caregivers shared the same concern. Informal caregivers and professional caregivers both thought older adults would need support (e.g. from their children or a company) to interact with the robot. The elderly participants did not share these worries and indicated that they found the interaction with the robot rather pleasant and clear, especially after the practise session. When discussing the use of the remote control through the tablet based interface, older adults stated that they appreciated the synchrony between the robot approaching them and the pop-up button appearing on the screen as this triggered them to look at the remote control. Some of the older adults also suggested that a sound could reinforce the feedback.

Informal caregivers preferred their parent(s) to have a human caregiver instead of a robot. However, the majority of the informal caregivers, as well as the professional caregivers, preferred the robot over a human caregiver since they disliked being dependent on others for support. An important note here is that they all expected to be able to maintain social relationships by themselves. Both informal caregivers and professional caregivers stated that social contact is extremely important. For some older 
adults the moment their caregiver visits them is the only social contact during the whole day. For them these moments are indispensable. Informal caregivers and professional caregivers therefore believed that a robot would not be suitable for such older adults. They preferred older adults to be given the choice between a human caregiver or a robot. The older participants had different opinions concerning this topic. Half of the older adults preferred to receive support from a robot, especially the ones that expected to need more intensive support in the future. Older adults, informal caregivers and professional caregivers stated that one of the biggest advantage of the robot was to be available to support during the whole day whereas a human carer is usually available only on fixed times. The main reason for the older adults to prefer the human care was related to the social interaction; they liked to have a chat with their carer and were not willing to give this up.

\section{Discussion}

This study enabled us to evaluate and discuss from a multiple perspective the performance, use and interaction of the Care-O-bot ${ }^{\circledR} 3$ robot in a home-like environment with older adults, informal caregivers and professional caregivers living in the Netherlands. The scenario was fully working, which made it possible to have realistic interaction with the robot, and required no need to instruct or support the elderly participants during the evaluation. The use of the questionnaire highlighted emotional aspects as well as the subtleties of the interaction (e.g. it was pleasant to walk to the kitchen together with the robot), while the interviews provided more in-depth information.

Although participants found that the robot with its current functionalities was still too limited, they were positive towards the idea of a robot that would provide sufficient support to prolong independent living of older adults. In order to do so successfully, the robot should support activities related to self-care (e.g. washing, toileting, feeding, drinking), mobility (e.g. making transfers, mobility in and around the home), and social participation (e.g. visiting others, communicating, receiving visitor) [11]. In the implemented scenario, the robot is only able to perform a very small subset of these complex activities since picking up a parcel at the front door is related to mobility and reminding the user to drink is related to self-care. It is therefore not surprising that older adults, informal caregivers and professional caregivers wished a future robot would be able to execute more complex tasks. However, when the robot would be able to perform more complex tasks, participants also wanted the robot to be able to execute these tasks according to the personal preferences of the user in order to be found acceptable. And also the role of the robot should depend on these personal preferences, for example who should take the lead in which situation. This requires the robot to have a high level of intelligence and again highlights the importance that not only the technical development 
deserves the attention of robot developers, but also the development of social behaviour and skills [12].

Elderly participants had mixed responses on specific robot's behaviours. For example they did not agree on where the robot should stop when serving a drink and where it should to place the drink on the table. This debate shows that they paid attention to the subtleties of the interaction with the robot (like the expressivity of the movement), and not only to the functionality offered by the robot. When testing a robot with real people in a realistic home environment, a successful task execution from a technical point of view is just a starting point for an engaging human-robot interaction. The trial allowed the participants to focus on the experience of living with the robot, focusing on feelings of engagement rather than considering only functional aspects.

Additionally, the changing coloured lighting was not noticed/understood by the majority of the participants. Again this is an indication that abstract or arbitrary representations of the robot behaviours do not work. People need to make sense of the interaction, and they pay attention to natural cues that express the robot's behaviour (e.g. movement) rather than arbitrary feedback.

Previous experience of participants with technology also plays a role in the acceptance of robots [16]. This means that both informal caregivers and professional caregivers are more likely to have a positive and open attitude towards the robot as they most likely have more experience with using technology. Nevertheless, the informal caregivers and professional caregivers in this study expressed more concerns than the older adults about the acceptance of the robot also related to potential technical issues. The older adults were rather positive about performing the scenario with the robot and found the robot clear and pleasant to operate. This is also in line with the results of a previous study which showed that older adults were open to the idea of having a robot supporting them in their daily life [12] as well as with the results of a study by Broadbent et al. [17] in which residents of a retirement village showed a more positive attitude towards a health-care robot than both staff and relatives.

Informal caregivers and professional caregivers preferred the robot over a human caregiver for themselves, but only when being able to maintain a social life on their own. For their parents, the informal caregivers preferred a human caregiver. Their motivation for refusing a robot for their parent(s) was unclear, but mostly related to the lack of social contact since all participants agreed that the robot could not be a replacement for human contact. In line with the findings of Sparrow \& Sparrow [18] and Decker [19], also the professional caregivers participating in our study preferred a robot able to assist human caregivers rather than replace them.

\section{Limitations}

The inclusion criteria for participants were rather broad. For example, no specific criteria concerned the gender balance of the sample. This resulted in an overrepresentation of 
females. The user tests were performed in a home-like lab setting reproducing a living room area, a kitchen area, bathroom and a front door. Even if the setting was realistic, it was not the real home environment of the older adults participating to the study. Additionally, the elderly participants only performed the scenario twice with the robot. This limits the possibility for the participants to make sense of what living with a robot means.

\section{Conclusion}

In this paper we presented the findings of a scenario-based evaluation involving older adults interacting with a robot at home. The evaluation was multi-perspective since it involved also other stakeholders like professional and informal caregivers who evaluated the role of a robotic assistant at home. This article underlines the importance of taking different perspectives during the evaluation to improve the robot acceptance. The stakeholders involved in the study turned out to have a different attitude towards the robot. Older adults turned out to be more positive about performing the scenario, while informal caregivers and professional caregivers were more sceptical on the use of an assistive robot, especially concerning technical issues. The current version of the robot was judged too limited by all participants. They all stated that a future version of the robot should be able to support more complex tasks (related to the problematic activities of older adults) in order to actually be able to prolong independent living of older adults. Additionally, a future robot should also be able to execute tasks in an acceptable manner that matches the personal preferences of the user. It's behaviour and support should also be comparable to the care delivered by a human caregiver. Implementing the functional features to perform various activities is therefore not the only challenge in robot development. The robot's social behaviour should be carefully addressed as well. 


\section{References}

[1] Soede, A.J., Vrooman, J.C., Ferraresi, P.M., \& Segre, G. (2004). Unequal welfare states: Distributive consequences of population ageing in six European countries. The Hague: Social and Cultural Planning Office.

[2] Verzijden, D. and J. Fransen (2004). Vergrijzing in Nederland - onderzoek uitgevoerd in opdracht van de Rijksvoorlichtingsdienst/Publiek en Communicatie ten behoeve van het ministerie van Volksgezondheid, Welzijn en Sport Veldkamp.

[3] Suzman, R., \& Beard, J. (2011). Global health and aging. (2014, February 4). Retrieved from http://www.nia.nih.gov/research/publication/global-health-and-aging/preface

[4] Vlaskamp, F., Soede, T., \& Gelderblom, G.J. (2011). History of assistive technology: 5000 years of technology development for human needs. Heerlen: Zuyd University of Applied Sciences.

[5] Bekey, G., Ambrose, R., Kumar, V., Sanderson, A., Wilcox, B., \& Zheng, Y. (2006). WTEC Panel Report on International Assessment of Research and Development in Robotics. World Technology Evaluation Centre.

[6] Bedaf, S., Gelderblom, G. J., \& de Witte, L. (2015). Overview and Categorization of Robots Supporting Independent Living of Elderly People: What Activities Do They Support and How Far Have They Developed. Assistive Technology: The Official Journal of RESNA, 27(2), 88-100. doi: 10.1080/10400435.2014.978916.

[7] Butter, M., Rensma, A., Boxsel, J. V., Kalisingh, S., Schoone, M., Leis, M., ... \& Thielmaan, A. (2008). Robotics for healthcare: final report. DG Information Society, European Commission, Brussels.

[8] ACCOMPANY (2016, February 22). Retrieved from http://accompanyproject.eu/

[9] Amirabdollahian, F., Op Den Akker, R., Bedaf, S., Bormann, R., Draper, H., Evers, V., ... \& Hu, N. (2013). Assistive technology design and development for acceptable robotics companions for ageing years. PALADYN: Journal of Behavioural Robotics. doi: 10.2478/pjbr-2013-0007.

[10] Fraunhofer IPA (2016, February 21). Retrieved from http://www.care-o-bot.de/en/care-o-bot-3.html

[11] Bedaf, S., Gelderblom, G.J., Syrdal, D. S., Lehmann, H., Michel, H., Hewson, D., ... \& de Witte, L. (2014). Which activities threaten independent living of elderly when becoming problematic: inspiration for meaningful service robot functionality. Disability and Rehabilitation: Assistive Technology, 9(6), 445-452. doi: 10.3109/17483107.2013.840861.

[12] Bedaf, S., Draper, H., Gelderblom, G.J., Sorell, T., \& de Witte, L. (2016). Can a service robot which supports independent living of older people disobey a command? The views of older people, informal carers and professional caregivers on the acceptability of robots. International Journal of Social Robotics, 8(3), 409420. doi: 10.1007/s12369-016-0336-0.

[13] Fraunhofer IPA (2013, December 5). Robot companion for the elderly. [Video file]. Retrieved from https://www.youtube.com/watch?v=Z1MJPdhniXc

[14] lacono, I., \& Marti, P. (2014, October). Engaging older people with participatory design. In Proceedings of the 8th Nordic Conference on Human-Computer Interaction: Fun, Fast, Foundational (pp. 859-864). ACM. doi: $10.1145 / 2639189.2670180$.

[15] Hsieh, H.F., \& Shannon, S.E. (2005). Three approaches to qualitative content analysis. Qualitative health research, 15(9), 1277-1288. doi: 10.1177/1049732305276687.

[16] Flandorfer, P. (2012). Population ageing and socially assistive robots for elderly persons: the importance of sociodemographic factors for user acceptance. International Journal of Population Research. doi:10. 1155/2012/829835.

[17] Broadbent, E., Tamagawa, R., Patience, A., Knock, B., Kerse, N., Day, K., \& MacDonald, B.A. (2012). Attitudes towards health-care robots in a retirement village. Australasian journal on ageing, 31(2), 115120. doi: 10.1111/j.1741-6612.2011.00551.x.

[18] Sparrow, R., \& Sparrow, L. (2006). In the hands of machines? The future of aged care. Minds and Machines, 16(2), 141-161. doi:10.1007/s11023-006-9030-6.

[19] Decker, M. (2008). Caregiving robots and ethical reflection: the perspective of interdisciplinary technology assessment. Al \& society, 22(3), 315-330. doi: 10.1007/s00146-007-0151-0. 


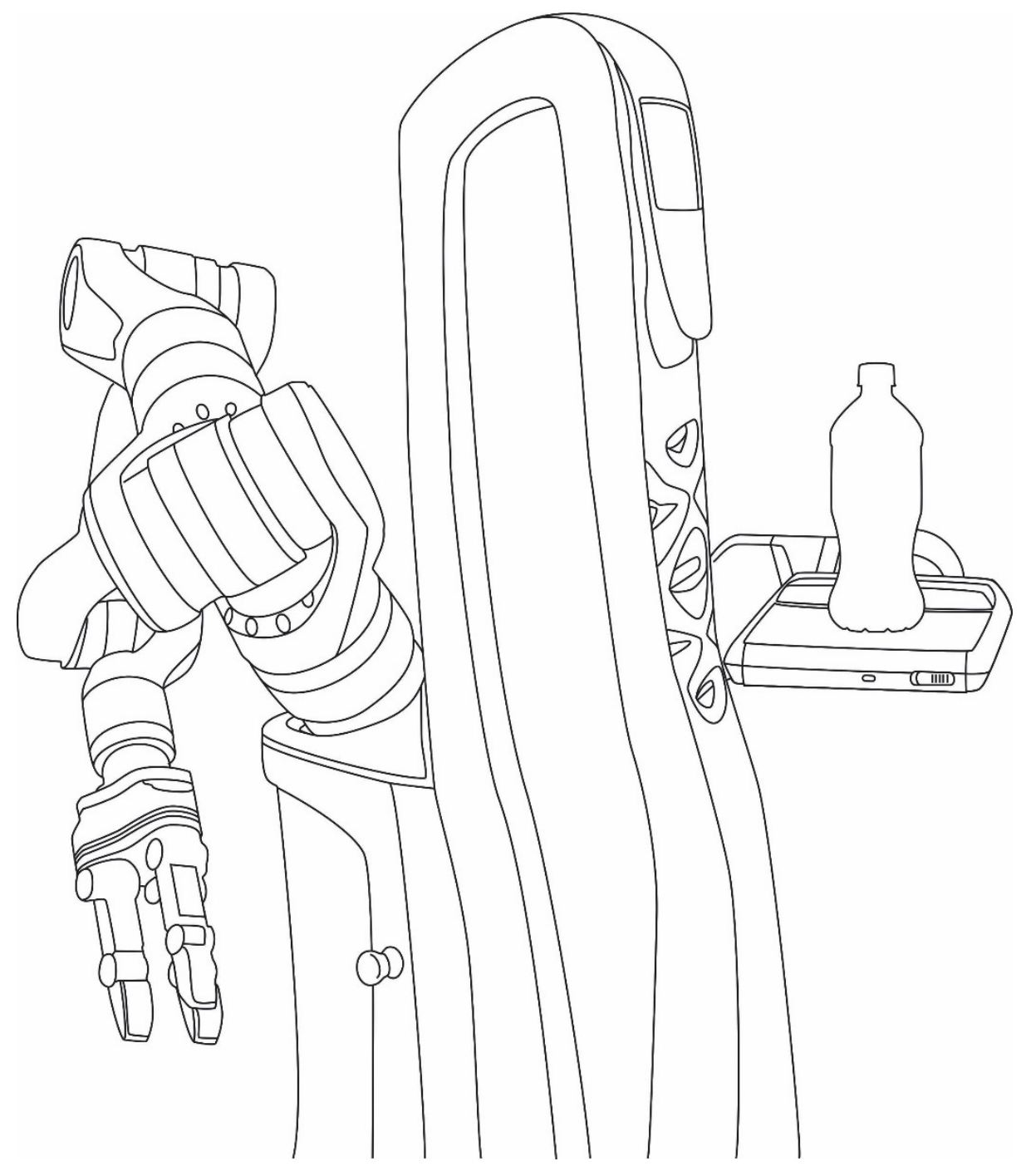




\section{CHAPTER 8}

General Discussion 

The main objective of this thesis was to contribute to the development of service robots to prolong independent living of older adults from a user perspective through gaining knowledge on what potential end users need, want and find acceptable. To achieve this, the following research questions were addressed:

1. What kinds of robots are available for older adults living independently?

2. Do these robots match the needs of older adults?

3. What ethical boundaries should be taken in to account when developing robots for older adults?

4. What are the preferred characteristics of service robots for older adults?

5. How do potential users experience executing a task together with a service robot?

The work described in this thesis was part of the larger Acceptable robotiCs COMPanions for AgeiNg Years (ACCOMPANY) project (see Chapter 2) [1, 2]. The overall goal of this project was to further develop the functionalities of an existing service robot, the CareO-bot ${ }^{\circledR} 3$ [3], in order to prolong independent living of older adults by providing physical, cognitive and social assistance for everyday home tasks in a socially acceptable manner, and to contribute to the re-enablement of the user (i.e., enable older adults to carry out relatively difficult daily tasks on their own).

A total of five studies were conducted as part of this research. First, an extensive systematic literature review was performed to obtain an overview of available robots that aim to support independent living of older adults without cognitive decline. Secondly, the activities that can potentially compromise the independence of older adults were assessed through a literature study and focus group sessions with potential end users (i.e., older adults, informal caregivers and professional caregivers). Thirdly, a scenario especially designed to investigate the ethical aspects of living with a robot was used to discuss the ethical boundaries concerning the use of a service robot with potential end users during focus group sessions. Fourthly, a second scenario was discussed during focus group sessions to ascertain the characteristics of a service robot that are preferred by potential end users, and are considered necessary in order for the robot to be found acceptable when executing a task. Finally, a multi-perspective evaluation of a service robot, involving potential end users, was conducted.

This general discussion chapter presents the main findings and lessons learned from these five studies, as well as relevant methodological and theoretical considerations and suggestions for future research. This knowledge is highly relevant to robot developers and contributes to the development of service robots for older adults. Further, it may also be relevant to the related field of service and assistance robotics (e.g., in the care of disabled and chronically ill people), as well as the general domains of home assistance and entertainment robotics. 


\section{Main findings}

Robots currently available to older adults living independently

The development of service robots for older adults living independently has been paid an increasing amount of attention in recent years. In the systematic review described in Chapter 3, a total of 107 robots that serve this function were identified [4]. However, the study also illustrated the fact that the development of these types of robots is still in its infancy, as only a limited number of robots have reached the market and are commercially available to consumers $(n=6)$, while the majority $(n=95)$ are still in development (i.e., robots with a physical prototype for research purposes).

The commercially available robots encountered during this study were usually only capable of supporting one specific activity (e.g., eating or bathing), while almost all robots 'under development' aimed to support multiple activities. In general, robots have the potential to support multiple activities. However, such robots are more difficult to introduce to the market as it is expected that their reliability and robustness are often compromised with increasing level of complexity. Additionally, some of the robots that are 'under development' can be regarded as technology development platforms, and lack a solid commitment towards market introduction. In the case of others that are 'under development', it is uncertain as to whether they will reach the market given that their efficacy in terms of providing the support they claim to provide is yet to be demonstrated in a home setting. Even if a robot has been proven to be capable of performing certain functions in a laboratory environment, this does not necessary guarantee that it can perform this function in a safe and robust manner in the home of an older adult.

It will likely be a long time before service robots are capable of supporting multiple activities in the homes of older adults. In addition, it is important to know what daily activities of older adults cause dependency as, were the robot to be made available to an individual user these activities should be supported in a manner that is found to be acceptable by potential end users (i.e., older adults, informal carers, and professional caregivers).

\section{The match between currently available robots and the needs of older adults}

The findings of our research indicated that it is difficult to identify one single activity that, on its own, leads to the decision of having to leave home [5]. Most often, it is a unique combination of problems, which may differ between individuals, that contributes to such a decision given that it depends on the abilities of the person in relation to their own perceptions and wishes, and the environment of independent living (in a social, physical and financial sense). From the study described in Chapter 4, we can conclude that activities within the International Classification of Functioning (ICF) domains [6] of mobility (d4), self-care (d5), and interpersonal interactions \& relationships (d7), can 
potentially compromise the independence of older adults [5]. However, not all of the activities identified in this chapter are necessarily best solved by robotics. In general, the need for a robot is questionable for activities that do not require physical movement and/or force exertion. Looking at the three activity domains that were found to potentially compromise independence, it is clear that robots can support a number of tasks within the self-care (e.g., washing, toileting, dressing, and eating) and mobility (e.g., climbing stairs, lifting and carrying objects) domains as physical movement and/or force exertion is required for these activities.

When looking at the robots identified in Chapter 3, we see that almost all commercially available robots provide physical support for a single activity related to the domain self-care. However, robots in the development phase often aim to provide nonphysical support for various activities related to the domains mobility and/or self-care (e.g., provision of reminders, fall detections, doing health measurements). While this type of support can be useful, it likely does not prolong independent living as the problematic activities older adults experience primarily require physical support. Robots only providing non-physical support for activities related to the mobility and self-care domains will most likely fail to prolong independent living of older adults in a cost-effective manner, as cheaper alternative solutions are often available. To prolong independent living, the step towards a robot providing physical support is inevitable and needs to be taken. This carries many technical challenges and requirements (e.g. robots capable of handling and/or moving frail users). These technical challenges need to be overcome in order to create successful robots.

\section{The ethical boundaries of robots for older adults}

Older adults must stay active as long as possible in order to maintain their physical abilities ("use it or lose it"). Therefore, one of the aspects the ACCOMPANY project sought to promote was re-enablement. When the Care-O-bot ${ }^{\circledR} 3$ functions as a re-enablement coach, it motivates and stimulates users to perform tasks, rather than performing tasks for users directly. This may imply that in some situations, it would be better if the robot would disobey commands given by the users, in order to encourage them to exercise abilities they might otherwise lose. This causes tension between respecting the autonomy of the user (i.e., the robot obeys all commands given by the user) and the promotion of independence in the long term (i.e., the robot is programmed to maintain the abilities the user still has).

A qualitative study, that was conducted to gain insight into the ethical boundaries that should be taken into account when developing a robot for older adults, showed that potential end users acknowledged that a re-enablement coach robot would create such tension between respecting the autonomy of the user and the promotion of independence in the long term (see Chapter 5) [7]. The results of this study indicated that older adults preferred to resolve this tension in favour of autonomy. Therefore, in order 
for the robot to be found acceptable, it must be within the control of the user. It would, therefore, be unacceptable for the robot to be programmed to resist a given command. This choice, however, may diminish the user's abilities in the longer term, because when such a robot does too much, it can de-skill, de-motivate and/or erode the abilities the user still has, and thereby undermine their ability to live independently.

Additionally, potential end users generally regarded a robot providing reminders as acceptable and useful, but only if the robot would be capable of responding to the user's habitual behaviour and would provide useful reminders depending on the situation. However, the abilities of users may differ between people, as well as over time. Therefore, in order to function in an acceptable manner, the robot should be able to recognize circumstances, interpret them and make decisions accordingly. This means that the robot should, ideally, operate at the same level of intelligence as a human carer.

Potential end users also indicated the importance of striking a balance between encouraging health-promoting behaviour (e.g., stimulate the user to get a drink by themselves) and protecting the user from dangerous situations (e.g., dehydration). In order to avoid dangerous situations prompting health-promoting behaviour was found to be less acceptable as providing reminders.

\section{Preferred characteristics of a service robot for older adults}

Guidelines on how a robot should behave in a home environment are essential for its acceptance by users [8]. From the qualitative study described in Chapter 6, it is apparent that potential end users find it imperative that a service robot behaves according to their wishes[9]. This suggests that it should, ideally, be possible to personalise the robot for each individual user in terms of many different aspects. For example, users should be able to determine how to communicate with the robot, how the robot should execute a task, what data should be stored, and who can have access to this data. This adds to the complexity of developing service robots for older adults living independently as a universal solution will not be appropriate - i.e. "one size fits all" does not apply here.

Potential end users were also not in agreement on all aspects. For example, older adults preferred the robot to behave rather passively and wanted the robot to obey all orders given by the user, while caregivers preferred to have the robot and user performing tasks together in order to keep the user active as long as possible. This is consistent with the results of the study concerning the ethical boundaries of a robot [7]. As such, when developing a robot, one should be aware of diversity of preferences between different stakeholders.

Additionally, potential end users wanted the robot to look friendly. However, the robot used in this study, the Care-O-bot ${ }^{\circledR} 3$, is relatively large and machine-like in appearance. In order to make the appearance of this robot friendlier, potential end users suggested making the robot smaller and adding human features (e.g., face, blinking eyes, 
two arms). This is in line with prior research in which participants aged 65+ preferred assistive robots to be discrete and small, with human traits [10].

\section{User experiences of executing a task together with the robot}

The multi-perspective evaluation study described in Chapter 7, in which older adults were invited to perform two tasks together with the Care-O-bot ${ }^{\circledR} 3$ (i.e., picking up a parcel at the front door and getting a drink from the kitchen), revealed that older adults were, more keen to accept the service robot than their informal caregivers and professional caregivers [11]. This is consistent with the findings of the studies presented in Chapters 5 [7] and 6 [9].

Potential end users who participated in this study also stated that the Care-O-bot ${ }^{\circledR} 3$ needs to expand its functionalities and should be able to perform more complex tasks to provide added value to older adults living independently. This was expected, as the tasks the robot could perform during the multi-perspective evaluation study were only a very small subset of the activities that were found to potentially compromise the independence of older adults. Additionally, potential end users stated, in line with the results of the studies described previously, that the robot should behave according to the wishes of its user. This emphasizes the fact that it is not only the technical development of robots that robot developers should be concerned with. The development of the social behaviour and skills of a service robot should also be addressed in order for it to be found acceptable by potential end users.

\section{Methodological considerations}

Exploring the needs and wishes of potential end users

The use of a user-centered approach to developing a service robot is essential throughout the process in order to optimise usability and the acceptability by future users [12]. Potential end users (i.e., older adults, their families and caregivers) should be actively involved during the development process [10,13]. Focus group sessions are particularly useful to explore what potential end users think, how they think and why they think in that way [14]. Additionally, focus group sessions are also suitable when you have to involve different stakeholders, with different backgrounds and roles in the context of a project. During focus group sessions, a facilitator guides the discussion, keeping it focussed on a particular topic, while avoiding to take a leading role [15]. Such a facilitator can be considered as the interface between users and designers [16] and the users as the subject of the study [17].

A large number of potential end users (i.e., $n=113, n=122$, and $n=97$ ) in three different countries (i.e. the Netherlands, the UK, and France) were included in the focus group 
sessions that were conducted throughout the different stages of the work presented in this thesis. We were specifically looking for an open approach to explore the needs and wishes of these potential end users. By using focus group sessions participants were not restricted in their thinking. It also provoked discussion as participants were encouraged to react on each other. This enabled us to get more valuable insights than we would have gotten with, for example, questionnaires or individual interviews. The main goal of our studies was to get insight into the themes that were found to be most important from the perspective of older adults, informal caregivers and professional caregivers in order to support the further development of an existing service robot, the Care-O-bot ${ }^{\circledR} 3$. The studies were supposed to generate input and inform the development process. Conducting focus group sessions has been an appropriate method to distract the input needed to take the next steps in the development process.

The large number of participants, and the international character of the studies, can be seen as major strengths of this thesis. However, one must be aware that the personal interests and views of facilitators may steer the content of the session, and may, therefore, have influenced the results described in this thesis. Although detailed topic guides were created for these studies, it is recommended that a strict protocol is created, and regular meetings with all researchers involved are convened to create a shared understanding of this protocol, in order to minimize the influence of the facilitator. Looking back at our studies, a more strict protocol and more regular meetings, to ensure a shared understanding, could have been beneficial for our studies. The concept of living with a robot may be difficult to grasp for potential end users as these types of users are often unlikely to have had previous experience with robotics. Scenarios and storyboards can be used to create a shared understanding among people about how a service robot might operate in the home of an older adult. Scenarios are detailed realistic examples of how a user may carry out tasks in a specific context with a future product [18]. Storyboards are aids that provide a common visual language that people from different backgrounds can understand, and enable participants to experience the visualized interactions by empathizing with the user of the scenario, project themselves into the story and reflect based on their own experiences [19]. In this thesis, the Care-O-bot ${ }^{\circledR} 3$ functioned as a concrete case for the scenarios and storyboard used. The use of such a concrete case to explore the needs and wishes of potential end users is relatively new in the field of developing service robots for older adults living independently. The methodology and approach described in this thesis can, therefore, be seen as an example for future studies concerning the development of service robots.

User studies should be part of the development of robots as they provide useful suggestions for the improvement both of the technical, and interaction, capabilities of a 
robot [20]. Often the Wizard of $\mathrm{Oz}$ method $^{5}$ is used to simulate intelligent interfaces and systems when testing with potential end users. It is a quick method to implement complex robot behaviour $[21,22]$. However, simulating robot interaction puts a heavy burden on the human operator to act as the robot, and as such, this approach can easily result in inconsistencies between sessions as it is difficult for a human operator to perform consistently, even in similar situations $[22,23]$. The expectations people have of what robots can and cannot do are also often far removed from their real capabilities, as representations of robots, for example in movies or on the Internet, show smart robots capable of performing complex activities, and simulating interaction can feed further systematic distortion [23].

During our evaluation study described in Chapter 7, a fully working scenario was created and used for a multi-perspective evaluation. This is another strong aspect of this thesis, as it provided potential end users an opportunity to have a realistic interaction with a service robot, without the interference of a researcher, in a home-like environment, as well as experience performing tasks together with a robot. However, it must be noted that real life user tests are very time consuming, complicated and expensive to run to test a relatively small sample of potential end users [20, 22]. For studies that do not have a fully developed and working prototype (yet) or for in-between evaluations, a video-based Human-Robot interaction (VHRI) study ${ }^{6}$ may be a good alternative. With VHRI, a large number of participants in different locations can be studied in a relatively short time. However, VHRI studies are less suitable in studies that entail relatively more user-robot interactions, given the increased importance of aspects of embodiment, dynamics and contingency of interaction [20]. VHRI studies can, therefore, be considered as a supplementary method that can be used in combination with real life studies that involve working prototypes, rather than a replacement.

Several key principles of User-Centered Design (UCD) were applied during the ACCOMPANY project [24] in order to explore the needs and wishes of potential end users. For future research, it would be interesting to attempt even closer collaboration between the potential end users, researchers and engineers and use a participatory design approach (i.e., co-design) in which the potential end user becomes a partner in the development team as an 'expert of their experiences' $[17,25]$. Participatory design in research is an upward trend due to the social movement 'Nothing about us without us'. Applying a participatory design approach requires different roles for researchers, engineers and users [25]. Attempting to work with users in the development team can be problematic due to various problems. For example: a paucity of user skills necessary to engage in a meaningful way with the development team, both at the level of design skills,

\footnotetext{
${ }^{5}$ The Wizard of $\mathrm{Oz}$ method is a method whereby users interact with an interface, system or physical object without knowing the interface, system or physical object is operated by a person.

${ }^{6}$ In VHRI studies potential end users watch a videotape of the robot system interaction with a human actor instead of performing the scenario themselves [20].
} 
to articulating and communicating their concepts with the design group (e.g., brainstorming and sketching ideas) and at the level of project management (e.g., securing sufficient time away from their regular activities to engage meaningfully in the design activities required) [26]. Therefore, appropriate tools should be provided to users to allow them to express themselves effectively [25].

\section{Analysis of our qualitative studies in an international context}

Our qualitative studies, in the form of focus group sessions [14] held in the Netherlands, the UK, and France $[5,7,9]$, were conducted to investigate differences concerning the acceptance of service robots for older adults living independently and to collect broader generalizable data. No obvious differences in attitude of users towards the use of service robots in elderly care between the three countries became apparent in the studies described in this thesis. This does, however, not imply that there are no differences. Our studies were embedded in a larger technology development project, with its own planning and pace. Due to the given time constraints and the fact that we needed to keep in pace with the technical development in the ACCOMPANY project, we have not been able to analyse the data to its full potential. If more time could have been spend on the data analysis, it is likely more could have been said about the possible differences in attitudes of users towards the use of service robots in elderly care between the three countries.

Language plays an important role in qualitative research [27] and language differences in qualitative research may have consequences as concepts in one language may be understood differently in another language [28]. The impact language differences can have, in combination with the analysis of the focus group sessions, may have influenced the results described in this thesis. The focus group sessions were all conducted by local researchers in local languages. To analyse these focus group sessions, all sessions should, ideally, be transcribed verbatim [14]. Further, to improve the validity of the data, and to overcome the challenges of language differences for these types of research, it is suggested that studies work with the original data as long as and as much as possible, use fluid descriptions of meanings using various English formulations (as the common language in international projects and publications is often English), and work with a professional translator [28]. As already mentioned before, the studies described in this thesis were part of a larger project. The results of these studies were needed as input for other workpackages. Therefore, it was not always possible to apply all these approaches and it sometimes caused us to choose pragmatic solutions. For example, for some sessions, it was only possible to create extensive summaries instead of full transcripts of the focus groups.

We tried to find the best compromise between the demands from a technology development point of view and those from a research point of view. Again, if more time could have been spend on the data analysis, it is likely more could have been said about potentially relevant aspects. For the purpose of our studies as part of the larger project, 
we do think the methods used are appropriate. For future research, it would be useful to transcribe all data verbatim and, in case only summaries are created, to involve the participants to a greater extent when creating these extensive summaries. This could be done, for example, by letting participants record the key issues and outcomes on a flip chart. In order to address the challenges posed by working in different languages it may be useful to conduct the analysis with the local researchers involved and, if possible, use the services of professional translators. In this way, the original language can be used as long and as much as possible and potential limitations in the analysis avoided. Although this might improve the validity of the research, is would also add complexity to the analysis, as well as to the costs associated with the study.

\section{Theoretical considerations}

\section{Acceptability of service robots by potential end users}

The acceptance of robots is complex. Stereotypes often suggest that older adults tend to be less open to the idea of living with a robot. The findings reported in the literature concerning this topic are also inconsistent. On the one hand, there are several studies that reveal that, in line with the findings presented in this thesis, older adults have a more positive attitude towards robots than their caregivers [29], seem to be more open to the idea of having robots and do not express any concerns with regard to using them [30]. On the other hand, there are also other sources that present a contrasting view. For example, Scopelliti et al. found that older people show more mistrust towards new technologies and are more fearful of new technologies and robots than younger people [31].

Acceptance models for technology are often used to analyse multiple variables and the acceptance of a technological product. However, such models are not always applicable to the acceptance of robots. Robots are more complex than other technology devices, such as computers, and their acceptance may also depend on social ability and shape, which are not included in traditional technology acceptance models [30]. A literature review conducted by Flandorfer revealed that, although socio-demographic factors, such as age, gender, education, technological experience, family status and cultural background play an important role in the acceptability of technology, previous experience with technology seems to be the most decisive factor with regard to the acceptance of robot, even mitigating the influence of socio-demographic factors [32]. This would suggest that informal caregivers and professional caregivers are likely to have a more positive attitude towards the acceptance than older adults, as they are more likely to have more experience in using technology (e.g., computers, tablets). However, the results described in this thesis do not confirm this. It is possible that professional caregivers that participated in the study responded negatively towards the robot due to fear of replacement by the robot [29]. The presumption that robots have a 'cold' and 
inhuman character, which is considered to be in contrast with the fundamentals of taking care of older adults [33], could have also influenced the views of informal and professional caregivers. Nevertheless, there are already several robots for older adults that invalidate this presumption, for example Paro [34]. This interactive baby seal-like robot is covered with soft natural-feeling fur and interacts with people as if it is 'alive', moving its head, legs and making sounds. Nevertheless, potential end users in our studies were, in contrast to many previous studies about robot acceptance, able to experience the execution of performing tasks together with the robot in a realistic home-like environment.

\section{Interprofessional collaboration}

It is important to match the robot's role, appearance and behaviour to the needs of the user in order to increase acceptance by end users [7, 9, 11, 13]. Engineers are good at developing technical products, but often have a limited understanding of the social context, and the needs and wishes of the user [35]. On the other hand, professionals in the elderly care domain have good insight into the needs and wishes of users, but lack the technical qualifications needed to develop such technologies. Therefore, a bridge between these groups of professionals must be established when creating a service robot that is considered to be acceptable by potential end users. However, working together is not easy and an interprofessional collaboration between professionals with different backgrounds requires more than placing them in the same room as they speak "different languages".

Interprofessional collaboration is already often used in health care to deal with complex health care demands that are often beyond the expertise of a single profession $[36,37]$. It offers a diversity of knowledge and experiences that can make a team more flexible and effective, but it also introduces risks, such as miscommunications, misunderstandings, conflicts or inadequate commitment [38]. Interprofessional collaboration is certainly complex, and influenced by many interrelating factors, even when it exclusively involves healthcare professionals, [39]. Team structure (i.e., team premises, size and composition, and organisational support) and team process (i.e., team meetings, clear goals and objectives, and audit) both have an impact on interprofessional teamwork [39]. In order have a successful and effective collaboration between engineers and professional caregivers, one should bear in mind that it is essential to pay attention to the factors that impact interprofessional collaborations. For example creating a clear and shared understanding of the project objectives, having regular team meetings, and evaluating the team performance can help in this regard [39]. 


\section{Implications}

\section{Education}

There is often little interest in the relationship between older adults and technology in the elderly care domain, and care personnel, as well as health care students, often are unfamiliar with (the potential of) service robots, as well as the newest care technologies in general [35]. This is one of the reasons why care technologies are often not used in the home care situations [40]. The results of this thesis also revealed that professional caregivers were more reluctant to the use of a service robot than the older adults. However, professional caregivers play an important role in the acceptance of care technologies in general [40]. It is therefore important to inform and educate this group about the potential benefits of care technologies. This implies that more attention should be paid to care technologies during the education of healthcare students. Healthcare studies should embed technology in their daily practice and educate students about how care technologies can be implemented successfully in a home care setting. On the other hand, it is of course, also important to educate engineering students how to design products for the healthcare domain and to provide them with the tools that enable them to investigate the needs of users. A bridge between the technical domain and the healthcare domain should be created during the education of both groups. Multidisciplinary projects that lie at the intersection between care and technology are an effective way for technical students to learn how to communicate with healthcare students with a non-technical background and vice versa.

All these care technology developments also create the need for a new type of professional: the healthcare engineer. It is essential that this healthcare engineer has excellent communication skills. Additionally, he or she should have sufficient knowledge when it comes to the content, organisation and culture of the healthcare domain. It is suggested that this healthcare engineer needs to have around $80 \%$ technological knowledge and skills and about 20\% medical knowledge and skills [41].

\section{Care practise}

Professional caregivers should be actively involved in the process of developing service robots for older adults living independently. However, whenever such a robot would become available in the future, changes should be made within the healthcare domain. At present, technology is not seen as a possible solution within current models used in the healthcare domain. For example, the self-care framework developed by Orem examines the self-care needs of people or communities and the roles of the caregivers in assisting or supporting persons in meeting these needs [42]. Technology is not included as a possible solution in this framework, while technology, and more specifically robotics, certainly has the potential to support care and independence of individuals in many ways 
[43]. Within this context, further research is required to develop a model that does not only focusses on the provision on human support, but also acknowledges the role technology can play in supporting people to meet their needs.

\section{Future research}

Even though considerable time, effort and money is invested in the development of care robots for older adults living independently, many of these robots stagnate in their development phase and will likely never reach the consumer market [4]. It is realistic to expect that many more robots will be developed over the next few years. In order to be effective, it is essential that these robots have the functionalities required to support independent living of older adults in an acceptable manner. However, even if these robots meet this criterion, it is uncertain as to whether they will become commercially available to potential users in the near future. Evidence that the use of robots is an effective solution in addressing the growing demand of homecare with a rapidly ageing population, is still lacking and more long term research studies on the impacts of service robots for older adults living independently are required. In order to be able to conduct such studies, more robust robotic platforms are needed. Although movies on the Internet show us smart robots capable of performing complex activities in a lab, it will be a long time before such robots are capable of performing such tasks in the home of an older adult in a safe and robust manner.

Further research is also required with regard to the implementation of service robots for older adults living independently and not only for robotics: care organisations often struggle with the question of how to implement new technologies to support care at home successfully [40]. Top down implementation in care organisations, which is often applied in the implementation of technology, will most likely fail as the employees (i.e., the professional caregivers who need to work with the technology) are the 'change agents' and decide if a technology can be implemented successfully or not [40]. This, once again, emphasises the importance of involving professional caregivers in the design process and the potential of using closer collaboration between engineers and potential end users such as a participatory design approach, when developing service robots for older adults living independently. Thus, professional caregivers are seen as partners in design teams as 'experts of their experiences' [17, 25]. Finally, it is also necessary to demonstrate the economic value of these types of robots and to develop appropriate business models [44].

To conclude: service robots for older adults living independently are likely to become a key aspect of the elderly care domain, and older adults are open to the idea of a robot supporting them in daily living. The results of this thesis emphasise the importance of paying attention, not only to the technical development of such robots, but also social behaviour and skills, in order to be found acceptable by potential end users. 


\section{References}

[1] ACCOMPANY (2017, May 31). Retrieved from www.accompany.eu

[2] Amirabdollahian, F., Op Den Akker, R., Bedaf, S., Bormann, R., Draper, H., Evers, V., ... \& Hu, N. (2013). Assistive technology design and development for acceptable robotics companions for ageing years. PALADYN: Journal of Behavioural Robotics. doi: 10.2478/pjbr-2013-0007.

[3] Fraunhofer IPA. (2017, May 31). Retrieved from http://www.care-o-bot.de/en/care-o-bot-3.html

[4] Bedaf, S., Gelderblom, G. J., \& de Witte, L. (2015). Overview and Categorization of Robots Supporting Independent Living of Elderly People: What Activities Do They Support and How Far Have They Developed. Assistive Technology: The Official Journal of RESNA, 27(2), 88-100. doi: 10.1080/10400435.2014.978916.

[5] Bedaf, S., Gelderblom, G. J., Syrdal, D. S., Lehmann, H., Michel, H., Hewson, D., ... \& de Witte, L. (2014). Which activities threaten independent living of elderly when becoming problematic: inspiration for meaningful service robot functionality. Disability and Rehabilitation: Assistive Technology, 9(6), 445-452. doi: 10.3109/17483107.2013.840861.

[6] Üstün, T.B. (2002). Towards a Common Language for Functioning, Disability and Health, ICF. World Health Organization Geneva, 23.

[7] Bedaf, S., Draper, H., Gelderblom, G.J., Sorell, T., \& de Witte, L. (2016). Can a service robot which supports independent living of older people disobey a command? The views of older people, informal carers and professional caregivers on the acceptability of robots. International Journal of Social Robotics, 8(3), 409420. doi: 10.1007/s12369-016-0336-0.

[8] Dautenhahn, K. (2007). Socially intelligent robots: dimensions of human-robot interaction. Philosophical Transactions of the Royal Society B: Biological Sciences, 362(1480), 679-704. doi: 10.1098/rstb.2006.2004.

[9] Bedaf, S., Marti, P., \& de Witte, L. What Are The Preferred Characteristics Of A Service Robot For The Elderly? A Multi-Country Focus Group Study With Older Adults And Caregivers. Revised version submitted at Assistive Technology: The Official Journal of RESNA.

[10] Wu, Y.H., Fassert, C., \& Rigaud, A.S. (2012). Designing robots for the elderly: appearance issue and beyond. Archives of gerontology and geriatrics, 54(1), 121-126. doi: 10.1016/j.archger.2011.02.003.

[11] Bedaf, S., Marti, P., \& de Witte, L. A Multiperspective Evaluation of a Service Robot for Seniors: The Voice of Different Stakeholders. Disability \& Rehabilitation: Assistive Technology, 1-8. doi: 10.1080/17483107. 2017.1358300.

[12] Doering, N., Poeschl, S., Gross, H.M., Bley, A., Martin, C., \& Boehme, H.J. (2015). User-centered design and evaluation of a mobile shopping robot. International Journal of Social Robotics, 7(2), 203-225. doi: 10. 1007/s12369-014-0257-8.

[13] Broadbent, E., Stafford, R., \& MacDonald, B. (2009). Acceptance of healthcare robots for the older population: review and future directions. International journal of social robotics, 1(4), 319-330. doi: 10. 1007/s12369-009-0030-6.

[14] Kitzinger, J. (1995). Qualitative research. Introducing focus groups. BMJ: British medical journal, 311(7000), 299. doi: 10.1136/bmj.311.7000.299.

[15] Gill, P., Stewart, K., Treasure, E., \& Chadwick, B. (2008). Methods of data collection in qualitative research: interviews and focus groups. British dental journal, 204(6), 291-295. doi: 10.1038/bdj.2008.192.

[16] Sanders, E.B.N. (2002). From user-centered to participatory design approaches. In Design and the social sciences: Making connections (pp. 1-8). CRC Press.

[17] Sanders, E.B.N., \& Stappers, P.J. (2008). Co-creation and the new landscapes of design. Co-design, 4(1), 518. doi: 10.1080/15710880701875068.

[18] Maguire, M. (2001). Methods to support human-centred design. International journal of human-computer studies, 55(4), 587-634. doi: 10.1006/ijhc.2001.0503.

[19] Van der Lelie, C. (2006). The value of storyboards in the product design process. Personal and ubiquitous computing, 10(2-3), 159-162. doi: 10.1007/s00779-005-0026-7. 
[20] Walters, M.L., Lohse, M., Hanheide, M., Wrede, B., Syrdal, D.S., Koay, K.L., ... \& Severinson-Eklundh, K. (2011). Evaluating the robot personality and verbal behavior of domestic robots using video-based studies. Advanced Robotics, 25(18), 2233-2254. doi: 10.1163/016918611X603800.

[21] Dahlbäck, N., Jönsson, A., \& Ahrenberg, L. (1993). Wizard of Oz studies-why and how. Knowledge-based systems, 6(4), 258-266. doi: 10.1016/0950-7051(93)90017-N.

[22] Walters, M. L., Woods, S., Koay, K. L., \& Dautenhahn, K. (2005). Practical and methodological challenges in designing and conducting human-robot interaction studies. In Proceedings of the AISB Symposium on Robot Companions. AISB.

[23] Jönsson, A., \& Dahlbäck, N. (2000). Distilling dialogues: a method using natural dialogue corpora for dialogue systems development. In Proceedings of the sixth conference on Applied natural language processing (pp. 44-51). Association for Computational Linguistics. doi: 10.3115/974147.974154.

[24] Gulliksen, J., Göransson, B., Boivie, I., Blomkvist, S., Persson, J., \& Cajander, Å. (2003). Key principles for user-centred systems design. Behaviour and Information Technology, 22(6), 397-409.

[25] Visser, F.S., Stappers, P.J., Van der Lugt, R., \& Sanders, E.B. (2005). Contextmapping: experiences from practice. CoDesign, 1(2), 119-149. doi: 10.1080/15710880500135987.

[26] Marti, P., \& Bannon, L.J. (2009). Exploring user-centred design in practice: Some caveats. Knowledge, technology \& policy, 22(1), 7-15. doi: 10.1007/s12130-009-9062-3.

[27] Temple, B., \& Young, A. (2004). Qualitative research and translation dilemmas. Qualitative research, 4(2), 161-178. doi: 10.1177/1468794104044430.

[28] Van Nes, F., Abma, T., Jonsson, H., \& Deeg, D. (2010). Language differences in qualitative research: is meaning lost in translation? European journal of ageing, 7(4), 313-316. doi: 10.1007/s10433-010-0168-y.

[29] Broadbent, E., Tamagawa, R., Patience, A., Knock, B., Kerse, N., Day, K., \& MacDonald, B.A. (2012). Attitudes towards health-care robots in a retirement village. Australasian journal on ageing, 31(2), 115120. doi: 10.1111/j.1741-6612.2011.00551.x.

[30] Beer, J.M., Prakash, A., Mitzner, T.L., \& Rogers, W.A. (2011). Understanding robot acceptance. Georgia Institute of Technology, 1-45.

[31] Scopelliti, M., Giuliani, M.V., \& Fornara, F. (2005). Robots in a domestic setting: a psychological approach. Universal access in the information society, 4(2), 146-155. doi: 10.1007/s10209-005-0118-1.

[32] Flandorfer, P. (2012). Population ageing and socially assistive robots for elderly persons: the importance of sociodemographic factors for user acceptance. International Journal of Population Research. doi: 10. $1155 / 2012 / 829835$.

[33] Roberts, C., Mort, M., \& Milligan, C. (2012). Calling for Care:'Disembodied' work, teleoperators and older people living at home. Sociology, 46(3), 490-506. doi: 10.1177/0038038511422551.

[34] Gelderblom, G.J., Bemelmans, R., Spierts, N., Jonker, P., \& De Witte, L. (2010). Development of PARO interventions for dementia patients in Dutch psycho-geriatric care. In International Conference on Social Robotics (pp. 253-258). Springer Berlin Heidelberg. doi: 10.1007/978-3-642-17248-9_26.

[35] Neven, L.B.M., \& van Son-van Emmerik, N. (2015). Innoveren voor actieve ouderen: zachte analyses als handreiking voor harde en hardnekkige problemen. (2017, May 30). Retrieved from http://www.avans.nl/ binaries/content/assets/nextweb/onderzoek/active-ageing/lectorale-rede-louis-neven.pdf

[36] Freeth, D. (2001). Sustaining interprofessional collaboration. Journal of interprofessional care, 15(1), 3746. doi: 10.1080/13561820020022864.

[37] van Dongen, J.J.J., Lenzen, S.A., van Bokhoven, M.A., Daniëls, R., van der Weijden, T., \& Beurskens, A. (2016). Interprofessional collaboration regarding patients' care plans in primary care: a focus group study into influential factors. BMC family practice, 17(1), 58. doi: 10.1186/s12875-016-0456-5

[38] Hofhuis, D., Mensen, M., ten Den, L., van den Berg, A., Koopman-Draijer, M., Smits, C., \& de Vries, C. (2015). Succesfactoren voor Interprofessioneel Samenwerken in de Wijk. (2017, May 30). Retrieved from http://www.nvmw.nl/nieuws/2-uncategorised/1100-succesfactoren-voor-interprofessioneelsamenwerken-in-de-wijk.html

[39] Xyrichis, A., \& Lowton, K. (2008). What fosters or prevents interprofessional teamworking in primary and community care? A literature review. International journal of nursing studies, 45(1), 140-153. doi: 10. 1016/j.ijnurstu.2007.01.015. 
[40] Peeters, J., Wiegers, T.A., de Bie, J., \& Friele, R.D. (2013). Technologie in de zorg thuis. Nog een wereld te winnen. (2017, May 30). Retrieved from https://www.nivel.nl/sites/default/files/bestanden/RapportTechnologie-in-de-zorg-thuis.pdf

[41] Sminia, T., Sanders, F. B. M., de Weerd, A. W., Wieringa, A. A., Duchatteau, D. C., Jongbloed, L. S., ... \& Borleffs, J. C. C. (2005). Techniek met zorg: kwantiteit en kwaliteit van zorgtechnologische opleidingen. Tijdschrift voor Medisch Onderwijs, 24(1), 35. doi: 10.1007/BF03056675.

[42] Van Hemel, L. (2008). Verpleegkundige concepten en methoden. Maklu. Antwerpen/Apeldoorn: Garant.

[43] Bekey, G., Ambrose, R., Kumar, V., Sanderson, A., Wilcox, B., \& Zheng, Y. (2006). WTEC Panel Report on International Assessment of Research and Development in Robotics. World Technology Evaluation Centre.

[44] Encarnação, P., \& Cook, A. (Eds.). (2017). Robotic Assistive Technologies: Principles and Practice. CRC Press. doi: 10.1201/9781315368788. 


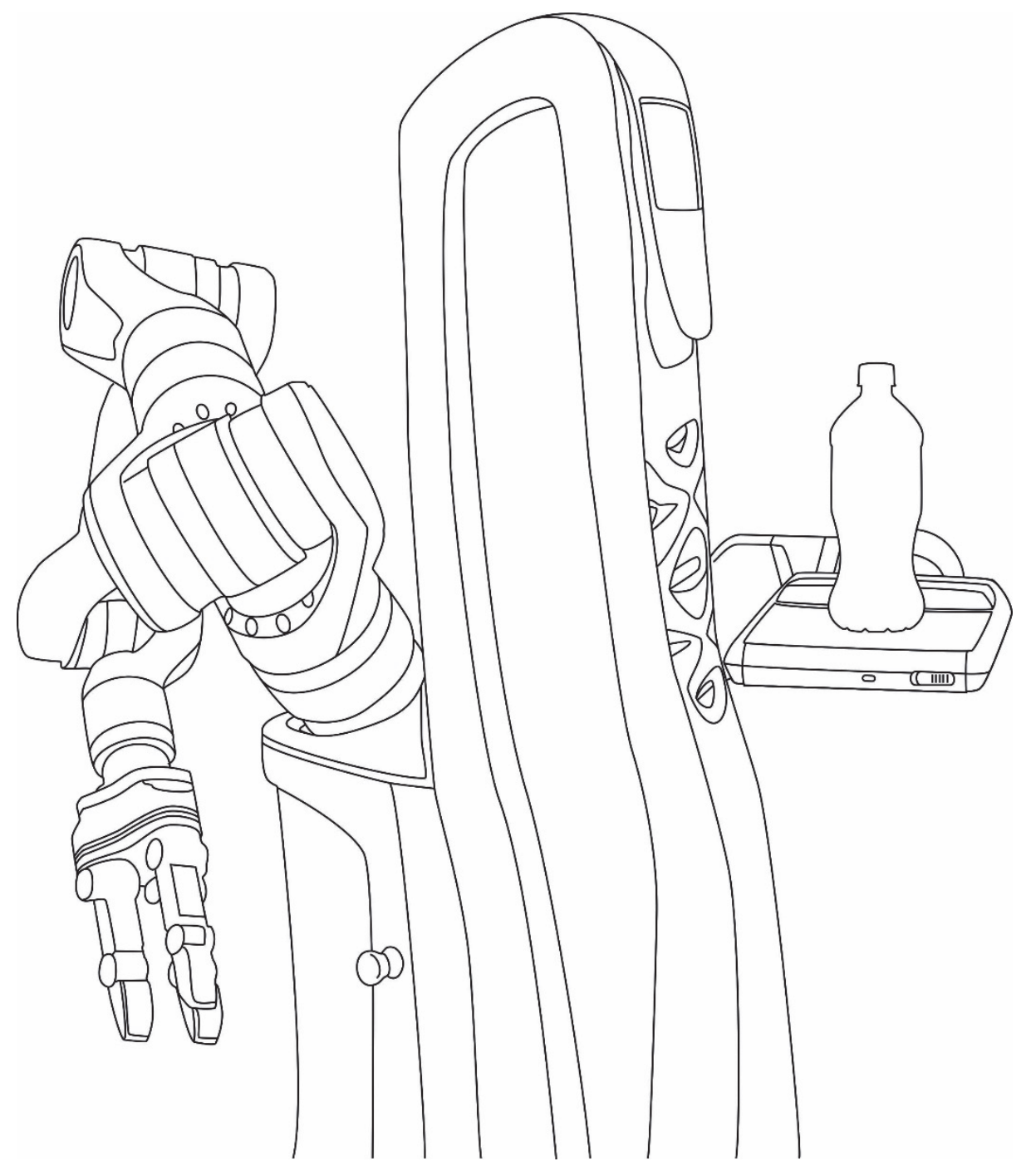




\section{CHAPTER 9 Valorisation}



The work described in this thesis was part of the larger project: Acceptable robotiCs COMPanions for AgeiNg Years (ACCOMPANY). A multidisciplinary consortium initiated this project in 2011. The aim of the ACCOMPANY project was to further develop the functionalities of an existing service robot, the Care-O-bot ${ }^{\circledR} 3$, in order to prolong independent living of older adults. It is important to note that the ACCOMPANY project was a research project. The ACCOMPANY robot can be seen as a novel technological solution towards facilitating independent living at home for older adults. It was not the intention of the project to commercially launch the ACCOMPANY robot. This chapter focuses on emerging opportunities for valorisation that could be taken on the basis of the research presented in this thesis. Furthermore, also the actions that have already been taken to disseminate the knowledge gained in this research are described.

\section{Innovation}

Service robots for elderly care is a hot topic in discussions about sustainable health and social care and the ACCOMPANY project is not the only project that aimed to (further) develop a service robot for independent living older adults. One way the ACCOMPANY distinguished itself is by the large number of potential end users (i.e., $n=113, n=122$, and $\mathrm{n}=97$ ) in three different countries (i.e., the Netherlands, the United Kingdom and France) that were included in the focus group session that were conducted throughout the different stages of the project, in order to explore their needs and preferences. Also, a fully working scenario was used for the multiperspective evaluation. This provided potential end users an opportunity to have a realistic interaction with a service robot, as well as experience performing tasks together with a robot. The results from the focus group sessions as well as the results from the multiperspective evaluation were used to adapt the technology so that it better suited user demands and preferences. The user-centered design approach used in this project resulted in a close collaboration between researchers and engineers and ensured that not only technical challenges were tackled in this project. Also questions how a robot should behave and interact with the user were studied as well as the ethical challenges related to developing a service robots for older adults.

\section{Relevance}

Many robot platforms have been developed over the past decades and substantial efforts are being made to develop new applications. The knowledge that is presented in this thesis is not only relevant for the Care-O-bot ${ }^{\circledR} 3$, but is also applicable to other robot development projects which focus on prolonging independent living of older adults. The results presented in this thesis can be seen as guidelines. These results also can, even though our study focused exclusively on the domain of elderly care, be of relevance for 
researchers working in the related fields of service and assistive robotics (e.g. in the care for disabled and chronically ill people) and the general domains of home assistance and entertainment robotics as it gives them insight in how a robot should behave when interacting with a user.

The work in this thesis also provided answers to certain research questions and highlighted some important insights. Though the outcomes of this thesis may not directly lead to new products tomorrow, the insights into the problematic activities of older adults living independently, the ethical boundaries of a service robot, the preferred characteristics and the outcomes of the multiperspective evaluation can be transferred to future studies on service robots.

Not only can future development projects for robots learn how a potential robot should behave and interact with a user, but also the methodology and approaches described can be seen as an example for future studies concerning the development of service robots. For example: the methodology and approach described the studies in which the Care-O-bot ${ }^{\circledR} 3$ functioned as a concrete case for the scenarios and storyboards used. The use of such a concrete case to explore the needs and wishes of potential end users is relatively new in the field of developing service robots for older adults living independently.

\section{Healthcare}

The outcomes of this thesis have no direct impact on the care delivery system as the evidence that the use of robots is an effective solution in addressing the growing demand of homecare is still lacking. More long term research studies on the impact of service robots for older adults living independently are needed before it becomes attractive for homecare organisations to offer it to their clients.

The current outcomes also have no impact on insurance companies. Once more long term studies are conducted and more proof of evidence that the use of robots is an effective solution addressing the growing demand of homecare is available, the topic will have impact for insurance companies.

\section{Research}

The multiperspective evaluation that has been conducted can be seen as a first step towards facilitating independent living at home for older adults. Nevertheless, more research is needed as regard to evaluating service robots in the actual homes of older adults. A robot that is capable of performing certain functionality in a lab is still a long way off from a robot that can perform this in the home of an older adult in a safe and robust manner. In order to take the development of service robots to the next level it is essential to start evaluating service robots in the actual homes of older adults. However, 
in order to be able to conduct such studies, more robust robotic platforms are needed. It is very likely that these will become available in the near future.

Furthermore, a number of privacy and ethical issues have to be solved. For example: how data should be stored and who can have access to the data on the robot.

\section{Education}

Professional caregivers play an important role in the acceptance of care technology in general. It is therefore important to pay more attention to care technologies during the education of healthcare students. This requires healthcare training curricula to embed technology in their daily practise and to educate students about how care technologies can be implemented successfully in a home care setting. But there is more. The cooperation between healthcare professionals and professionals with a technical background also needs to be improved. The development of training and courses can contribute to a successful interprofessional collaboration between both groups. The usercentered design approach used in the studies described in this thesis and lessons learned have already been used as input for the development of education material for bachelor students in engineering. However, there are still opportunities for the development of more courses (for students as well as for professionals) and multidisciplinary projects that lie at the intersection between care and technology, with an overall focus on assistive technology. To achieve this, a close collaboration between the different curricula (e.g., $I C T$, mechanical engineering, occupational therapy, healthcare) is required.

\section{Policy}

The work described in this thesis has no impact on policy.

\section{Activities undertaken so far}

Multiple activities were undertaken to disseminate the gained knowledge. The novel insights gained in this project were made publicly available, thereby strengthening the service robotics research and industry. Several studies have been published in international and national peer reviewed journals. Moreover, studies have been disseminated via posters, presentations and workshops at international conferences on various topics related to care and/or technology, but also at a national level (e.g., via presentations, workshops and demonstrations for healthcare organisations and at different exhibitions that were available for the general public). The achievements of the project also attracted the attention of different national and international media (e.g., it 


\section{Chapter 9}

was featured by CNN as 'breaking news'), as well as the attention of different researchers and health professionals working on similar topics.

Technological developments and advances progress quickly, while the implementation in education often stays behind. To educate future health professionals the knowledge gained in this research has already been made available for healthcare students through tutorials and info clips by the centre of Expertise for Innovative Care and Technology (EIZT) of Zuyd University of Applied Sciences. Additionally, the knowledge gained in the research underlying this thesis has already been used as input for the development of education material for students. 



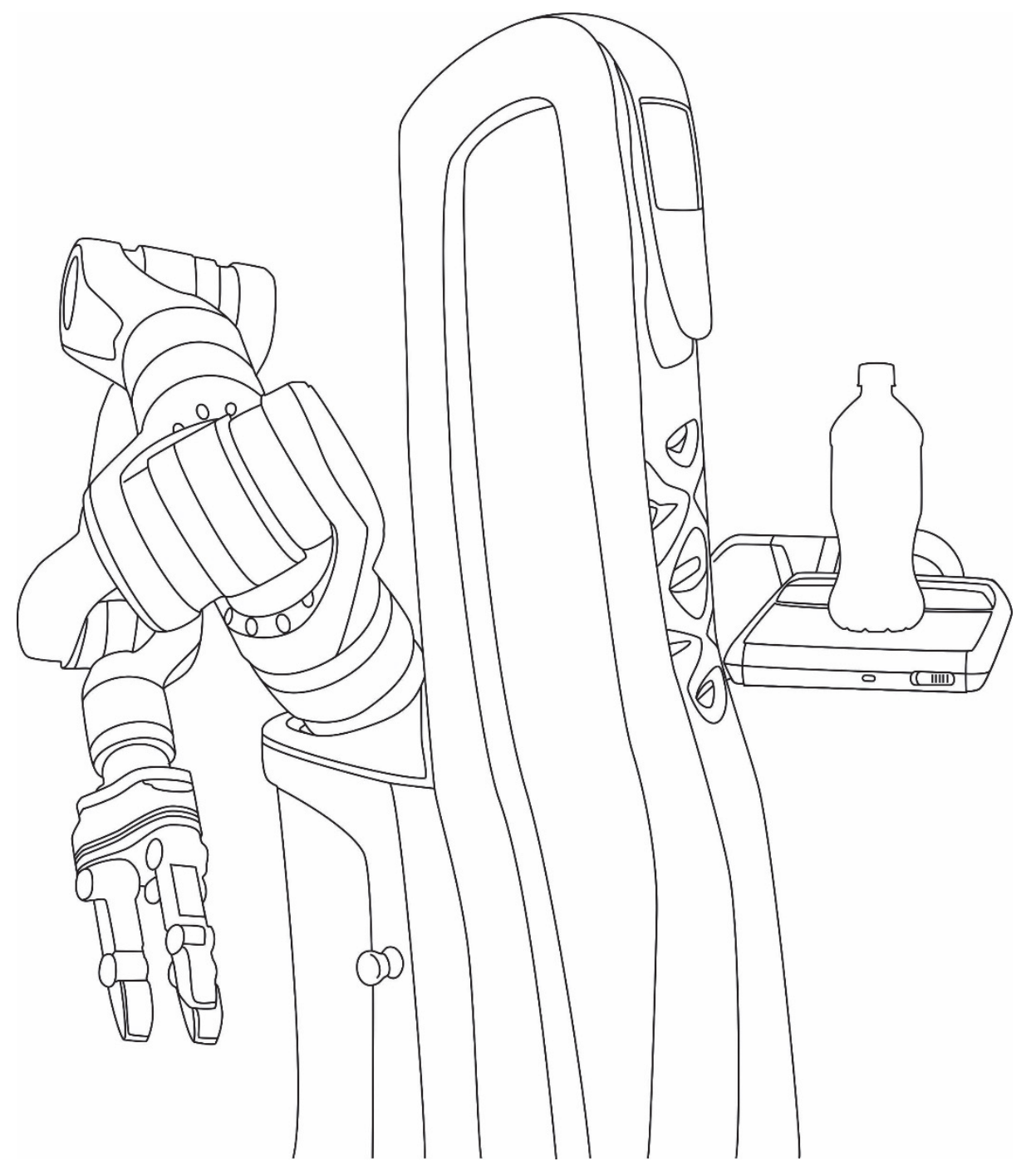


Summary 

The use of robots in daily life is no longer science fiction. Many robots have been developed over the past decades and substantial efforts are being made to develop new applications. A specific field that has been paid an increasing amount of attention in recent years is the development and design of service robots for older adults as the proportion of elderly citizens is growing rapidly. Most of these older adults generally prefer to live at home and may be reluctant to move to residential care facilities as they grow older. However, age-related changes in physical and mental abilities can make the performance of everyday tasks, that are needed to maintain independent living, difficult or challenging. Robotics has the potential to support the care and independence of these older adults in many ways.

The work described in this thesis was part of the larger Acceptable robotiCs COMPanions for AgeiNg Years (ACCOMPANY) project (chapter 2). The overall goal of this project was to further develop the functionalities of an existing service robot, the CareO-bot ${ }^{\circledR} 3$, in order to prolong independent living of older adults by providing physical, cognitive and social assistance in everyday home tasks in a socially acceptable manner, and to contribute to the re-enablement of the user (i.e., enable older adults to carry out relatively difficult daily tasks on their own). ACCOMPANY identified three types of potential users: (1) cognitively unimpaired older adults who need some support to remain independent in their own homes; (2) informal caregivers; and (3) professional caregivers.

The main objective of this thesis was to contribute to the development of service robots to prolong independent living of older adults from a user perspective through gaining knowledge on what potential end users need, want and find acceptable. To achieve this, the following research questions were addressed:

1. What kinds of robots are available for older adults living independently?

2. Do these robots match the needs of older adults?

3. What ethical boundaries should be taken in to account when developing robots for older adults?

4. What are the preferred characteristics of service robots for older adults?

5. How do potential users experience executing a task together with a service robot?

First a systematic review in four scientific literature databases (i.e., Cinahl, IEEE, PubMed, and Psyclnfo), reference tracking and grey literature was performed in order to create an overview of robots supporting independent living of older adults with no cognitive decline (chapter 3). Retrieved titles and subsequently abstracts were independently scored for relevance by two reviewers. Articles prior 1997 were excluded. If the full text was not written in English the article was also excluded. Quality assessment of the publications retrieved was not part of this study. Full texts were scanned for robots for older adults. Potential relevant robots found were added to the database. Three reviewers screened and scored this database for possible robots for older adults. A total of 107 robots were identified that could be categorized into three groups based on their development stage: 
concept phase $(n=6)$, development phase $(n=95)$ and commercially available for consumers $(n=6)$. Further categorization was based on the activity domains these robots claimed to support, and the type of support they provide (i.e., physical, non-physical, and/or non-specified).

Chapter 4 reports on a study in which the activities that can potentially compromise the independence of older adults, were investigated. Firstly, a systematic literature review in PubMed and grey literature, focused on the risk factors (related to daily activities) for institutionalization, was performed. Retrieved titles and subsequently abstracts were independently scored for relevance by three reviewers. There were no limitations on dates of publication or venue. If the full text was not written in English the article was excluded. Quality assessment of the publications retrieved was not part of this study. Secondly, a qualitative study was conducted in which focus group sessions with potential end users (i.e., older adults, informal caregivers and professional caregivers) were performed in the United Kingdom (UK), France and the Netherlands. During these focus group sessions the problematic activities threatening the independence of older adults were discussed. The results from the focus group discussion were compared to the results of a systematic literature review. To deal with the variety of pertinent activities, the International Classification of Functioning (ICF) of the World Health Organization (WHO) was adopted to group activities human perform. The consensus between results of the literature review and the focus group sessions lead to a top 3 of most problematic activity domains threatening independent living of older adults: mobility (d4), self-care (d5), and interpersonal interactions \& relationships (d7). Note that not all of the problematic activities identified in this study are necessarily best-solved by robotics.

The ethical boundaries that should be taken into account when developing a robot for older adults were studied in chapter 5 . This was done in a second qualitative study in which focus group sessions with potential end users were held in the UK, France and the Netherlands. During these focus group sessions a short scenario was presented to the potential end users. This scenario was designed by partners within the ACCOMPANY project to highlight the potential tensions between three values that were identified during a previous theoretical analysis performed within the ACCOMPANY project. Potential end users were asked to comment on various aspects of this scenario. Overall, potential end users found it unacceptable for the robot to be programmed to resist a given command. This choice, however, may decrease the user's abilities in the longer term, because when such a robot does too much it can de-skill, de-motivate and/or erode the abilities the user still has and thereby undermine users' ability to live independently. Additionally, potential end users generally regarded a robot providing reminders as acceptable and useful, but only if the robot would be capable of responding to the user's habitual behaviour and would provide useful reminders depending on the situation. However, the abilities one still has is likely to differ between people, and over time for the same person. In order to be effective and efficient the robot not only has to be flexible, but also should be able to recognize circumstances, interpret them and make 
decisions accordingly. This means that the robot should, ideally, operate at the same level of intelligence as a human carer. In order to avoid dangerous situations, promoting health-promoting behaviour (e.g., stimulate the user to get a drink by themselves) was found to be less acceptable as providing reminders.

In chapter 6 the characteristics of a service robot that are preferred by potential end users, and necessary in order to be found acceptable when executing a task, are discussed. A third qualitative study was conducted, in which focus group sessions with potential end users were held in the UK, France and the Netherlands. A second more elaborate scenario, created by the ACCOMPANY consortium based on the results of the study presented in chapter 4 as well as the feasibility of the technical development within the ACCOMPANY project, was used to facilitate the group discussion during the focus group sessions. Potential end users found it imperative that a service robot behaves according to the wishes of the user. This suggests that it should, ideally, be possible to personalise the robot for each individual user in terms of many different aspects. Potential end users were not in agreement on all aspects. In line with the results of the previous study, older adults did not express any concerns towards using a service robot at home. However, the professional caregivers in this study were convinced that it would be difficult to convince older adults to use the robot. They expected that older adults would be very suspicious towards new technologies and would therefore not trust the robot.

Chapter 7 reports on a multiperspective evaluation of a service robot for older adults. For this evaluation a fully working realistic user scenario was realised at Zuyd University of Applied Sciences in Heerlen, the Netherlands. Older adults were invited to individually perform two tasks together with the Care-O-bot ${ }^{\circledR}$ 3: (1) picking up a parcel at the front door and (2) getting a drink together from the kitchen. A Likert-scale questionnaire was used to assess the experience of the older adults when executing a task together with the robot. Additional semi-structured interviews were conducted with older adults, informal caregivers and professional caregivers in order to reflect on the interaction with the robot and to discuss the possible role of the robot in the daily living situation. Older adults turned out to be more keen to accept the service robot than their informal caregivers and professional caregivers as these were more sceptical on the use of an assistive robot, especially concerning technical issues. All participants stated that a future version of the robot should be able to support more complex tasks. Also the importance of the robot being able to execute tasks according to the user preferences was again highlighted in this study. The desired behaviour and support the robot should provide, according to the participants, could even be compared to the care delivered by a human caregiver. Implementing functional features to perform various activities is therefore not the only challenge in robot development. The social behaviour of the robot should be carefully addressed as well.

The main findings of this thesis, as well as the methodological and theoretical considerations, are described in chapter 8 . The usage of focus groups sessions to explore 
the needs and wishes of potential end users and the analysis of these sessions in an international context are discussed as methodological considerations. The studies described in this thesis were embedded in a larger technology development project. This sometimes caused us to choose pragmatic solutions. However, we tried to find the best compromise between the demands from a technology development point of view and those from a research point of view. The acceptability of service robots by potential end users and the need for interprofessional collaboration are addressed in the theoretical consideration section. Additionally, the implications for education, care practise and future research are addressed in this chapter. More attention should be paid to care technologies during the education of healthcare studies. On the other hand, it is also important to educate engineering students how to design products for the healthcare domain. A bridge should be created between both studies. Additionally, technology is often not seen as a possible solution within current models used in the healthcare domain. Further research is required to develop a model that acknowledges the role technology can play in supporting people to meet their needs. Additionally, long term research studies on the impact of service robots for older adults living independently are required to study if the use of robots is an effective solution. For such research more robust robotic platforms are needed.

Finally, in chapter 9 the possibilities for the valorisation of knowledge that was gained during the studies included in this thesis are described. 



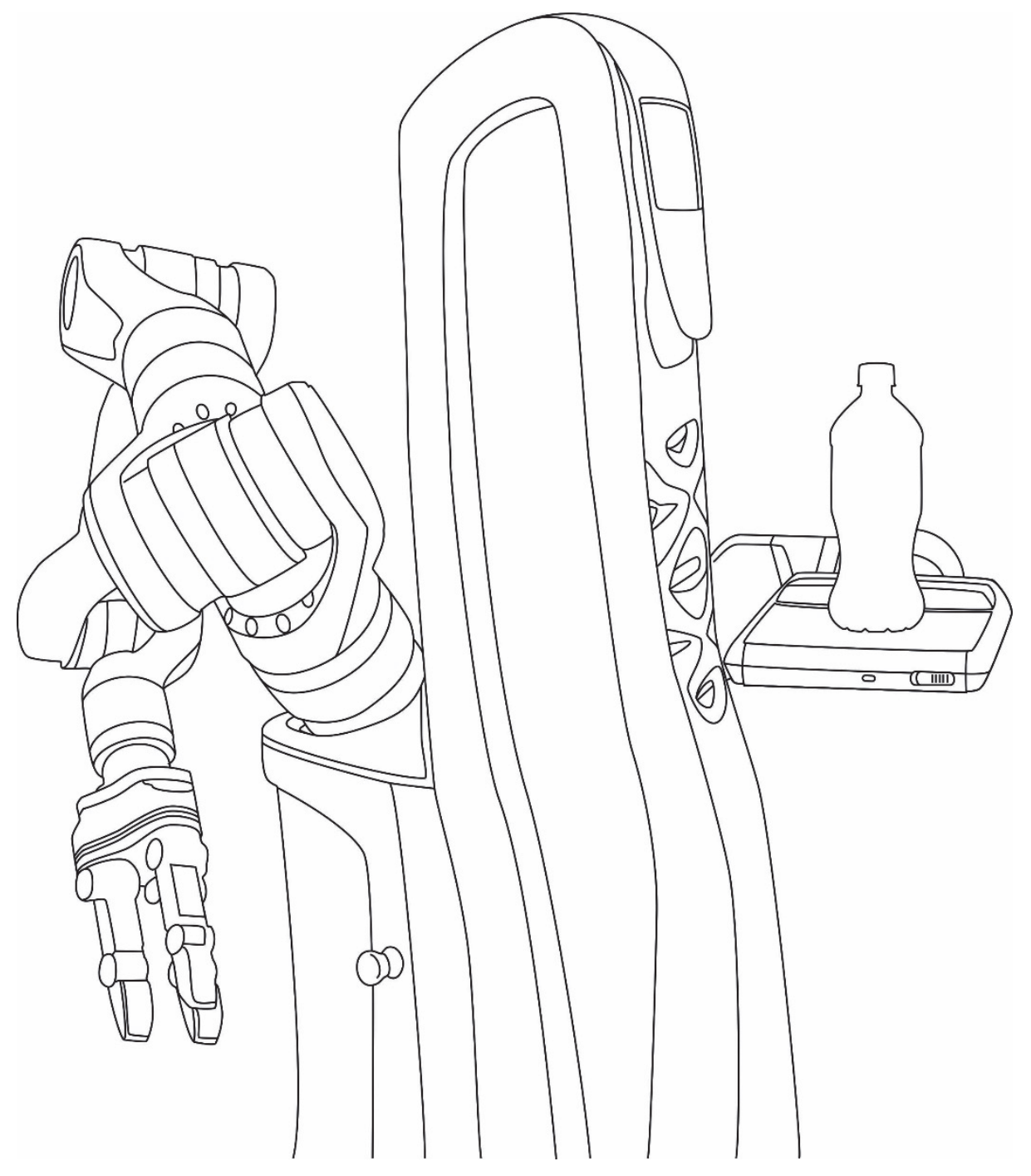


Nederlandse Samenvatting 

Het gebruik van robots in het dagelijks leven is steeds normaler. Menig huishouden heeft bijvoorbeeld al een robot stofzuiger in dienst. Robots zijn 'booming business' en er zijn dan ook vele ontwikkelingen op het gebied van robotica gaande. Een specifiek domein waar de laatste jaren veel aandacht naar uit gaat is de ontwikkeling van een service robot voor ouderen. Nederland vergrijst. En niet alleen Nederland; in veel landen neemt het percentage ouderen (65+) toe. Het merendeel van deze groep wil het liefste zo lang mogelijk thuis blijven wonen en bij voorkeur niet verhuizen naar een verzorgingshuis. Om zelfstandig te kunnen blijven wonen, dient men echter diverse dagelijkse activiteiten te kunnen uitvoeren. Denk hierbij aan douchen, aankleden, naar het toilet gaan en koken. Vanwege de lichamelijke en mentale veranderingen die gepaard gaan met het ouder worden, zal een groot deel van deze groep echter problemen ervaren met het uitvoeren van dergelijke activiteiten. Dit vormt een bedreiging voor het zelfstandig wonen van deze ouderen. Robotica heeft de potentie om het zelfstandig wonen van ouderen te ondersteunen.

De onderzoeken die in dit proefschrift beschreven staan waren allen onderdeel van het overkoepelende Acceptable robotiCs COMPanions for AgeiNg Years (ACCOMPANY) project (hoofdstuk 2). Het doel van dit project was om het zelfstandig wonen van ouderen te ondersteunen met de hulp van een service robot. Om dit doel te realiseren zijn de functionaliteiten van een bestaande robot, de Care-O-bot ${ }^{\circledR} 3$, verder doorontwikkeld. Deze robot diende de gebruiker op een sociaal acceptabele manier fysieke, cognitieve en sociale ondersteuning te bieden bij het uitvoeren van dagelijkse activiteiten en moest daarnaast ook bijdragen aan de 're-enablement' van de gebruiker (d.w.z., ervoor zorgen dat ouderen op de lange termijn weer zelfstandig lastige taken zouden kunnen uitvoeren). Het ACCOMPANY project richtte zich op drie groepen potentiële gebruikers: (1) ouderen zonder geheugenproblemen die ondersteuning nodig hebben om zelfstandig te kunnen blijven wonen; (2) mantelzorgers; en (3) zorgprofessionals.

Het doel van deze studie was om vanuit een gebruikersperspectief bij te dragen aan de ontwikkeling van service robots, die zich specifiek richten op het bevorderen van het zelfstandig wonen van ouderen, door kennis te vergaren over de behoeftes van potentiële eindgebruikers, wat ze willen en wat ze acceptabel vinden. Om dit te bereiken zijn de volgende onderzoeksvragen geformuleerd:

1. Wat voor soort robots zijn er beschikbaar voor zelfstandig wonende ouderen?

2. Komen deze robots overeen met de behoeftes van ouderen?

3. Welke ethische grenzen moet met in acht nemen bij de ontwikkeling van een robot voor ouderen?

4. Welke eigenschappen moet een service voor ouderen bezitten?

5. Hoe ervaren potentiële eindgebruikers het samen uitvoeren van een taak met een service robot?

Een uitgebreid literatuuronderzoek is uitgevoerd om een overzicht te creëren van robots die het zelfstandig wonen van ouderen zonder cognitieve beperkingen ondersteunen (hoofdstuk 3). Hiervoor werd gezocht in de volgende databases: Cinahl, IEEE, PubMed, en 
Psyclnfo. Daarnaast is er ook gebruik gemaakt van 'reference tracking' en grijze literatuur. Titels, en vervolgens ook de abstracts van de gevonden artikelen werden door twee onderzoekers onafhankelijk van elkaar gescoord op relevantie. Alleen artikelen van 1997 of later en artikelen geschreven in het Engels werden meegenomen. Er waren geen beperkingen voor de inclusie van artikelen wat betreft de kwaliteit van de studies. De volledige tekst werd gescand op robots voor ouderen. Potentiële relevante robots werden aan een database toegevoegd. Alle robots in deze database werden vervolgens door drie onderzoekers gescoord. In totaal werden er 107 robots gevonden die in 3 groepen, gebaseerd op het ontwikkelingsstadium waarin ze zich bevonden, onderverdeeld konden worden: concept fase $(n=6)$, ontwikkelingsfase ( $n=95)$ en voor consumenten commercieel beschikbaar $(n=6)$. Nadere indeling werd gedaan op basis van de activiteiten die ze claimde te ondersteunen en het type ondersteuning (i.e., fysiek, niet-fysiek, en/of niet-gespecificeerd).

In hoofdstuk 4 wordt ingegaan op de problematische activiteiten die ouderen ervaren en die ervoor kunnen zorgen dat iemand niet langer zelfstandig kan blijven wonen. Als eerste is een literatuuronderzoek in PubMed en grijze literatuur uitgevoerd met als doel om inzicht te krijgen in de risicofactoren (gerelateerd aan dagelijkse activiteiten) voor een opname in een verzorgingshuis. Titels, en vervolgens ook de abstracts van de gevonden artikelen werden door drie onderzoekers onafhankelijk van elkaar gescoord op relevantie. Er waren geen beperkingen voor de inclusie van artikelen wat betreft de kwaliteit van de studies en periode waarin zij gepubliceerd zijn. Alleen artikelen in het Engels werden meegenomen. Daarnaast is er ook een kwalitatieve studie gedaan. Voor deze studie zijn focusgroep sessies met potentiele eindgebruikers (i.e., ouderen, mantelzorgers en zorgprofessionals) gehouden in het Verenigd Koninkrijk, Frankrijk en Nederland. In deze focusgroep sessies werden de problematische activiteiten die het zelfstandig wonen van ouderen bedreigen, besproken. De resultaten van de focusgroep sessies zijn vervolgens vergeleken met de resultaten van het literatuuronderzoek. De Internationale Classificatie van het menselijke Functioneren (ICF) van de Wereldgezondheidsorganisatie (WHO) is toegepast om de gevonden activiteiten te groeperen. De consensus tussen de uitkomsten van het literatuuronderzoek en de focusgroep sessies hebben geleid tot een top 3 van meest problematische activiteitendomeinen die het zelfstandig wonen van ouderen bedreigen: mobiliteit ( $d 4)$, zelfverzorging (d5), en tussenmenselijke interacties en relaties (d7). Het is echter belangrijk om te beseffen dat niet al deze problematische activiteiten per definitie het beste opgelost kunnen worden door een robot.

De ethische grenzen waar men rekening mee moet houden bij de ontwikkeling van een robot voor ouderen zijn in hoofdstuk 5 onderzocht. Hiervoor is een tweede kwalitatieve studie uitgevoerd. Voor deze studie zijn opnieuw focusgroep sessies met potentiële eindgebruikers gehouden in het Verenigd Koninkrijk, Frankrijk, en Nederland. Tijdens deze focusgroepen werd er een kort scenario gepresenteerd aan de deelnemers. Dit scenario was opgesteld door partners van het ACCOMPANY project om de spanningen 
tussen verschillende aspecten, die in een eerder theoretisch onderzoek naar voren waren gekomen, te onderzoeken. Deelnemers werden gevraagd om commentaar te geven op dit scenario. Over het algemeen vonden de deelnemers het onacceptabel wanneer de robot zou weigeren om een opdracht uit te voeren. Echter, een robot die alle bevelen opvolgt kan er juist voor zorgen dat de gebruiker op de lange termijn steeds minder zelfredzaam wordt. Daarnaast vonden de deelnemers een robot die reminders geeft (bijvoorbeeld: "het is tijd om uw medicatie in te nemen") nuttig en acceptabel, maar alleen wanneer de robot rekening kon houden met het doen en laten van de gebruiker. De robot mocht volgens de deelnemers ook alleen reminders geven die op dat specifieke moment nuttig en relevant waren. Het doen en laten verschilt echter tussen mensen en het vermogen om dagelijkse activiteiten uit te voeren kan ook voor dezelfde persoon in de loop van de tijd veranderen. Dit zou betekenen dat de robot niet alleen flexibel moet zijn, maar ook dat een dergelijke robot omstandigheden zou moeten kunnen herkennen, deze omstandigheden moet kunnen interpreteren om vervolgens een keuze te maken. Dit betekent dat een robot, ideaal gezien, op hetzelfde intelligentie niveau als een zorgprofessional moet kunnen functioneren. Deelnemers vonden het aansporen van gezond gedrag (bijvoorbeeld door de gebruiker te stimuleren om zelf drinken te halen) minder acceptabel dan het geven van reminders, omdat dit tot gevaarlijke situaties kon leiden (bijvoorbeeld uitdroging van de gebruiker).

In hoofdstuk 6 worden de gewenste eigenschappen, die een service robot moet bezitten om acceptabel gevonden te worden door potentiële eindgebruikers, besproken. Opnieuw zijn focusgroep sessies met potentiële eindgebruikers gehouden in het Verenigd Koninkrijk, Frankrijk en Nederland. Een uitgebreider tweede scenario is tijdens deze focusgroep sessies besproken met de deelnemers. Dit scenario was opgesteld door het ACCOMPANY consortium en was gebaseerd op de resultaten van de studie beschreven in hoofdstuk 4. Daarnaast is er bij het opstellen van dit scenario ook rekening gehouden met de technische realiseerbaarheid binnen de project periode. Deelnemers vonden het uiterst belangrijk dat een service robot functioneert volgens wensen van de gebruiker. Dit betekent dat het idealiter mogelijk moet zijn om verschillende aspecten van de robot te personaliseren. De verschillende deelnemers zaten niet altijd op één lijn met elkaar. De zorgprofessionals waren er bijvoorbeeld van overtuigd dat het moeilijk zou zijn om ouderen te overtuigen een robot te gebruiken. Ze dachten dat ouderen achterdochtig zouden zijn tegenover nieuwe technologieën en dat ze daarom de robot niet zouden vertrouwen. Dit kwam echter niet naar voren in de focusgroep sessies van ouderen.

Hoofdstuk 7 rapporteert over een multiperspective evaluatie studie van een service robot voor ouderen. Om dit onderzoek uit te kunnen voeren is er een volledig werkend scenario verwezenlijkt op Zuyd Hogeschool in Heerlen, Nederland. Ouderen zijn vervolgens uitgenodigd om individueel twee taken uit te voeren samen met de Care-Obot ${ }^{\circledast}$ 3: (1) een pakketje ophalen bij de voordeur en (2) een drankje uit de keuken halen. Een Likertschaal vragenlijst is gebruikt om de ervaring van ouderen te beoordelen. 
Daarnaast zijn er ook semigestructureerd interviews gehouden met deze ouderen, mantelzorgers en zorgprofessionals. Tijdens deze interviews werd er gereflecteerd op de interactie tussen de gebruiker en de robot en werd de toekomstige rol van de robot in het dagelijks leven besproken. Uit deze studie kwam naar voren dat ouderen meer open staan voor service robots dan hun mantelzorgers en zorgprofessionals. Mantelzorgers en zorgprofessionals waren beide sceptischer over het gebruik van een service robot, met name op het gebied van technische problemen. Alle deelnemers waren het er wel over eens dat een toekomstige versie van een dergelijke robot in staat zou moeten zijn om meer complexe taken uit te voeren. Tijdens deze studie kwam ook ter sprake dat het belangrijk is dat een service robot taken uitvoert volgens de voorkeuren van de gebruiker. Het gewenste gedrag en ondersteuning van deze robot kan, volgens de deelnemers, zelfs vergeleken worden met de zorg die zorgprofessionals leveren. Het technische aspect van het uitvoeren van verschillende activiteiten is dan ook niet de enige uitdaging van de ontwikkeling van een service robot. Ook de ontwikkeling van het sociale gedrag van een service robot verdient de nodige aandacht.

Hoofdstuk 8 bevat de belangrijkste bevindingen van dit proefschrift. Daarnaast worden ook de methodologische en theoretische overwegingen gepresenteerd waarmee rekening gehouden dient te worden bij de interpretatie van de resultaten. Het gebruik van focusgroep sessies in drie verschillende landen, om de eisen en wensen van potentiële eindgebruikers te onderzoeken, en de analyse van deze sessies worden, onder andere, in dit hoofdstuk besproken. De studies die beschreven zijn in dit proefschrift waren allen onderdeel van een groter technologisch ontwikkelingsproject. Dit had tot gevolg dat er soms voor pragmatische oplossingen is gekozen. We hebben geprobeerd om een goede balans te vinden tussen het doen van wetenschappelijk onderzoek en het meedraaien in een technologisch ontwikkelingstraject. Daarnaast staan ook de implicaties voor onderzoek, de zorg en toekomstig onderzoek beschreven in dit hoofdstuk. Aandacht voor technologie zou moeten worden ingebed in het onderwijs van zorgprofessionals. Aan de andere kant is het natuurlijk ook van belang om ingenieurs te onderwijzen hoe ze producten voor de zorg moeten ontwikkelen. Het is belangrijk dat er een brug wordt geslagen tussen beide studierichtingen. Technologie wordt vaak ook nog niet gezien als een mogelijke oplossing in de modellen die gebruikt worden in de zorg. Meer onderzoek is nodig om een model te ontwikkelen die de rol van technologie in het ondersteunen van mensen erkent. Daarnaast dienen er ook langdurige studies over de impact van service robots op het zelfstandig wonen van ouderen opgezet te worden. Deze zijn nodig om te kijken of de inzet van robots daadwerkelijk een effectieve oplossing is. Dergelijk onderzoek vraagt echter om robuustere platformen.

Ten slotte worden in hoofdstuk 9 de mogelijkheden voor de valorisatie van de kennis verworven tijdens de studies beschreven. 



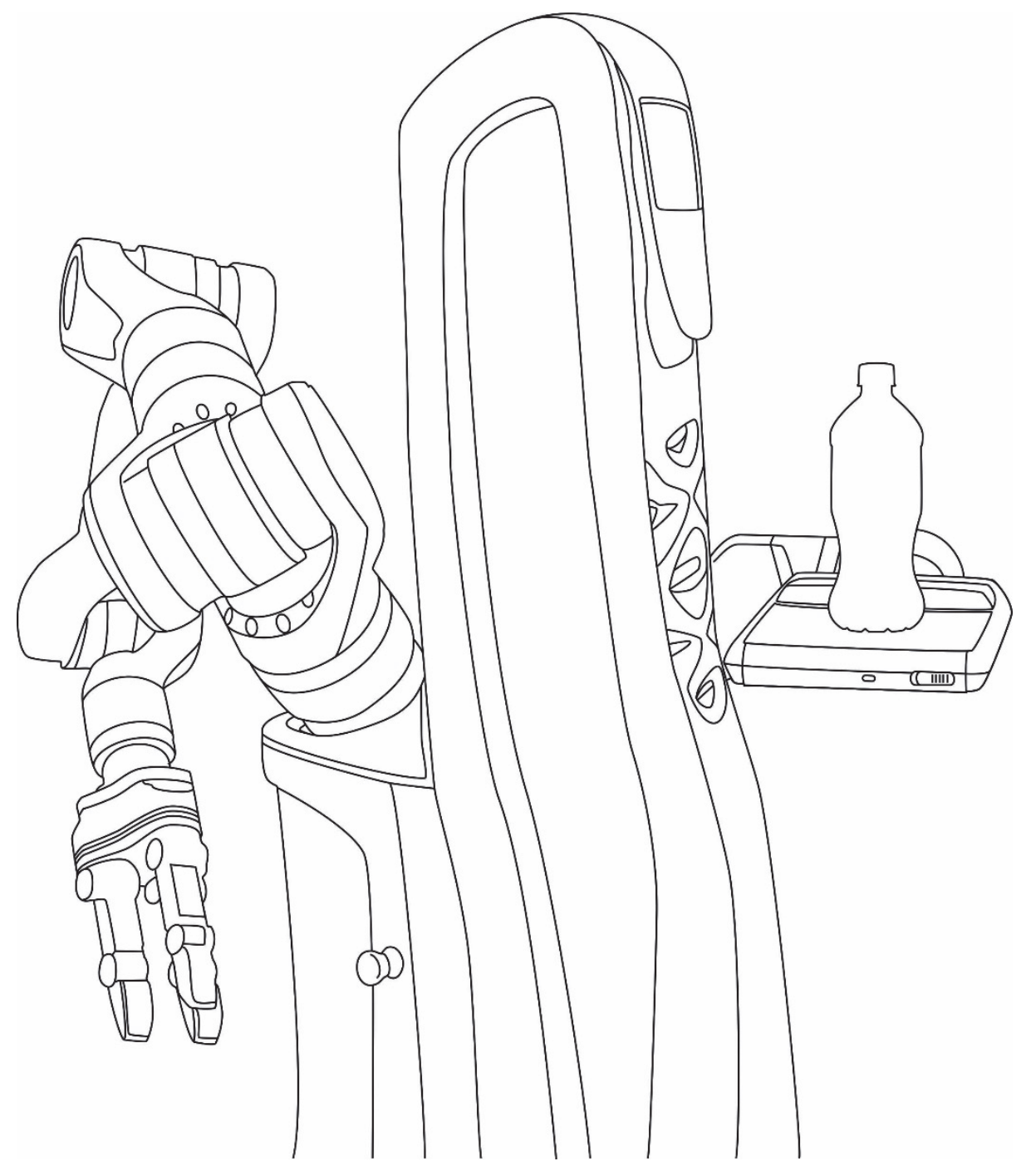


Dankwoord 

Het einde was al lange tijd in zicht, maar nu is het eindelijk zover: mijn proefschrift is klaar. Het zit erop. Ik wil mijn fijne collega's, fantastisch vrienden en lieve familie dan ook ontzettend bedanken voor alle hulp en/of afleiding.

Allereerst wil ik graag mijn team bedanken. Luc, ik heb ontzettend veel van je geleerd de afgelopen jaren. Je hebt geen moment getwijfeld dat dit proefschrift er zou komen. Op de momenten dat ik het soms even niet meer zag zitten (en ik het hele proefschrift het liefste ritueel wilde verbranden) was jouw raad altijd: je moet niet te moeilijk nadenken, maar gewoon opschrijven wat je gedaan hebt. Jouw pragmatische aanpak heeft me enorm geholpen en zonder jouw input en vertrouwen in mij was ik nooit tot dit eindresultaat gekomen.

lemand anders die ook ontzettend belangrijk is geweest voor dit alles is Gert Jan. Jouw rol is enorm groot geweest in dit hele traject en ik vind het dan ook enorm spijtig dat jij er niet bent om de afronding van dit proefschrift mee te vieren. Je hebt me echt wegwijs gemaakt in de wondere wereld van zorgrobotica en onderzoek doen. Je was niet alleen een fijne mentor/collega, maar ook een ontzettend fijn persoon. Ik ben dankbaar voor alles wat ik van je heb mogen leren!

Patrizia, I would really want to thank you for helping me during the final stage of my PhD. After Gert Jan passed away I thought I would never be able to finish this thesis. But thanks to your fresh view and feedback I can now say: I did it.

De leden van de beoordelingscommissie Prof. Jos Schols, Prof. Vanessa Evers en Prof. Klasien Horstman wil ik bedanken voor het lezen en beoordelen van mijn manuscript. Prof. Tony Prescott and Prof. Gerhard Weiss thank you for reading and evaluating my manuscript.

Daarnaast hebben veel verschillende mensen en organisaties inspanningen geleverd waarvoor ik hen graag wil bedanken. Ten eerste alle mensen die als deelnemer bij de studies betrokken waren. Zonder de bereidheid van de vele ouderen, mantelzorgers en zorgprofessionals (in het bijzonder van de zorgorganisaties Sevagram en Proteion) was dit proefschrift er nooit gekomen. Daarnaast wil ik ook zeker alle partners die betrokken waren bij het ACCOMPANY project bedanken. Birgit, Ulrich, Richard, Ben, Vanessa, Jorge, Kerstin, Farshid, Michael, Sinead, Kheng Lee, Dag, Patrizia, Iolanda, Jelle, David, Hervé, Carolina, Tom and Heather thank you for everything. I really enjoyed working with you. Heather, a special thank you for your support and input for writing the ethics article. I really enjoyed Birmingham!

Heerlen is best wel een eindje rijden vanuit het mooie Eindhoven. Loek, dankzij jou waren deze autoritten toch net iets leuker. De nodige liters thee makkten veel goed, net als onze vele gesprekken over eten. Daarnaast hebben we ook vele spannende avonturen mogen beleven tijdens onze dagelijkse ritjes naar het zuiden: hooiwagens die in brand vlogen, 
de vele ontmoetingen met de ANWB, jouw auto die als een gek begon te roken, de vele idioten op de weg (het was nooit onze schuld!) en ook de rit zonder verwarming in de winter staan in mijn geheugen gegrift. Samen met Laura vormden we het \#eindeinzicht groepje. Het gezegde 'gedeelde smart is halve smart' bleek zeker te kloppen. Beiden bedankt voor alle steun en support.

Ook de fijne collega's op de ZAP maakten de dagen in Heerlen allemaal net iets leuker (de altijd gevulde snoeppot heeft hier ook zeker aan bijgedragen). Bedankt Nadine, Loek, Renée, Claire, Bea, Marja, Marieke, Charles, Avanti, Monique, Uta, Paulette, Laura, Renée, Jeanne, Rianne, Saran, Edith, Lisette en Ramon. Ramon en Monique wil ik graag ook nog even apart bedanken voor alle hulp, input en feedback gedurende de laatste fase. Jullie hebben me enorm geholpen. Avanti bedankt voor het corrigeren van de vele stukken (I agree with Loek: you should be able to read Dutch by now).

Een speciaal woord van dank voor de Bende van Vijf. Lieve Judith, Karin, Marjolein en Mieke. Het liefst had ik jullie allemaal bij me gehad tijdens de verdediging, maar het regelement laat helaas maar twee paranimfen toe. De afgelopen jaren hebben jullie mijn gezeur en frustraties rondom dit proefschrift zonder klagen aangehoord. Jullie zijn al meer dan 15 jaar mijn beste vriendinnen en ik kan jullie niet vaak genoeg zeggen hoe erg ik onze vriendschap waardeer. Ik hoop dan ook zeker dat we later, wanneer we 80 zijn, we nog steeds samen gezellig theetjes doen (uiteraard geserveerd door een service robot).

En dan mijn favoriete (ex)buurman. Lieve Steeph, na een lange werkdag was het altijd gezellig om samen met jou op de bank een film/serie kijken onder het genot van sushi of wasabi-pinda's. En uiteraard mogen de vele fantastische feestjes (samen met Ronald), voorstellingen en leuke festivals (behalve dat ene stomme festival in België) zeker niet vergeten worden. Bedankt voor alle (zeer gewenste) afleiding!

Uiteraard wil ik ook al mijn andere vrienden bedanken voor hun bijdrage aan mijn proefschrift. In het bijzonder nog even Emma: bedankt voor al je aanmoedigingen met glitter pompons (het is een zonde dat Hyves niet meer bestaat), Monique: we zagen elkaar voor het eerst bij de Ladies Intro in Delft en tegenwoordig hebben we speeldates met onze kids (wie had dat kunnen bedenken), en Lobke: ik denk dat het tijd is voor een wodka lime!

Lieve familie, ik wil ook jullie graag bedanken. Allereerste mijn fantastische oma die, samen met de robot, veelvuldig model heeft gestaan voor de vele foto's (ze was tevens de inspiratie voor de omslag van dit boekje) en waar ik altijd een nachtje mocht blijven slapen als ik weer eens bizar vroeg in Heerlen moest zijn. Je bent een geweldige oma! Mijn lieve ouders, dit proefschrift is zeker ook jullie verdienste. Papa, jij bent de reden dat ik de techniek kant op ben gegaan. Een keuze waar ik nooit spijt van heb gehad. Ik hoef maar een kik te geven en jullie staat voor me klaar. Jullie hebben me altijd gesteund en dankzij jullie ben ik de persoon die ik vandaag de dag ben. Lieve mama en papa, jullie zijn fantastisch! En dan mijn lieve grote zus: ik kan niet wachten op mijn twee nichtjes (ik 
weet het bijna zeker!). Je gaat een super moeder worden! Mijn lieve schoonouders wil ik ook graag bedanken. Als 16-jarige mocht ik mee naar Rome en sindsdien voelt ook jullie huis als een thuis.

Lieve Erik, al 15 jaar delen we lief en leed. Als ik er even doorheen zat, wist jij me altijd weer aan het lachen te maken. Jij steunt me in alles, laat me vrij en zorgt ervoor dat ik het beste uit mezelf haal. Dankjewel voor alles. Ik zou niet weten hoe ik dit zonder jou had moeten doen. We hebben samen al vele avonturen beleefd en ik kan niet wachten op de avonturen die nog gaan komen. Ik hou van je!

Liefste Levi, zonder jou was dit proefschrift waarschijnlijk eerder klaar geweest. Sinds jij er bent weet ik pas echt wat onvoorwaardelijke liefde is. Ik hou van je! (ps. Ik zou het wel prettig vinden als je me vanaf nu Dr. Mama noemt.) 


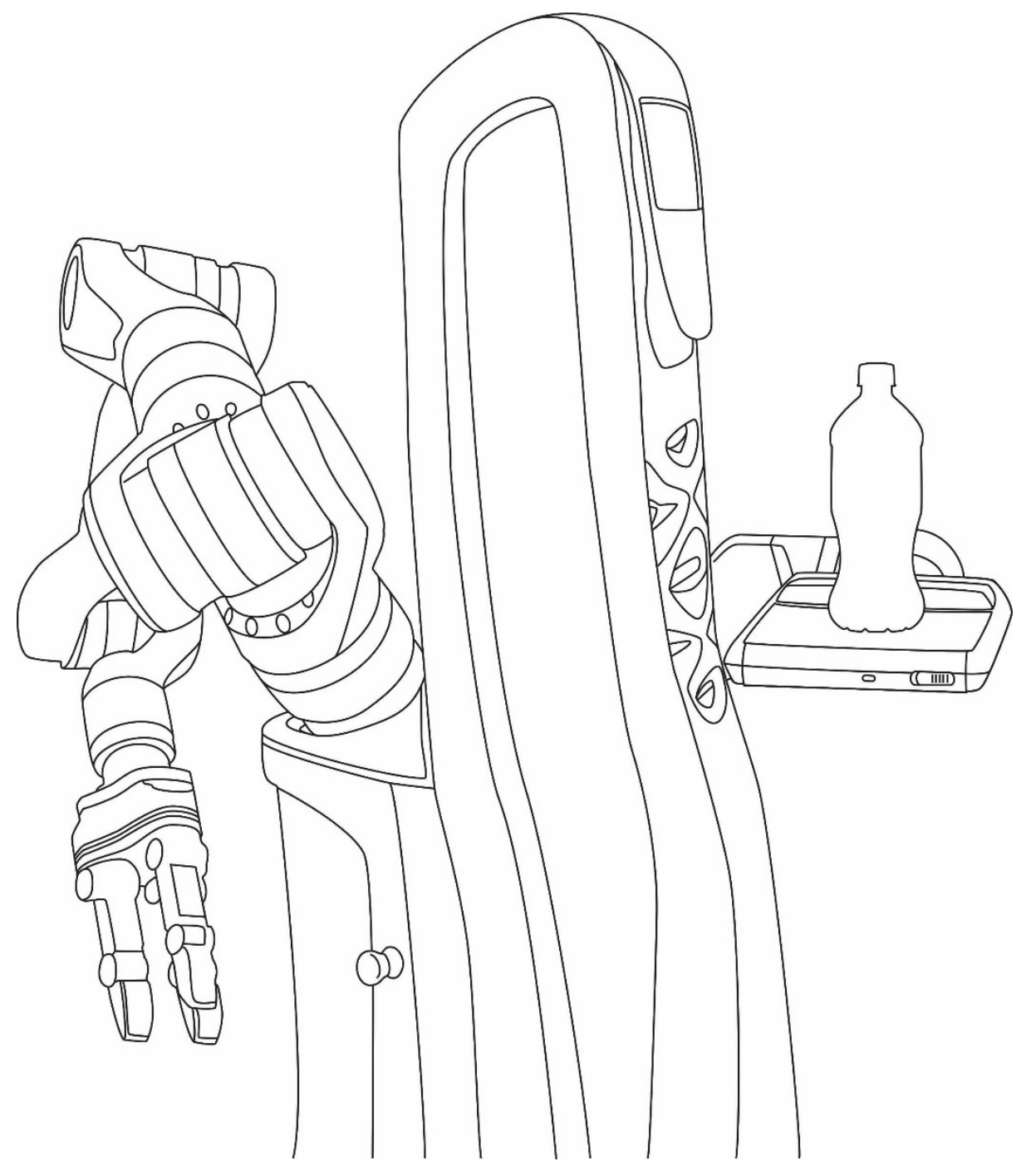


About the Author 

Sandra Bedaf was born in Nijmegen, the Netherlands (1985). After completing her secondary education (Gymnasium) at Pleincollege Van Maerlant in Eindhoven in 2004, she moved to Delft to study Industrial Design Engineering at the Technical University of Delft. In June 2007 she obtained her bachelor degree. Thereafter she started her master Design for Interaction at the Technical University of Delft, which she finished in May 2010.

In October 2011 she started working as a junior researcher at Zuyd University of Applied Sciences and started her PhD trajectory under supervision of Prof. dr. L.P. de Witte. As an external PhD student she was connected to CAPHRI, the School for Public Health and Primary Care, at the department of Health Services Research at Maastricht University.

During her PhD trajectory she got involved in various other research projects related to care and technology and presented her research at various national and international conferences. Additionally, she was involved in eduational activities primarily at the department of Healthcare Engineering at Zuyd University of Applied Sciences, and occasionally at other departments or faculties.

Currently she is still working as a researcher at Zuyd University of Applied Sciences, for the Research Centre of Assistive Technology in Care on projects related to care and technology and involved in educational activities at the department of Healthcare Engineering.

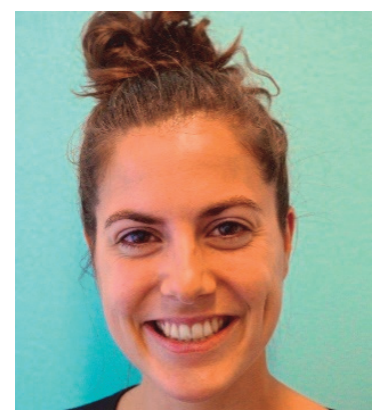




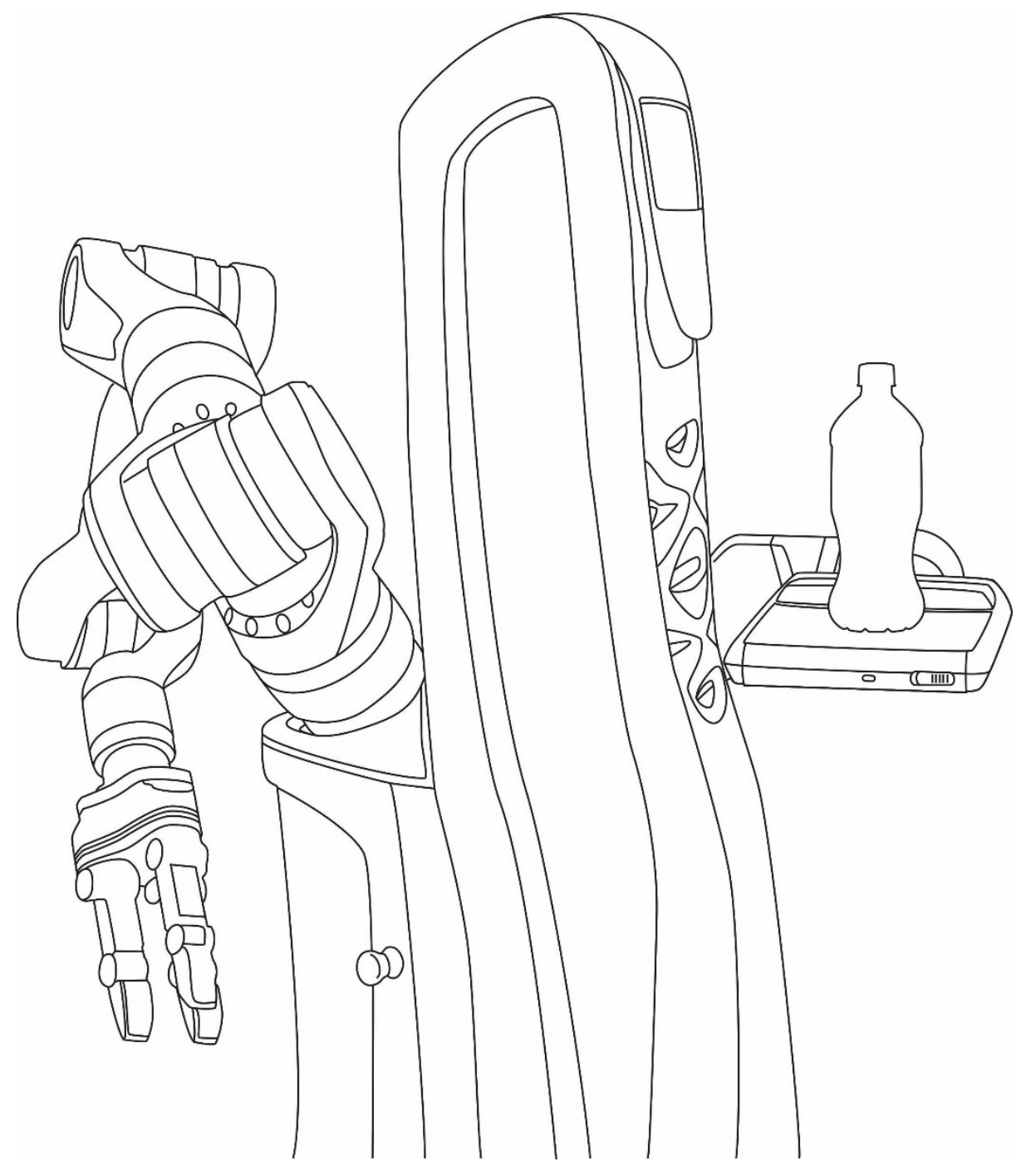




\section{List of Publications}





\section{International Publications}

- Bedaf, S., Marti, P., \& de Witte, L. (2017). A Multiperspective Evaluation of a Service Robot for Seniors: The Voice of Different Stakeholders. Disability \& Rehabilitation: Assistive Technology, 1-8. doi: 10.1080/17483107.2017. 1358300.

- Bedaf, S., Draper, H., Gelderblom, G.J., Sorell, T., \& de Witte, L. (2016). Can a service robot which supports independent living of older people disobey a command? The views of older people, informal carers and professional caregivers on the acceptability of robots. International Journal of Social Robotics, 8(3), 409-420. doi: 10.1007/s12369-016-0336-0.

- Bedaf, S., Gelderblom, G. J., \& de Witte, L. (2015). Overview and Categorization of Robots Supporting Independent Living of Elderly People: What Activities Do They Support and How Far Have They Developed. Assistive Technology: The Official Journal of RESNA, 27(2), 88-100. doi: 10.1080/10400435.2014.978916.

- Bedaf, S., Gelderblom, G.J., Syrdal, D. S., Lehmann, H., Michel, H., Hewson, D., ... \& de Witte, L. (2014). Which activities threaten independent living of elderly when becoming problematic: inspiration for meaningful service robot functionality. Disability and Rehabilitation: Assistive Technology, 9(6), 445-452. doi: 10.3109/17483107.2013.840861.

- Amirabdollahian, F., Op Den Akker, R., Bedaf, S., Bormann, R., Draper, H., Evers, V., ... \& Hu, N. (2013). Assistive technology design and development for acceptable robotics companions for ageing years. PALADYN: Journal of Behavioural Robotics, 4(2), 94-112. doi: 10.2478/pjbr-2013-0007

\section{Book Chapters}

- Bedaf, S., Huijnen, C., van den Heuvel, R., \& de Witte, L.P. (2017). Robots Supporting Care for Elderly People: Principles and Practice In P. Encarnação \& A. Cook (Eds.), Robotic Assistive Technologies: Principles and Practice (pp. 309332). Boca Raton, FL: CRC Press.

\section{Conference Proceedings and Abstracts}

- $\quad$ Bedaf, S., \& de Witte, L.P. (2017). Robots for Elderly Care: Their Level of Social Interactions and the Targeted End User. Studies in Health and Informatics, 242, 472-478. 
- $\quad$ Bedaf, S., \& de Witte, L. (2015). Acceptability Of A Service Robot Which Supports Independent Living Of Elderly People. In Conference Proceedings New Friends.

- Bedaf, S., \& de Witte, L. (2015). Working together with a robot: User experiences of elderly people. In International Psychogeriatrics (Vol. 27, pp. S179-S180). New York, NY: Cambridge Univ Press.

- $\quad$ Draper, H., Sorell, T., Bedaf, S., Syrdal, D.S., Gutierrez-Ruiz, C., Duclos, A., \& Amirabdollahian, F. (2014). Ethical dimensions of human-robot interactions in the care of older people: Insights from 21 focus groups convened in the UK, France and the Netherlands. In International Conference on Social Robotics, (pp. 135-145). Springer, Cham.

- $\quad$ Draper, H., Sorell, T., Bedaf, S., Lehmann, H., Hervé, M., Gelderblom, G.J., ... \& Amirabdollahian, F. (2014). What asking potential users about ethical values adds to our understanding of an ethical framework for social robots for older people. In Proceedings of MEMCA-14.

- Bedaf, S., Gelderblom, G.J., \& de Witte, L. (2013). Differentiation in Service Robot Behaviour based on User Ability. Assistive Technology: From Research to Practice: AAATE 2013, 33, 149.

- Bedaf, S., Gelderblom, G. J., de Witte, L., Syrdal, D., Lehmann, H., Amirabdollahian, F., ... \& Hewson, D. (2013). Selecting services for a service robot: Evaluating the problematic activities threatening the independence of elderly persons. In International Conference on Rehabilitation Robotics (ICORR), 2013 (pp. 1-6). IEEE.

- Amirabdollahian, F., op den Akker, R., Bedaf S., Bormann, R., Draper, H., Gelderblom, G.J., ... \& Dautenhahn K. (2013). Accompany: Acceptable robotiCs COMPanions for AgeiNg Years - Multidimensional Aspects of Human-System Interactions. HSI 2013, Gdansk.

- Lehmann H., Syrdal D., Dautenhahn K., Gelderblom G.J., Bedaf, S., \& Amirabdollahian, F. (2013). What can a robot do for you? - Evaluating the needs of the elderly in the UK. In the 6th International Conference on Advances in Computer-Human Interactions (pp. 83-88). Nice, France.

- Vermeulen J., Man Y.P., \& Bedaf, S. (2012). Nieuwe technologie in de ouderenzorg: hoe ouderen en onderzoekers samen producten ontwikkelen die aansluiten op de behoefte van de gebruikers. Tijdschr Gerontol Geriatr, 43(4), 213-215.

- $\quad$ Bedaf, S., Gelderblom, G.J., Guichet, F., lacono, I., Syrdal, D., Dautenhahn, K., ... \& Witte, L.P. (2012). Functionality of service robotics for aging-in-place: What to build?. Gerontechnology, 11(2), 361.

- Westebring-Van Der Putten, E.P., Bedaf, S., Winters, M., \& Goossens, R.H. (2008). Differences between Operator Reactions on Positions of Visual Feedback of Haptic Stimuli, in a Crossed or Uncrossed Position of Laparoscopic Tools. In 
International Conference on Human Haptic Sensing and Touch Enabled Computer Applications (pp. 400-408). Springer Berlin Heidelberg 


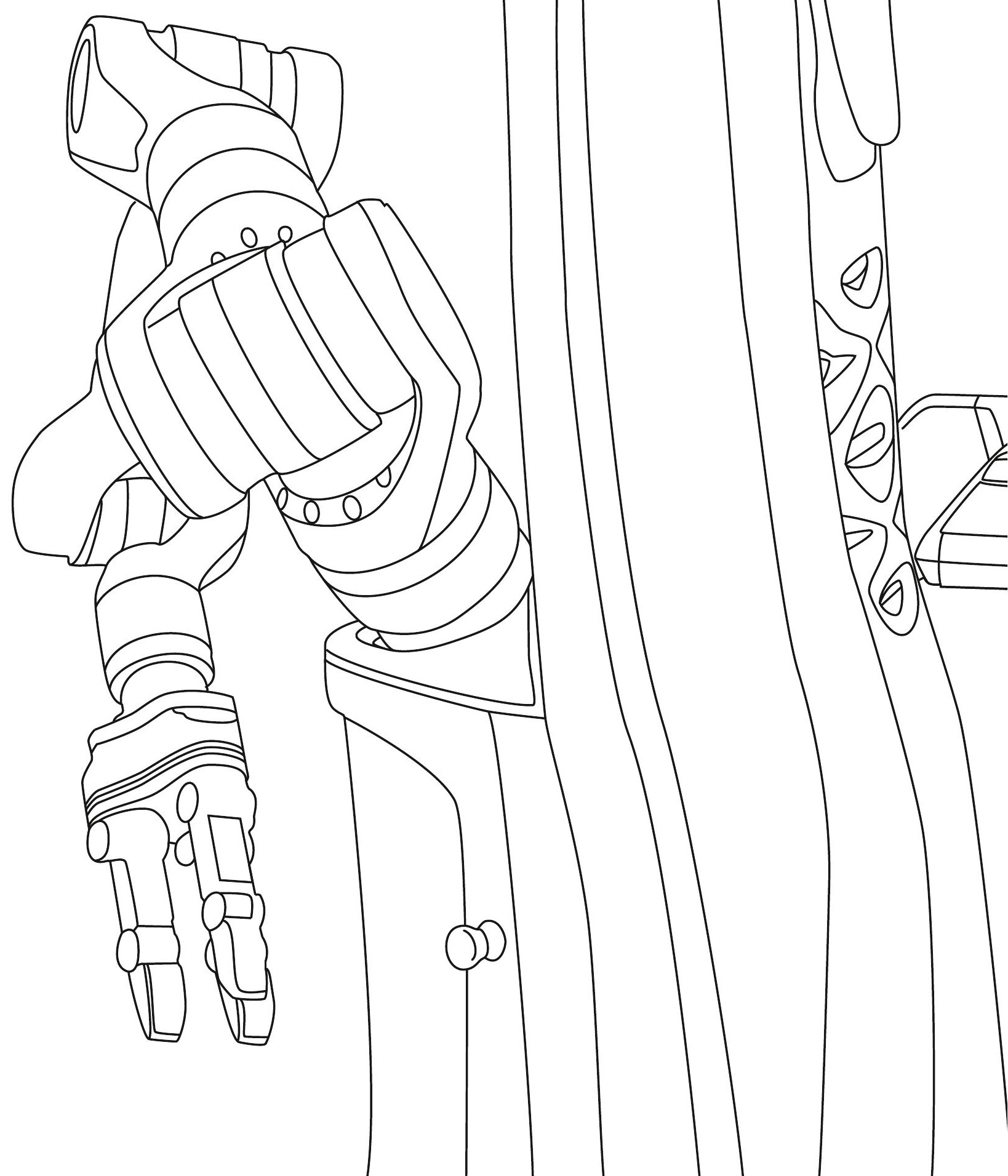

